\title{
A fauna de peixes nas bacias do sul do Espírito Santo, Brasil
}

\author{
Luisa Maria Sarmento-Soares ${ }^{1,2^{*}}$ \& Ronaldo Fernando Martins-Pinheiro ${ }^{1}$ \\ ${ }^{1}$ Museu de Biologia Prof. Mello Leitão/ Projeto BIOdiversES (www.nossosriachos.net), Santa Teresa, Espírito \\ Santo, Brasil. \\ ${ }^{2}$ Programa de Pós-Graduação em Biologia Animal, Universidade Federal do Espírito Santo, Campus de Maruípe, \\ Vitória, Espírito Santo, Brasil.
}

\begin{abstract}
Resumo - As bacias do sul do Espírito Santo incluem a bacia do rio Itapemirim, as microbacias de Marataízes e parte da bacia do rio Itabapoana, na Região Sudeste. Neste estudo, foram amostrados 92 pontos georreferenciados nessas bacias: 23 no Itabapoana, 66 no Itapemirim e três em Marataízes. O ambiente dos peixes foi descrito e a composição taxonômica da ictiofauna documentada. Foram registradas 79 espécies, 31 famílias e 11 ordens, sendo 17 espécies marinhas ou estuarinas. A grande maioria dos peixes de água doce foi de Siluriformes (29 espécies), seguidos de Characiformes (19). Rios torrenciais, protegidos pela Serra do Caparaó, apresentaram a menor riqueza, com poucas espécies nos altos vales fluviais. Por outro lado, foi observada uma excepcional diversidade de peixes de riacho nos baixos vales fluviais, no entorno da Serra das Torres. A presença da única população conhecida de Trichogenes claviger, uma espécie relictual de Trichomycteridae, torna a região do rio Caxixe estratégica no planejamento de áreas para conservação da ictiofauna da Bacia do Itapemirim. Alguns peixes do sul do Espírito Santo foram descritos a partir de amostras da histórica Expedição Thayer, que percorreu a região em 1865. Oligosarcus acutirostris, Astyanax microschemos e Trichogenes claviger também foram descritas a partir de exemplares dos rios do Sul. Foi observado acentuado endemismo para peixes de água doce, entre rios do sul e baixo Paraíba do Sul, sugerindo uma história biogeográfica comum entre estes sistemas hídricos do Atlântico Sudeste.
\end{abstract}

Palavras-chave adicionais: Caparaó, ictiofauna, Mata Atlântica, riachos costeiros, sudeste do Brasil.

\begin{abstract}
Fish fauna from South Espírito Santo River Basins, Brazil) - The South Espírito Santo river basins include the Rio Itapemirim basin, the small river basins in Marataízes and a portion of the Rio Itabapoana basin, in Southeast Brazil. Nighty-two geo-referenced sites were sampled: 23 in Itabapoana, 66 in Itapemirim and three in Marataízes. A species list has been prepared, giving habitat details. Seventynine species, in 31 families and 11 orders were, reported, 17 species being from marine or brackish-water/estuarine habitats. The great majority of freshwater species belong to the Siluriformes (29 species), followed by the Characiformes (19). Torrential rivers, protected by the Caparaó mountains, display the lowest richness, with only a few species recorded from the highest valleys. On the other hand, in lowland river valleys along the Serra das Torres, an exceptional diversity of stream fishes was observed. Because of the only known population of Trichogenes claviger, a relictual species of Trichomycteridae, in the river Caxixe, this area is highly strategic in planning conservation of the Icthyofauna of the Itapemirim basin. Some species from southern Espírito Santo were described based on material collected on the historic Thayer Expedition, which crossed the region in 1865. Likewise, Oligosarcus acutirostris, Astyanax microschemos and Trichogenes claviger were also described based on fishes from southern Espírito Santo. A high endemism of freshwater species was observed between southern Espírito Santo rivers and lower Paraíba do Sul, suggesting a common history among these rivers.
\end{abstract}

Additional key words: Caparaó, ichthyofauna, Atlantic forest, costal streams, southeastern Brazil.

\begin{abstract}
"[O rio Itabapoana] navegável por dezenas de quilômetros, embora torcidíssimo de meandros. Ambas suas margens são molhadas de extensões enormes de alagadiços de vários quilômetros de largura, sobremaneira acentuados nas proximidades da foz, onde um pontal e terra firme atingindo o rio na margem direita, atira-o sobre a esquerda $[\ldots] "$
\end{abstract}

(Lamego 1946: 50).

Os mais antigos habitantes dos vales dos rios Itabapoana e Médio Paraíba, entre os rios Pomba e Muriaé, até o século XVI, eram os Índios Goitacazes, que ocupavam as terras do litoral, e os Puris, habitantes do interior, ambos do grupo Gê (Falcão \& Teixeira 2010). Os Puris não tiveram contato permanente com o colonizador até o século XVIII, tendo sido desalojados de suas terras em consequência da expansão das fazendas de café (Freire \& Malheiros 2010).

\footnotetext{
*Autora para correspondência: biobahia@nossacasa.net

Editor responsável: Alexandre C. A. Santos

Submetido: 1 jul. 2012; aceito: 5 mar. 2013

Publicação inicial: 27 jul. 2013; versão final: 2 May 2014
}

Atualmente, a região sul do Espírito Santo é habitada principalmente por descendentes de imigrantes alemães, suíços e italianos que se instalaram nos contrafortes do Caparaó para produção agrícola, especialmente plantio de café. A partir do século XIX, o sul do Espírito Santo, já então colonizado, recebeu a visita de naturalistas. As mais antigas informações sobre a história natural da região, especialmente plantas, remontam a Viagem à Província do Espírito Santo, empreendida pelo naturalista francês Auguste de Saint Hillaire, que atravessou o Itabapoana e o Itapemirim em 1818, viajando pela costa em direção a Vitória (Papavero 1973). Ao final do século XIX, a Expedição Thayer, que atravessou o Brasil entre os 
anos de 1865 e 1866, fez possivelmente um dos primeiros registros sobre peixes de água doce do vale do Itabapoana, a jusante da Serra do Caparaó, e também do Itapemirim (Dick 1977).

Do ponto de vista das áreas protegidas, nas bacias do sul do Espírito Santo estão hoje as seguintes unidades: 1- Parque Nacional do Caparaó, 2- Floresta Nacional de Pacotuba, 3- Parque Estadual Cachoeira da Fumaça, 4- Parque Estadual de Forno Grande, 5- Parque Estadual de Mata das Flores, 6- Monumento Natural (MONA) Serra das Torres, 7- MONA O Frade e a Freira e 8- Parque Natural Municipal do Itabira. Além destas áreas públicas de preservação, o sul do Espírito Santo possui nove Reservas Particulares do Patrimônio Natural (RPPN).

O Projeto BIOdiversES - Distribuição e Endemismo de Peixes de Água Doce do Espírito Santo - estuda os sistemas hídricos capixabas e vem realizando uma avaliação da ictiofauna de água doce do Estado. Para este estudo ictiofaunístico, os sistemas hidrográficos do Espírito Santo foram divididos nos grupos de drenagem: 1- bacias do norte do Espírito Santo (Sarmento-Soares \& Martins-Pinheiro, 2012a); 2- bacias do Rio Doce no Espírito Santo (bacias dos rios Doce e Barra Seca e o vale do Suruaca); 3- bacias do nordeste do Espírito Santo (bacias dos rios Riacho e Piraquê-açu e as microbacias de Fundão e Aracruz); 4- bacias do Centro-Norte do Espírito Santo (Sarmento-Soares \& Martins-Pinheiro, 2010); 5- bacias do Centros-Sul do Espírito Santo (bacias dos rios Santa Maria da Vitória e Jucu); 6- bacias do sudeste do Espírito Santo (Sarmento-Soares et. al., 2012); e 7- bacias do sul do Espírito Santo (bacias dos rios Itapemirim e Itabapoana e microbacias de Marataízes). $\mathrm{O}$ presente trabalho tem como objetivo investigar os peixes das bacias do sul do Espírito Santo, analisando as condições dos cursos d'água, a composição das espécies, sua distribuição espacial e endemismo nas bacias dos rios Itabapoana e Itapemirim e nas microbacias de Marataízes.

\section{MATERIAL e Métodos}

Área de estudo. As bacias do Sul do Espírito Santo possuem uma área cartográfica total de $8.910 \mathrm{~km}^{2}$, formada pelas bacias dos rios Itapemirim ao norte, com $5.975 \mathrm{~km}^{2}$, e Itabapoana ao sul, com $2.680 \mathrm{~km}^{2}$ além das microbacias de Marataízes, com $255 \mathrm{~km}^{2}$ (Tabela 1; Figura 1), fazendo parte da Região Hidrográfica do Atlântico Sudeste (CNRH 2003). Estão limitadas ao noroeste pela bacia do rio Doce, ao norte pelas bacias dos rios Novo e Benevente, ao sul e sudoeste pela bacia do rio Paraíba do Sul e a leste pelo Oceano Atlântico. Praticamente toda a bacia do rio Itapemirim se encontra em território capixaba, sendo que apenas alguns córregos, contribuintes da sub-bacia do rio Pardo, drenam o estado de Minas Gerais. O rio Itabapoana define os limites entre os estados do Rio de Janeiro e do Espírito Santo, e sua bacia banha parte deste dois estados e ainda o estado de Minas Gerais. As microbacias de Marataízes estão confinadas entre as bacias do Itabapoana e Itapemirim e o Oceano Atlântico.

O relevo, com escarpas íngremes, compreende os setores da Mantiqueira Setentrional, com conjuntos de morros que funcionam como degraus de acesso aos seus diferentes níveis topográficos. O relevo bastante acidentado e homogêneo, marcado por forte controle estrutural registrado por vales e vertentes retilíneos, nivelamento de topo e pontões, faz com que a região receba a denominação geomorfológica de Patamares Escalonados do Sul Capixaba (Burgos et al. 2006). Colinas e maciços costeiros a leste envolvem o Maciço do Caparaó, refletindo intrusões graníticas que caracterizam a topografia do sul do Espírito Santo. As altitudes mais elevadas culminam no Pico da Bandeira, com $2.897 \mathrm{~m}$. Vales abertos, cortados por uma drenagem fluvial formando pequenos terraços $\mathrm{e}$ planícies, são comuns.

Tabela 1. Perímetros e áreas das bacias e sub-regiões hidrográficas que configuram as bacias do sul do Espírito Santo. Os perímetros e áreas correspondem às partes das bacias no estado do Espírito Santo.

\begin{tabular}{|c|c|c|c|c|}
\hline Bacia & Sub-região hidrográfica & Trecho & $\begin{array}{l}\text { Perímetro } \\
(\mathbf{k m})\end{array}$ & $\begin{array}{l}\text { Área } \\
\left(\mathbf{k m}^{2}\right)\end{array}$ \\
\hline & I - Alto Itapemirim & $\begin{array}{l}\text { Alto Itapemirim } \\
(E S-M G)\end{array}$ & 311 & 3.098 \\
\hline & II - Alto Itabapoana & $\begin{array}{l}\text { Alto Itabapoana } \\
(E S-R J-M G)\end{array}$ & 169 & 750 \\
\hline & III - Médio Itapemirim & Médio Itapemirim & 312 & 2.267 \\
\hline & IV - Médio Itabapoana & $\begin{array}{l}\text { Médio Itabapoana } \\
(E S-R J)\end{array}$ & 224 & 1.307 \\
\hline & V - Baixo Bacias do Sul & $\begin{array}{l}\text { Baixo Itapemirim + Baixo } \\
\text { Itabapoana } \\
\text { (ES-RJ) }+ \text { Microbacias } \\
\text { Marataizes }\end{array}$ & 229 & 1.488 \\
\hline Bacia do rio Itapemirim & & & 459 & 5.975 \\
\hline Bacia do rio Itabapoana & & & 490 & 2.680 \\
\hline Microbacias Marataízes & V - Baixo Bacias do Sul & & 92 & 255 \\
\hline Sul do ES & & & 548 & 8.910 \\
\hline
\end{tabular}




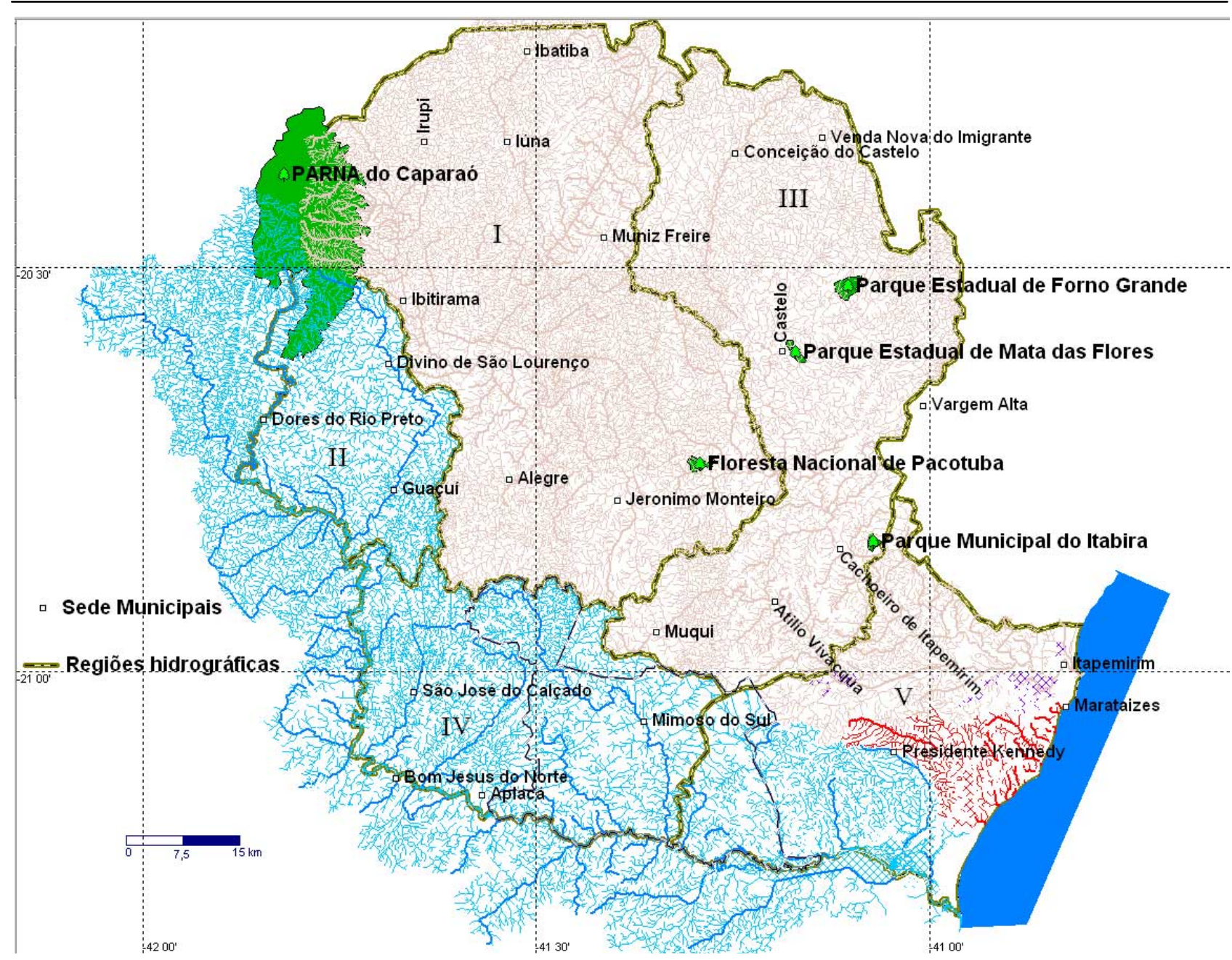

Figura 1. Mapa das bacias do sul do Espírito Santo (bacias do rio Itapemirim, ao norte, e do rio Itabapoana, ao sul, além das microbacias de Marataízes, em verde, a noroeste) e a divisão em sub-regiões hidrográficas (I- Alto Itapemirim, II- Alto Itabapoana, III- Médio Itapemirim, IV- Médio Itabapoana e V- Baixo Rios do Sul), indicando as unidades de conservação e as sedes municipais.

A área serrana capixaba foi originalmente inserida na ecorregião Florestas Costeiras Baianas, dominada por formações de floresta ombrófila densa de tabuleiros costeiros. Recentemente, esta inserção foi revisada, passando a região serrana do sul capixaba a pertencer à ecorregião Serra do Mar (Scaramuza et al. 2011). A área de estudo está totalmente inserida no domínio fitogeográfico da Mata Atlântica. Possui cobertura vegetal na maior parte de sua área de Floresta Estacional Semidecidual, com vegetação secundária e atividades agrárias. Apenas uma pequena área, ao sul de Cachoeiro do Itapemirim e na borda norte da bacia, é composta por Floresta Ombrófila Aberta, também com vegetação secundária e atividades agrárias (IBGE 2004).

Caracterização das sub-regiões hidrográficas e dos pontos de amostragem associados. As bacias do Sul do Espírito Santo foram divididas em cinco subregiões hidrográficas: I-Alto Itapemirim $\left(3.098 \mathrm{~km}^{2}\right)$, II-Alto Itabapoana $\left(750 \mathrm{~km}^{2}\right)$, III-Médio Itapemirim $\left(2.267 \mathrm{~km}^{2}\right)$, IV-Médio Itabapoana $\left(1.307 \mathrm{~km}^{2}\right) \mathrm{e} \mathrm{V}$ Baixo Rios do Sul $\left(1.488 \mathrm{~km}^{2}\right)$. Nesta última subregião, estão incluídas a foz dos grandes rios,
Itabapoana e Itapemirim, e as microbacias de Marataízes (Figura 1).

Rio Itapemirim (sub-regiões hidrográficas I e III). Com uma área de drenagem de $5.975 \mathrm{~km}^{2}$, a bacia formada pelo rio Itapemirim banha os municípios capixabas de Itapemirim, Cachoeiro de Itapemirim, Vargem Alta, Castelo, Venda Nova do Imigrante, Conceição do Castelo, Muniz Freire, Iúna, Ibatiba, Ibitirama, Alegre, Jerônimo Monteiro, Muqui, Atílio Vivacqua e Presidente Kennedy, e ainda uma pequena parte do estado de Minas Gerais. Além da Usina Hidrelétrica Muniz Freire, no rio Pardo, município de Muniz Freire (capacidade instalada de 25 MW), se encontra ainda na bacia do Itapemirim, as Pequenas Centrais Hidroelétricas: Ilha da Luz, em Cachoeiro do Itapemirim (2,8 MW); Viçosa, no rio Castelo, em Conceição do Castelo (24,5 MW); Alegre, no ribeirão Alegre, em Alegre (2,1 MW); Fruteiras, no rio Fruteiras, em Cachoeiro de Itapemirim (8,7 MW); São João, no rio Castelo, entre os municípios de Castelo e Conceição do Castelo (25,0 MW); e Francisco Gros (antiga Santa Fé), no rio Itapemirim, em Alegre (29,0 MW). 
I-Alto Itapemirim. Os principais formadores do Itapemirim são os rios Braço Norte Esquerdo e Braço Norte Direito. O Braço Norte Esquerdo tem suas nascentes no Espírito Santo, no extremo norte do município de Muniz Freire, próximo à divisa com Itatiba. Desce no sentido sudoeste até encontrar o Braço Norte Direito, formando o rio Itapemirim. O rio Braço Norte Direito nasce no limite oeste do município de Ibitirama (ES), quase na fronteira com o Alto Caparaó (MG). Desce em sentido Oeste-Leste até Iúna, quando muda o sentido para Sudeste, recebendo o rio Braço Norte Esquerdo, para dar início ao rio Itapemirim. A sub-região hidrográfica Alto Itapemirim inclui toda a área de drenagem dos rios Braço Norte Esquerdo e Direito e do rio Itapemirim até a jusante da foz do Córrego Olho D'Água, antes da foz do rio Castelo.

III-Médio Itapemirim. No terço médio, destaca-se a sub-bacia do rio Castelo, que nasce na divisa norte do Município de Conceição do Castelo, desce no sentido sul passando por Castelo e indo desaguar no rio Itapemirim. A sub-região hidrográfica "Médio Itapemirim" inclui a área drenada pelo rio Itapemirim, desde a montante da foz rio Castelo até a jusante da foz do córrego Independência, no limite leste do Município de Cachoeiro de Itapemirim.

Rio Itabapoana (sub-regiões hidrográficas II e IV). Com uma área em território capixaba de $2.680 \mathrm{~km}^{2}$, a bacia do rio Itabapoana entrecorta 20 municípios de três Estados: Minas Gerais, Rio de Janeiro e Espírito Santo. As cabeceiras do Itabapoana estão abrigadas nos contrafortes da serra do Caparaó, e entrecortam os municípios mineiros de Espera Feliz, Alto Caparaó, Caiana e Caparaó. O rio São João, que nasce no sudeste de Minas Gerais, e o rio Preto, que nasce na Serra do Caparaó, são os principais formadores do rio Itabapoana. Após o encontro dos dois rios, forma-se o rio Itabapoana, fazendo a divisa estadual Rio de Janeiro/ Espírito Santo, com tributários na margem direita em território Fluminense e na margem esquerda em território capixaba. A margem direita do rio Itabapoana, em águas fluminenses, banha os municípios de Bom Jesus do Itabapoana e parte dos municípios de Porciúncula, Varre-e-Sai, Campos dos Goytacazes, São Francisco do Itabapoana e São João da Barra. Em sua margem esquerda, as águas da bacia do rio Itabapoana banham os municípios capixabas de Dores do Rio Preto, Divino São Lourenço, Guaçuí, São José do Calçado, Bom Jesus do Norte, Apiacá, Mimoso do Sul, Presidente Kennedy, Itapemirim e Muqui. Os principais afluentes do lado do Espírito Santo são os rios Muribeca, São Pedro, Muqui do Sul, Preto, Calçado, Ribeirão, Barra Alegre, Boa Vista e os córregos São Pedro e São Bento. Do ponto de vista ambiental, o emprego de agrotóxicos nos altos vales fluviais para pulverizar, sobretudo a cultura de café, contribuiu para a degradação hídrica. Mais abaixo o rio Itabapoana recebe efluentes domésticos e urbanos sem tratamento na altura da cidade ribeirinha de Bom Jesus do Norte (ES), apesar de utilizarem as águas do rio para consumo próprio. Estudos de concepção para projetos de sistemas de esgotamento sanitário local ainda estão em andamento (Portal da Transparência 2011; CESAN 2012). Além dos resíduos de agrotóxicos da área rural, dos efluentes domésticos e do lixo, o Itabapoana é vitimado pela supressão da vegetação ciliar e consequente assoreamento e erosão das margens. A maior parte da cobertura vegetal natural foi substituída por agricultura e pastagens, com predomínio absoluto de áreas antropizadas (Bizerril \& Primo 2001). As enchentes causadas pelo rio constituem um problema frequente para as cidades ribeirinhas atualmente. A exploração de ouro no leito do rio Itabapoana foi prática comum no passado, mas a garimpagem está proibida devido à utilização do mercúrio pelos garimpeiros (Alves \& Barbosa 2009).

O rio Itabapoana é usado para geração elétrica através da Usina Hidrelétrica de Rosal, na cachoeira de mesmo nome, com dois saltos de aproximadamente 80 m, cercada pela Serra do Bálsamo (RJ) e pela Serra do Cachoeirão (ES), município de São José do Calçado (capacidade instalada de $55 \mathrm{MW}$ ). No seu curso, encontram-se ainda as Pequenas Centrais Hidroelétricas: Pirapetinga, no rio Itabapoana (20 MW); Calheiros, no rio Itabapoana (19 MW); e Franca Amaral, na Cachoeira do Inferno (4,5 MW); todas localizadas na divisa dos municípios de Bom Jesus de Itabapoana (RJ) e São José do Calçado (ES); além da Central Pedra do Garrafão, no rio Itabapoana, entre os municípios de Campos dos Goytacazes (RJ) e Mimoso do Sul (ES) (19 MW).

II-Alto Itabapoana. As atividades econômicas de maior destaque no vale do Itabapoana são ligadas ao café, à pecuária leiteira, à cana-de-açúcar e à fruticultura tropical (Barros 1999). Do ponto de vista meteorológico, as montanhas do Caparaó favorecem a ocorrência de chuvas orográficas. Quando a massa é forçada a ascender, precipita a barlavento (no Espírito Santo), em muitos casos não precipita do outro lado, a sotavento (em Minas Gerais). $\mathrm{O}$ alto vale do Itabapoana no Espírito Santo, em Ibitirama, apresenta maiores índices pluviométricos, possivelmente ligados à ascensão e condensação das massas de ar ao encontrarem a barreira montanhosa. A chuva orográfica, por outro lado, é possivelmente uma das causas da seca na outra vertente do vale fluvial, em Alto Caparaó, Minas Gerais. A direção do vento a baixos níveis reflete a circulação dos sistemas de grande escala e sofre grande influência do relevo (Melo Junior et al. 2006).

Altos vales fluviais entrecortam a Serra do Caparaó e chegam a alcançar atitudes de $1.450 \mathrm{~m}$, como nas cabeceiras do rio Preto. O terço superior do rio Itabapoana no Espírito Santo compreende principalmente as sub-bacias do rio Preto e do córrego do Veado, na margem esquerda. O trecho se estende até a montante da confluência com o ribeirão Varre-eSai, tributário da margem direita. No seu trajeto, forma 
muitas cachoeiras: Santo Antônio, Inferno, Limeira e Fumaça, essa última com queda de 100 metros. A parte do rio onde se encontram a maior parte das cachoeiras está entre a divisa de Minas Gerais e a cidade fluminense de Bom Jesus do Itabapoana. O terço superior da bacia no Espírito Santo compreende ainda o município de Guaçuí, onde o Córrego do Veado deságua no Itabapoana, e inicia-se o trecho médio.

IV-Médio Itabapoana. Compreende o trecho a jusante da confluência com o ribeirão Varre-e-Sai até a montante do rio Muqui do Sul. A declividade neste trecho é mais suave, com assoreamento do rio em grandes extensões, devido às dragagens que revolveram o seu leito e a remoção da vegetação ciliar (Universidade Federal Fluminense 1996). A baixa declividade facilitou a ocupação dos vales fluviais pela pecuária, e os animais ocupam inclusive o leito dos rios. "Antes mesmo da construção do ramal férreo essa zona já era favorecida pelo porto de Limeira, onde findam as quedas do Itabapoana, através do qual um ativo comércio de madeiras se fazia com o Rio de Janeiro. Além do jacarandá, o sobro, o vinhático, a peroba, o tapinhoã, o cedro e a canela saíam das grandes selvas à margem do rio, e, juntamente com o café desciam até à foz" (Lamego 1963: 295-296). A pesca de subsistência é praticada no trecho médio e inferior do Itabapoana. $\mathrm{O}$ pescado era comercializado na residência dos próprios pescadores, nas estradas ou em pequenos comércios, como a feira de Bom Jesus de Itabapoana. As principais espécies comercializadas foram cascudos, piaus e traíras (Bizerril \& Primo 2001).

V-Baixo Rios do Sul. Com uma área de $1.488 \mathrm{~km}^{2}$, inclui o baixo curso fluvial dos rios Itabapoana $\mathrm{e}$ Itapemirim e as microbacias de Marataízes. Esta subregião está incluída na região fisiográfica do litoral oriental do Recôncavo Baiano até o sul do Espírito Santo, mas com as escarpas da Serra do Mar, ainda relativamente interiorizadas e que atingem a costa, próximo a região de Vitória (Silveira 1964).

O rio Itabapoana inicia o terço inferior após receber o rio Muqui do Sul, com ampla planície inundável, marcada por lagoas, brejos e várzeas. A planície costeira do Itabapoana apresenta na porção distal um amplo desenvolvimento de depósitos arenosos marinhos em forma de sucessivas cristas de praia (inteiramente no estado do Espírito Santo), estando a barra do rio localizada no limite sul deste compartimento. Isto sugere um transporte litorâneo residual para o sul. Como ressaltado por Lamego (1945), o rio Itabapoana era originalmente meandrado. $\mathrm{O}$ rio sofreu retificação em seu terço inferior e perdeu parte de seus característicos meandros. O manguezal do estuário do rio Itabapoana encontra-se entre os mais degradados regionalmente (Bernini \& Rezende 2010). No manguezal, junto à foz do rio, observa-se uma urbanização descontrolada, tendo sofrido com o corte de vegetação e aterros. Ali se instalou, ainda no século XIX, o povoado de São Sebastião, atual Barra de
Itabapoana, na margem direita, no Rio de Janeiro (Bernini et al. 2010). A margem esquerda, no Espírito Santo, em 1980, ainda encontrava-se preservada. Nesta margem próxima à foz do Itabapoana, no balneário de Praia das Neves, ainda existe um complexo estuarino com a presença de vegetação de manguezal (Soffiati Netto 2011). Há indicativos de que, tal como aconteceu com o rio Paraíba do Sul, o rio Itabapoana teria perdido vazão com a construção de barragens em seu leito para a geração de energia elétrica. Assim, o rio não teria mais competência para enfrentar o mar e manter sua foz em posição perpendicular a ele. Em seu trecho final, o Itabapoana, sofre um desvio para o sul (Soffiati Netto 2007).

Entre a foz do rio Itapemirim e a margem norte da desembocadura do rio Itabapoana, o relevo litoral é marcado pelas falésias vivas da formação Barreiras e por praias estreitas com baixa declividade (Santos 2005). A formação Barreiras é marcada pelo relevo suave e se estende, irregularmente, ao longo da região costeira, entre o litoral do Pará e o Rio de Janeiro (Bigarella \& Andrade 1964). No Espírito Santo, os depósitos terciários da Formação Barreiras encontramse distribuídos por todo o litoral, sendo sua presença mais pronunciada ao norte do rio Doce. Aí, se alarga até os limites das Minas Gerais, e rumo ao sul sofre um decréscimo de largura, limitando-se aos vales litorâneos, marcadamente ao sul da desembocadura do rio Itapemirim (Amador \& Dias 1978).

Neste trecho de relevo suave, entre os rios Itapemirim e Itabapoana, encontram-se as microbacias de Marataízes. Nela existem pequenos riachos correndo isolados, e outros que chegam a formar microbacias independentes, mas que não conseguem manter suas barras permanentemente abertas por deficiência de vazão. Sua fisionomia se assemelha à de lagoas alongadas, como as Lagoas Funda, D'Antas, do Siri, Lagoinha, dos Cações, das Pitas, do Mangue, de Caculucaje, da Tiririca, da Boa Vista e do Criador (Soffiati Netto 2011). A maioria destas limita-se ao município de Marataízes. A microbacia do córrego São Salvador é a maior da região e tem suas nascentes no município de Presidente Kennedy e Itapemirim, desaguando na divisa com Marataízes. Estes pequenos córregos entrecortam áreas de brejo, mata paludosa, restinga, e manguezais.

Do ponto de vista geológico, esta área delimita uma das feições costeiras mais originais do sul do Espírito Santo, estendendo-se até o norte do estado do Rio de Janeiro, no rio Macaé. As formações cristalinas PréCambrianas descrevem um quase semicírculo tocando o mar na extremidade sul, no rio Macaé, e mergulhando novamente nele na extremidade norte, no rio Itapemirim. Do Terciário, existe uma unidade do Grupo Barreiras, ao norte, entre a margem esquerda do rio Paraíba do Sul, até o rio Itapemirim. A parte mais externa da porção continental é constituída por restingas, a setentrional - a menor delas - na Praia das Neves, no litoral capixaba (Soffiati Netto 2011). 
Os rios do sul do Espírito Santo receberam a visita da Expedição Nathaniel Thayer, então liderada por Louis Agassiz, em meados do século XIX. Após aportarem no Rio de Janeiro, em 1865, seus participantes se dividiram entre vários roteiros para percorrer o Brasil. Ao geólogo Frederick C. Hartt e o voluntário Edward Copeland, coube percorrer o trecho entre o Rio de Janeiro e a Bahia. Alcançaram Bom Jesus do Norte, e dali desceram pelo rio Itabapoana, passando por Porto da Limeira até a desembocadura do rio: "Dessa serra até Bom Jesus, a região é toda de gnaisse, com morros baixos arredondados, tudo coberto de florestas do máximo vigor de vegetação: [...] Entre Bom Jesus e Ribeirão do Jardim a terra é quase sempre baixa, entremeada de morros gnáissicos arredondados de pouca elevação. O rio é ladeado por terras planas de aluvião, frequentemente alagadiças, servindo de refúgio a grande número de aves aquáticas, piaçocas (Parra jacana), grous, etc. [...] Descendo o rio a partir de Porto da Limeira, deixa-se logo a região gnáissica, e penetra-se numa região plana, na sua maior parte bem revestida de matas, e mais ou menos entremeada de lagoas raras, uma das quais, a Lagoa Feia $[R J]$, é realmente muito extensa. O rio é muito estreito e sinuoso [...]" (Hartt 1941: 76-77). Do Itapemirim, seguiram para o norte até o lago Marobá e daí até o rio Itapemirim em Itapemirim (Dick, 1977). Ficaram registradas as amostragens da Expedição Thayer, no rio Itabapoana e no rio Itapemirim, ao sul do Espírito Santo (Higuchi 1996).

Amostragem. As atividades de campo foram realizadas durante o dia, pela manhã até o crepúsculo, cobrindo quatro ou cinco localidades por dia. As rotas de coletas do projeto foram estabelecidas com base nas regiões menos amostradas das bacias. Os pontos de amostragem foram previamente planejados, levando-se em conta o acesso, inclusive as travessias por vias menores não pavimentadas. Cada um dos pontos de amostragem foi localizado por GPS (Global Positioning System), fotografado e caracterizado quanto às condições ambientais. Foram, ainda, realizadas anotações sobre horário e artefatos de pesca empregados. As amostragens realizadas com o uso de puçás, picarés, covos, rede de arrasto tipo trawl, redes de arrastos, tarrafa tipo argola, rede passaguá, tarrafa multifilamento e redes de espera. Em cada ponto foi usada uma combinação dos recursos de pesca de forma a assegurar uma exaustiva amostragem de leito, fundo e margem do local. Cada localidade foi amostrada, sempre que possível, percorrendo-se um trecho de aproximadamente $50 \mathrm{~m}$ rio acima. Alguns exemplares coletados foram fotografados vivos, fixados em formalina a $10 \%$ e transportados para o laboratório, onde foram triados, transferidos para conservação em álcool a 70\%, identificados e catalogados. Alguns lotes foram separados e conservados em álcool absoluto para exame de tecidos (Sarmento-Soares \& MartinsPinheiro 2012b).
Taxonomia. A classificação dos exemplares seguiu Buckup et al. (2007) para peixes de água doce e Carvalho Filho (1999) e Menezes et al. (2003) para peixes marinhos. Os exemplares coletados durante o projeto foram examinados e tombados na coleção ictiológica do Museu de Biologia Professor Mello Leitão (MBML) e do Museu Nacional, Universidade Federal do Rio de Janeiro (MNRJ). Materiais históricos foram consultados nestas duas coleções ictiológicas e nos bancos de dados da Coleção Ictiológica da Universidade Federal do Espírito Santo (CIUFES), do Museu de Zoologia da Universidade de São Paulo (MZUSP), do Museu de Ciências da Pontifícia Universidade Católica do Rio Grande do Sul (MCP), da Universidade Federal do Rio Grande do Sul (UFRGS), da Coleção de Peixes do Laboratório de Ictiologia de Ribeirão Preto (LIRP), da Coleção de Peixes do Museu de Zoologia da UNICAMP (ZUEC) e da Harvard University Museum of Comparative Zoology (MCZ) (Sarmento-Soares \& Martins-Pinheiro 2012c).

Análise de dados. Mapas georrefenciados dos rios foram elaborados usando o programa GPS Trackmaker Professional 4.8 (Ferreira Júnior 2012), com base nas cartas do IBGE de 1:100.000 e 1:50.000 e verificações de campo. Com base nesses mapas, foram calculados os comprimento e áreas cartográficos e estimadas as localidades históricas. Informações sobre pontos de coletas próximas foram algumas vezes agrupadas em um único ponto para a elaboração dos mapas e tabelas.

Para caracterizar a ictiofauna, foram utilizadas avaliações de constância, rarefação, riqueza, dominância, diversidade e uniformidade. Os valores de Constância de Ocorrência (C) das diferentes espécies foram calculados, segundo Dajoz (1983), a partir da equação: $C=\frac{p}{P} * 100 \quad \begin{aligned} & \text {, onde } \mathrm{C} \text { é o valor de } \\ & \text { constância da espécie, } \mathrm{p} \text { é a }\end{aligned}$ quantidade de pontos em que apareceu a espécie e P é $\mathrm{o}$ número total de pontos. As espécies foram consideradas constantes $(C \geq 50)$, acessórias $(25 \leq C<50)$ ou ocasionais $(\mathrm{C}<25)$. As curvas de suficiência da amostragem construídas pelo método Mao Tau (Colwell et al. 2004) não foram utilizadas pela grande quantidade de dados amostrais históricos, com procedimentos de coletas muito distintos entre si. Como estimadores de riqueza foram usados os índices de riqueza não-paramétricos Chao 2, Jackknife 1, Jackknife 2 e Bootstrap. Esses índices estimam o número de espécies ainda por serem coletadas, com base numa quantificação de raridade. São índices baseados em incidência e utilizam o número de "Uniques" e "Duplicates", que são o número de espécies encontradas em somente uma e/ou duas amostras, respectivamente, para as estimativas de riqueza (Colwell \& Coddington 1994). 
Para estimativa da dominância (D), foi usada a relação: $\quad \mathrm{D}=\sum\left(\frac{\mathrm{n}_{\mathrm{i}}}{\mathrm{n}}\right)^{2} \quad \begin{aligned} & \text {, onde ni é a quantidade de } \\ & \text { exemplares da espécie i. }\end{aligned}$ A dominância varia de 0 (todas as espécies estão igualmente representadas) a 1 (uma espécie domina a comunidade completamente). A estimativa da diversidade foi realizada utilizando o Índice de Shannon-Wiener:

$$
H=-\sum \frac{n_{i}}{n} \ln \left(\frac{n_{i}}{n}\right) \quad \begin{aligned}
& \text {. Este índice de } \\
& \text { diversidade leva }
\end{aligned}
$$

em conta o número de indivíduos e a quantidade de espécies. Varia de 0 para comunidades com uma única espécie até valores elevados (acima de 5.0) para comunidade com muitas espécies e poucos exemplares de cada espécie (Magurran 1988). Como indicador de biodiversidade, foi utilizado o índice de riqueza de Margalef: $\mathrm{M}=(\mathrm{S}-1) / \ln (\mathrm{n})$, onde $\mathrm{S}$ é o número de táxons e $\mathrm{n}$ o número de exemplares coletados (Magurran 1988). A uniformidade (equitability) foi

calculada usando-se o índice de Pielou (1969): $\quad e=\frac{H}{\log S}$ utilizado o programa PAST 2.17b (Hammer et al. 2001).

\section{RESULTADOS}

Foram amostrados 92 pontos georreferenciados em rios e córregos, sendo 23 na bacia do Itabapoana, 66 na bacia do Itapemirim e três nas microbacias de Marataízes (Figura 2): 41 na sub-região hidrográfica Alto Itapemirim, 18 no Médio Itapemirim, oito no Alto Itabapoana, 10 no Médio Itabapoana e 25 no Baixo Bacias do Sul (as Figuras 3-6 ilustram alguns dos pontos de coleta). O comprimento dos rios, altitudes das nascentes e áreas dessas sub-regiões hidrográficas estão apresentadas em Sarmento-Soares \& MartinsPinheiro (2012d) e os parâmetros ambientais encontrados em cada ponto de amostragem no Apêndice 1.

Foram encontradas 79 espécies, incluindo registros históricos e recentes, pertencentes a 30 famílias e 11 ordens (Apêndice 1; para ilustração de algumas espécies, veja Figuras 7-9), a grande maioria pertencente à ordem dos Siluriformes, com sete famílias e 29 espécies (36,71\%), seguida dos Characiformes, com seis famílias e 19 espécies

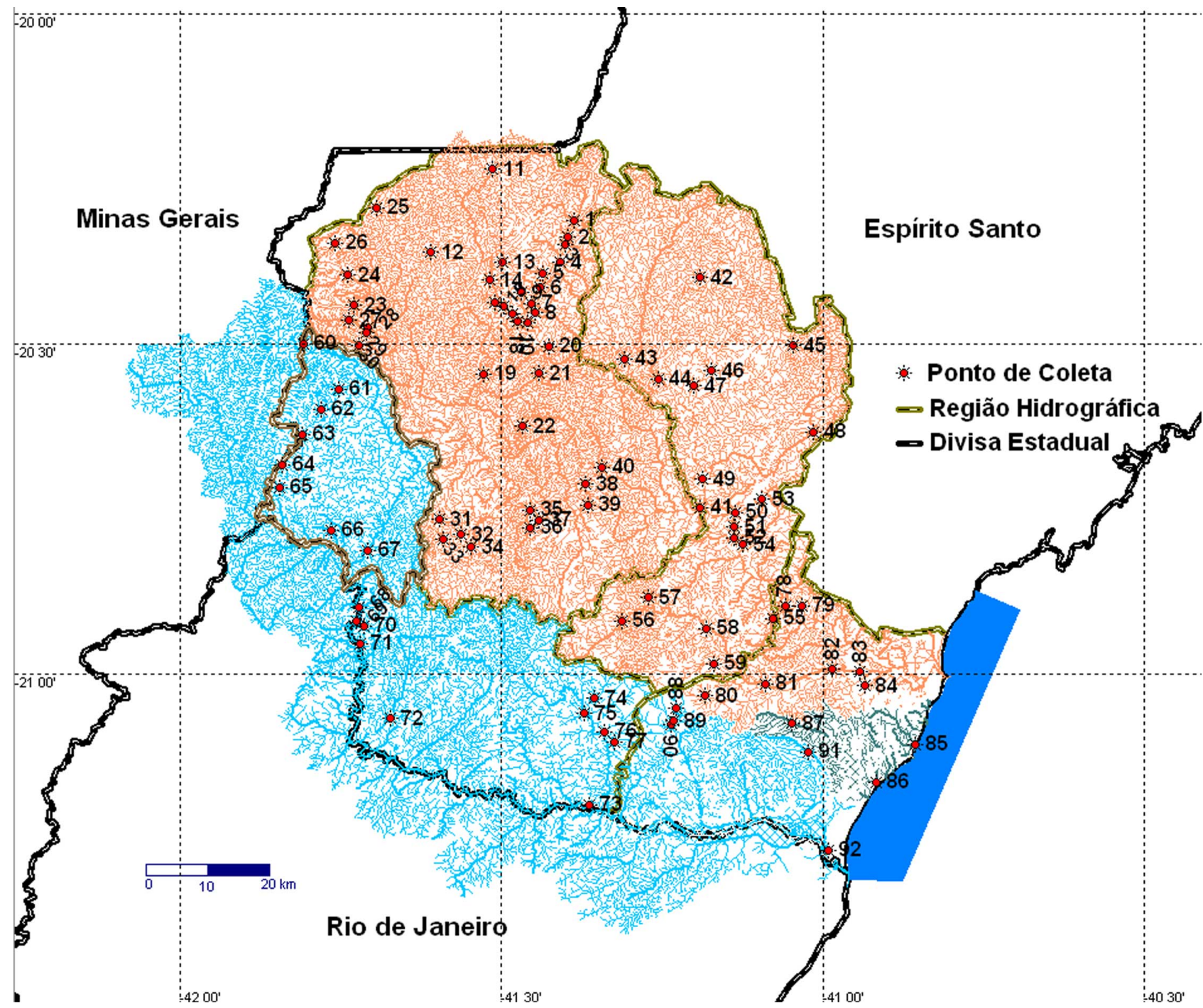

Figura 2. Mapa da área de estudo indicando os pontos de amostragem nas respectivas sub-regiões hidrográficas de amostragem (veja o Apêndice 1 para identificação e caracterização dos pontos). 


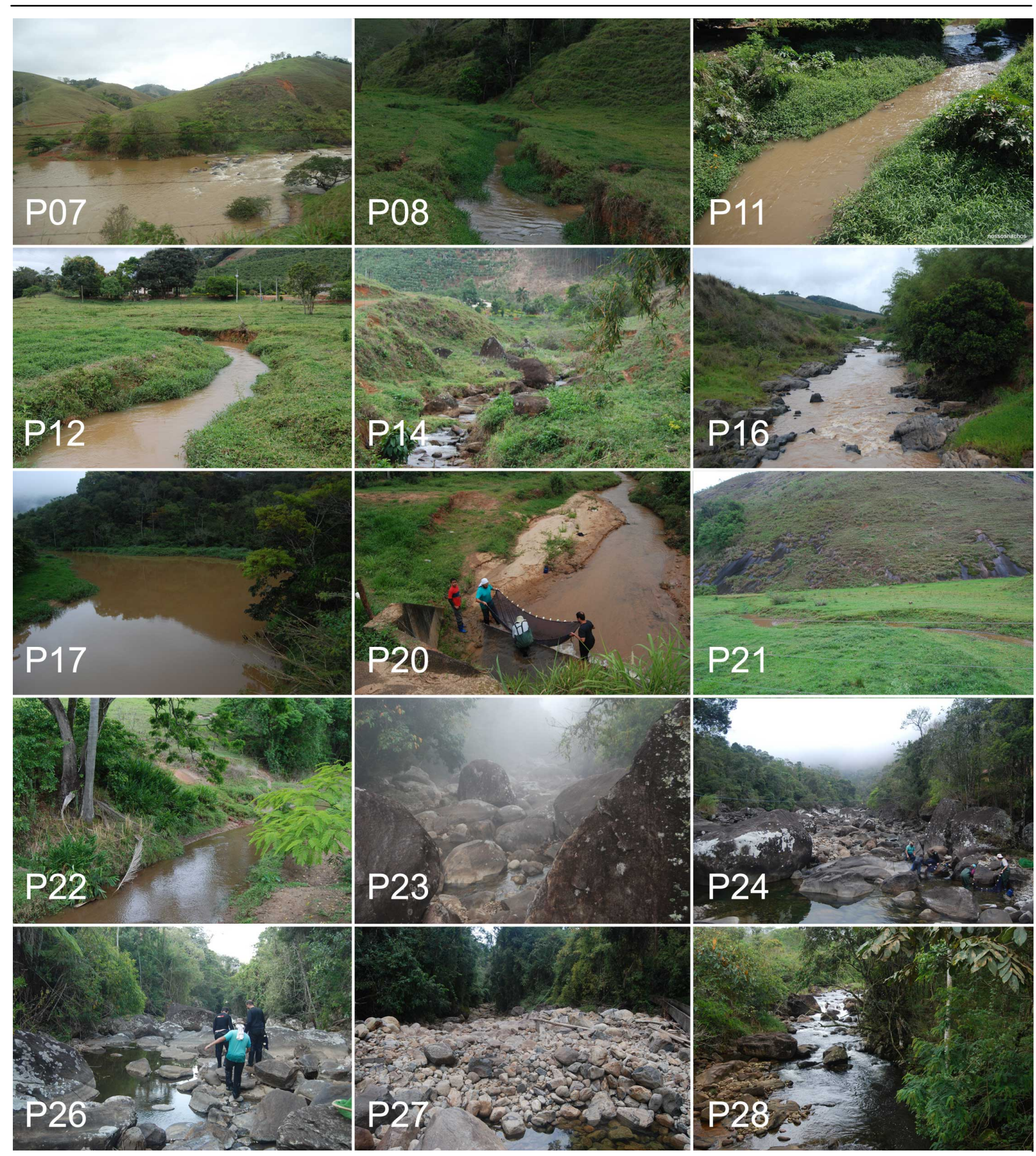

Figura 3. Pontos de amostragem no Alto Itapemirim (veja o Apêndice 1 para identificação e caracterização dos pontos).

(24,05\%), e dos Perciformes, com sete famílias e 18 espécies (22,78\%); seguem os Cyprinodontiformes, com uma família e três espécies $(3,80 \%)$, os Clupeiformes, Pleuronectiformes e Gymnotiformes, com duas famílias e duas espécies cada $(2,53 \%)$. Finalmente, com apenas uma espécie cada, estão os Mugiliformes, Atheriniformes, Gasterosteiformes e Synbranchiformes $(1,27 \%)$. Os peixes de hábitos marinhos encontrados nos estuários somaram 17 espécies. Foram encontradas 62 espécies em ambientes de água doce: na sub-região hidrográfica Alto Itapemirim, foram encontradas 40 espécies; no Médio Itapemirim, 41; no Alto Itabapoana, 23; no
Médio Itabapoana, 39; e no Baixo Rios do Sul, 61 (a Tabela 2 assinala a presença de cada espécie por sub-região).

Das espécies amostradas, 72 ocorrem na bacia do rio Itabapoana, sendo 27 delas encontradas exclusivamente nesta bacia: Ancistrus multispinnis, Brycon insignis, Centropomus parallelus, Hasemania $s p$., Ituglanis parahybae, Loricariichthys castaneus, Mimagoniates microlepis e Synbranchus marmoratus; além de espécies de influência marinha com presença estuarina: Achirus declivis, Anchovia clupeoides, Archosargus probatocephalus, Bairdiella ronchus, 


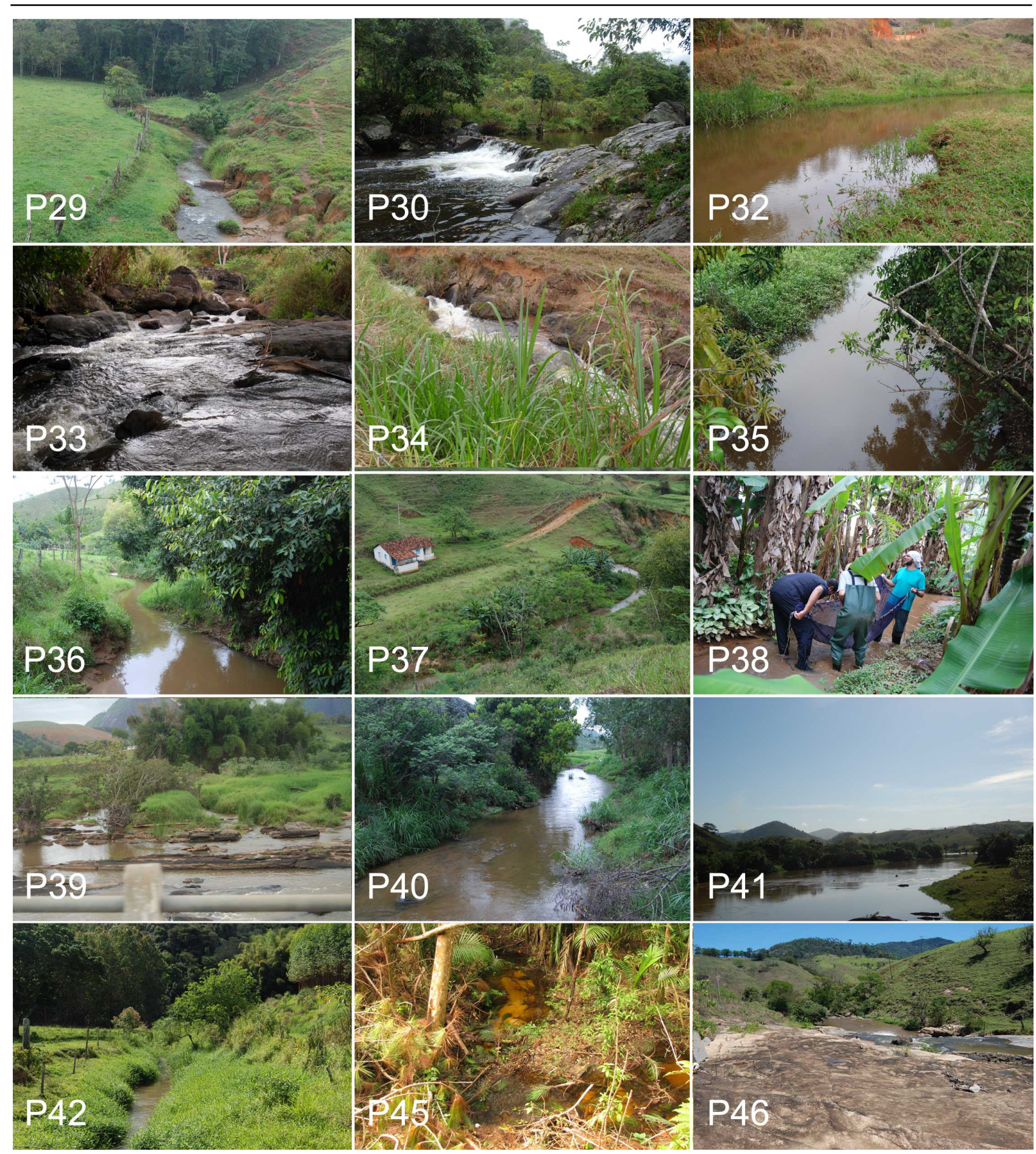

Figura 4. Pontos de amostragem no Alto e Médio Itapemirim (veja o Apêndice 1 para identificação e caracterização dos pontos).

Caranx latus, Citharichthys arenaceus, Ctenogobius boleosoma, Diapterus rhombeus, Dormitator maculatus, Eucinostomus melanopterus, Eugerres brasilianus, Genidens genidens, Lutjanus jocu, Microphis brachyurus, Micropogonias furnieri, Mugil curema, Paralichthys brasiliensis e Pomadasys crocro. Oito espécies foram encontradas nas microbacias de Marataízes, sendo Brevoortia pectinata registrada unicamente para estas microbacias. Cinquenta e seis espécies estão presentes na bacia do rio Itapemirim, 12 exclusivamente nesta bacia: Awaous tajasica, Aspidoras virgulatus, Astyanax microschemos, Astyanax parahybae, Callichthys callichthys,
Centropomus undecimalis, Pterygoplichthys sp., Hypostomus auroguttatus, Leporinus mormyrops e Trichogenes claviger; além de Gobionellus stomatus, espécie marinha com presença estuarina. Cinco espécies foram registradas em todas as bacias do sul: Eucinostomus lefroyi, Geophagus brasiliensis, Hyphessobrycon bifasciatus, Phalloceros harpagos e Poecilia vivipara. Quinze espécies foram encontradas em todas as sub-regiões hidrográficas: Astyanax giton, Astyanax sp. 2 aff. A. lacustris, Bryconamericus ornaticeps, Characidium sp., Cyphocharax gilbert, Geophagus brasiliensis, Gymnotus carapo, Hoplias malabaricus, Hypostomus affinis, Leporinus copelandii, 


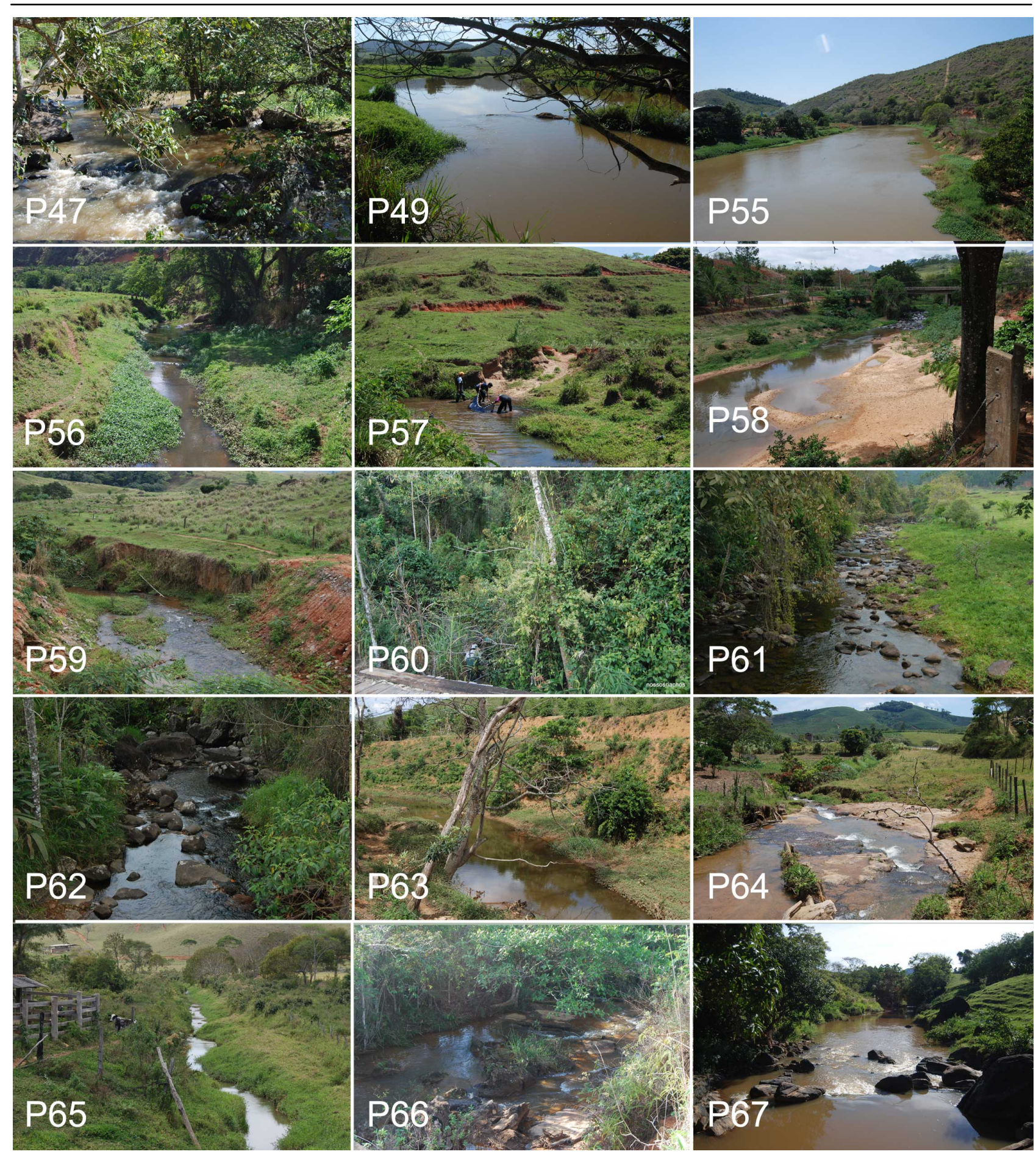

Figura 5. Pontos de amostragem no Médio Itapemirim (veja o Apêndice 1 para identificação e caracterização dos pontos).

Pimelodella lateristriga, Poecilia vivipara, Rhamdia sp. e Trichomycterus caudofasciatus. Apenas uma espécie foi considerada constante, com presença em mais da metade dos pontos amostrados: Geophagus brasiliensis $(67,0 \%)$. Doze foram consideradas acessórias, com presença em mais de um quarto dos pontos amostrados e as restantes foram reconhecidas como ocasionais (Apêndice 2).

A maior riqueza de espécies foi na sub-região hidrográfica do Baixo Rios do Sul: considerando as marinhas, que frequentam o estuário, foram 60 espécies $(75,95 \%$ da riqueza das bacias do sul), e desconsiderando as espécies marinhas, foram
$43(69,35 \%)$ (Tabela 3). As estimativas de riqueza de espécies para as bacias do sul do Espírito Santo considerando também os peixes marinhos apresentaram uma variação de $34,2 \%$ entre o maior valor (117) calculado pelo método Jackknife 2 e o menor (90) calculado pelo método Bootstrap. As estimativas usando os outros métodos apresentaram valores intermediários a estes. Desconsiderando os peixes marinhos, esta variação foi de $107,9 \%$ entre o maior valor com a aplicação do método Jackknife 2 (74) e o menor valor com a aplicação dos método Bootstrap e Chao 2 (67), ficando a estimativa usando o método Jackknife 1 com valor intermediário (Tabela 3). 


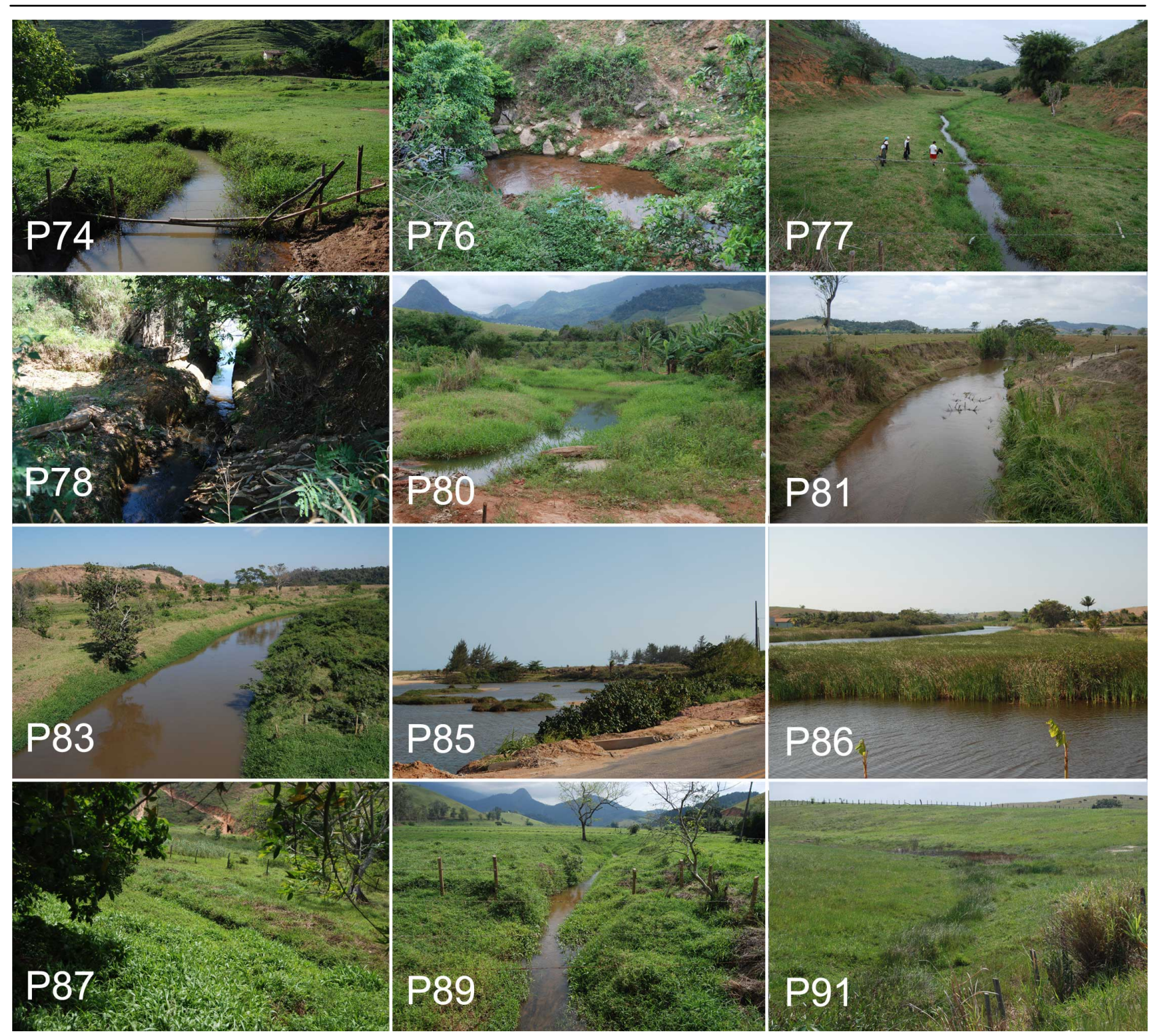

Figura 6. Pontos de amostragem no Médio Itabapoana e Baixo das Bacias do Sul (veja o Apêndice 1 para identificação e caracterização dos pontos).

A sub-região hidrográfica Alto Itabapoana apresentou o índice de riqueza de Margalef mais baixo entre todas as sub-regiões das bacias do sul $(3,09)$, sendo apenas $46,77 \%$ do índice calculado para o conjunto das bacias $(6,60)$. A diferença também foi elevada para os índices de diversidade de Shannon $(2,10)$, sendo apenas $66,87 \%$ do índice calculado para o conjunto das bacias $(3,14)$. Chama atenção a riqueza de espécies registrada para o Ponto 90, no rio das Flores, região de São José das Torres, com 27 espécies representando quase metade de todas as espécies dulcícolas das bacias.

Seis peixes não foram identificados no nível de espécie: Astyanax sp.2 aff. A. lacustris, Characidium sp., Eigenmannia sp., Hasemania sp., Imparfinis sp. e Rhamdia sp., e podem representar novos táxons, necessitando de mais investigações. Os espécimens reconhecidos como Hasemania sp. estão sendo investigados por nós conjuntamente com F.M.R.S. Pupo, F.R. Carvalho e J.P. Serra; Imparfinis sp. também está sendo avaliada por nossa equipe.
As únicas espécies exóticas com registro para a região foram a tilápia Tilapia rendalii, da África, e o barrigudinho Poecilia reticulata, do litoral norte da América do Sul, entre a Venezuela e o estado brasileiro do Amapá (Lucinda \& Costa 2007). Relatos sobre a presença do bagre africano Clarias gariepinnus foram fornecidos por J.L. Helmer (com. pess.).

\section{DISCUSSÃo}

Expedição Thayer. Os relevos, com escarpas íngremes, nos contrafortes do Caparaó, chamaram a atenção de estudiosos que atravessaram o sudoeste capixaba ainda no século XIX: "As Serras se interrompem ao atingir o vale do rio Paraíba [...] e então, formando serras destacadas, afastam-se algum tanto da costa, passam pelas cabeceiras dos rios Muriaé e Itabapuana, ligam-se a serra de Itabapuana e Itapemirim, dando origem a alguns cenários de 

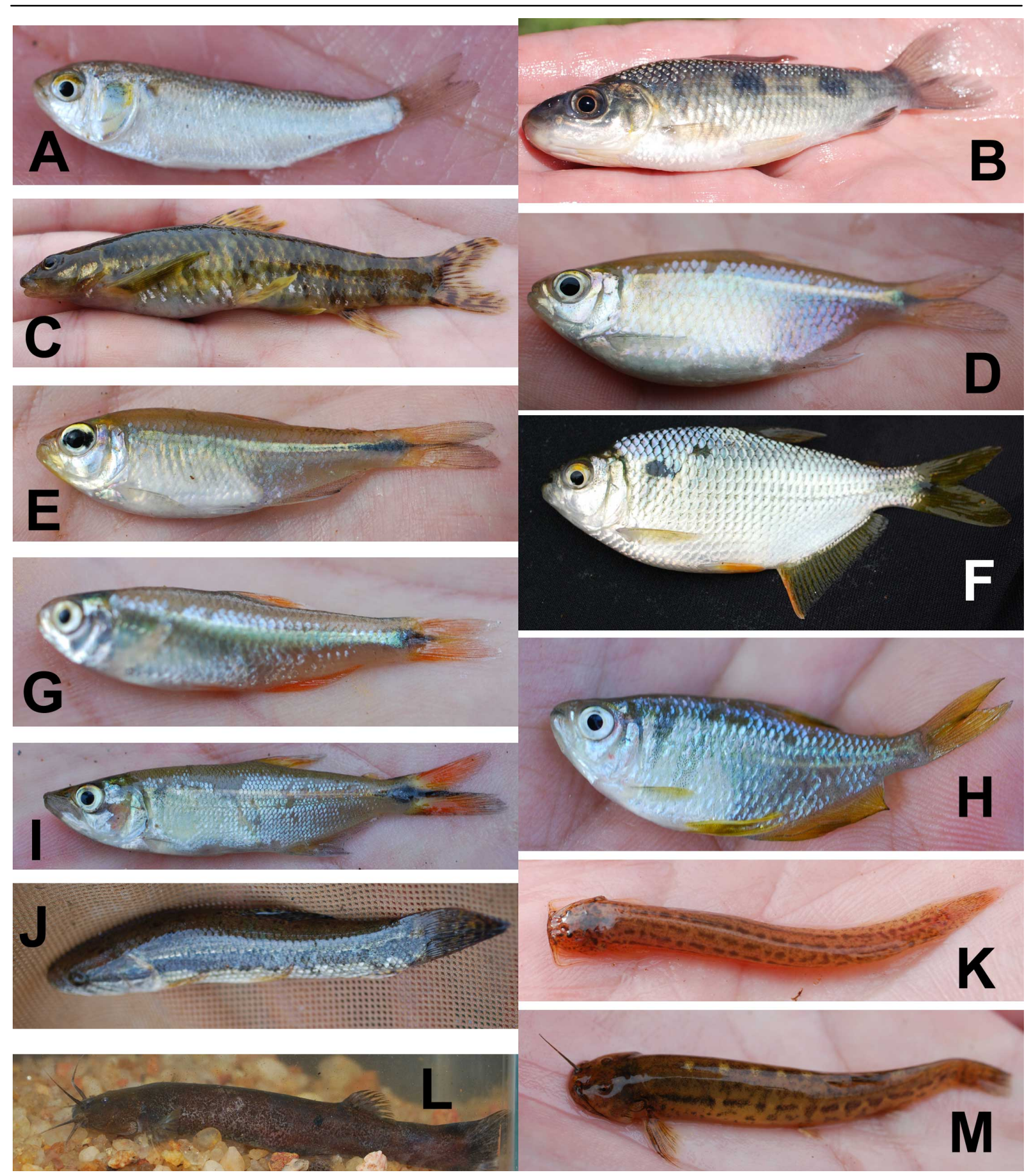

Figura 7. Espécies de peixes encontradas nas bacias do sul do Espírito Santo: A- Brevoortia pectinata; B- Leporinus copelandii; C- Characidium sp.; D- Astyanax giton; E- Astyanax janeiroensis; F- Astyanax sp.2 aff. A. lacustris; G- Hasemania sp.; H- Hyphessobrycon bifasciatus - macho; I- Oligosarcus acutirostris; J- Hoplias malabaricus; K- Ituglanis parahybae; L- Trichomycterus brunoi; M- Trichomycterus caudofasciatus.

montanhas muito pitorescos. [...]" Hartt (1870: 65). Este relato se refere ao percurso entre o Rio de Janeiro e o Espírito Santo, acompanhado pela Expedição Thayer. Higuchi (1996) reconstruiu as estações de coleta ictiológica da Expedição Thayer, verificando datas, coletores e localidades. Das bacias do sul do Espírito Santo, ficaram dois registros de coletas, uma no rio Itabapoana (THAYER044) e outra no rio
Itapemirim (THAYER045). O material coletado durante a expedição Thayer corresponde ao mais antigo registro conhecido sobre peixes de água doce do Espírito Santo. Estima-se que as espécies provenham de diferentes pontos do rio Itabapoana, pois há registros de 15 espécies eminentemente de água doce: Characiformes (Curimatidae, Characidae), Siluriformes (Auchenipteridae, Loricariidae), Gymnotiformes 

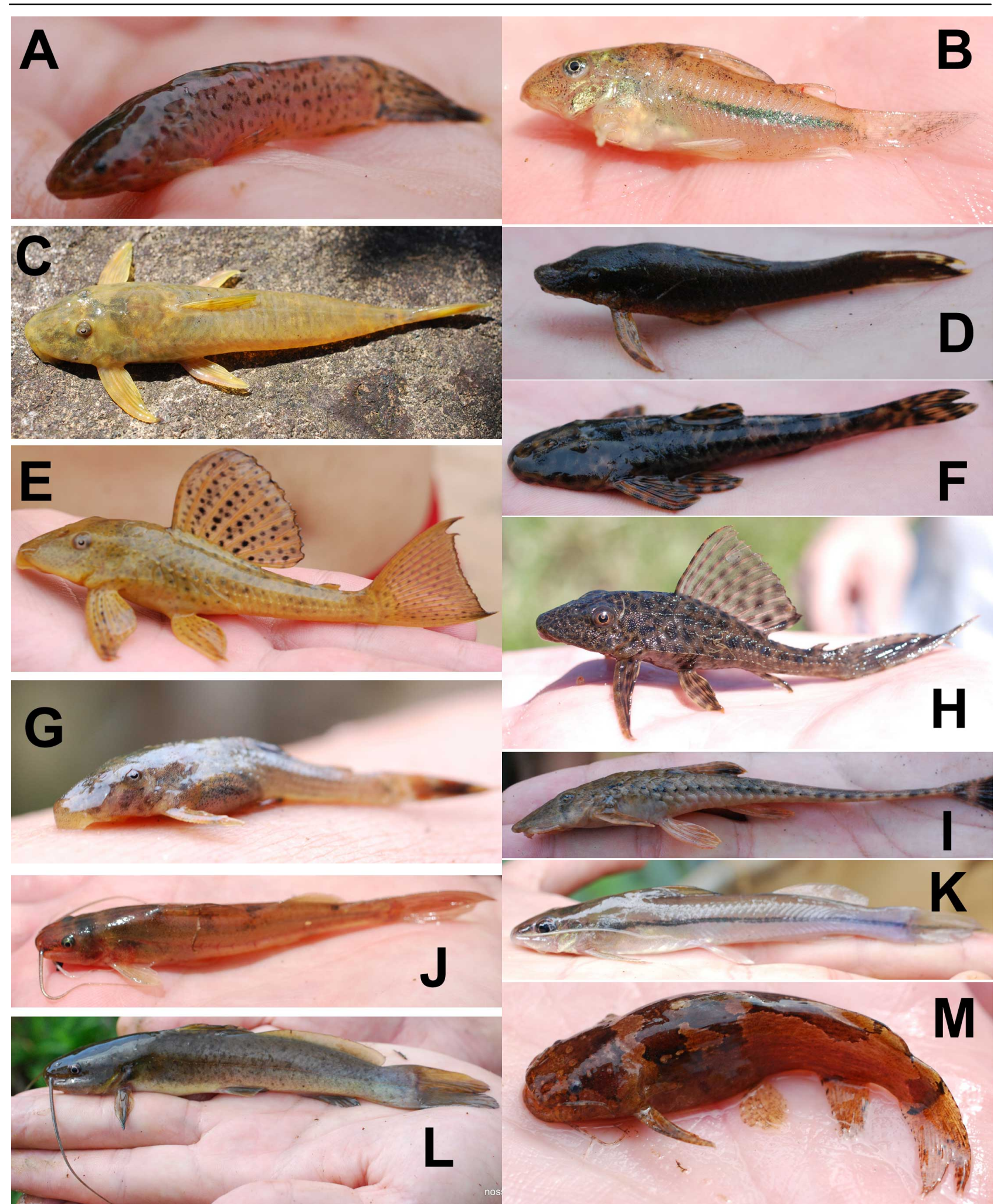

Figura 8. Espécies de peixes Siluriformes encontradas nas bacias do sul do Espírito Santo: A- Callichthys callichthys; B- Corydoras nattereri; C- Harttia loricariformis; D- Hisonotus notatus; E- Hypostomus affinis; F- Neoplecostomus microps; G- Parotocinclus maculicauda; H- Pterygoplichthys sp.; I- Rineloricaria steindachneri; J- Imparfinis sp.; K- Pimelodella pectinifer; L- Rhamdia sp.; M- Microglanis parahybae.

(Gymnotidae), Perciformes (Cichlidae) e ainda um conjunto de 12 espécies marinhas Perciformes (Carangidae, Gerreidae, Sparidae, Sciaenidae, Gobiidae), Mugiliformes (Mugilidae) e Pleuronectiformes (Paralychthyidae). Uma espécie foi descrita a partir do material coletado pela expedição
Thayer no sul do Espírito Santo: 'Deuterodon' parahybae. Apesar de ter como nominal o gênero, 'Deuterodon' parahybae é atualmente considerada espécie incertae sedis em Characidae, pois não compartilha as características de Deuterodon sensu Lucena \& Lucena (2002). Na ausência de um nome 


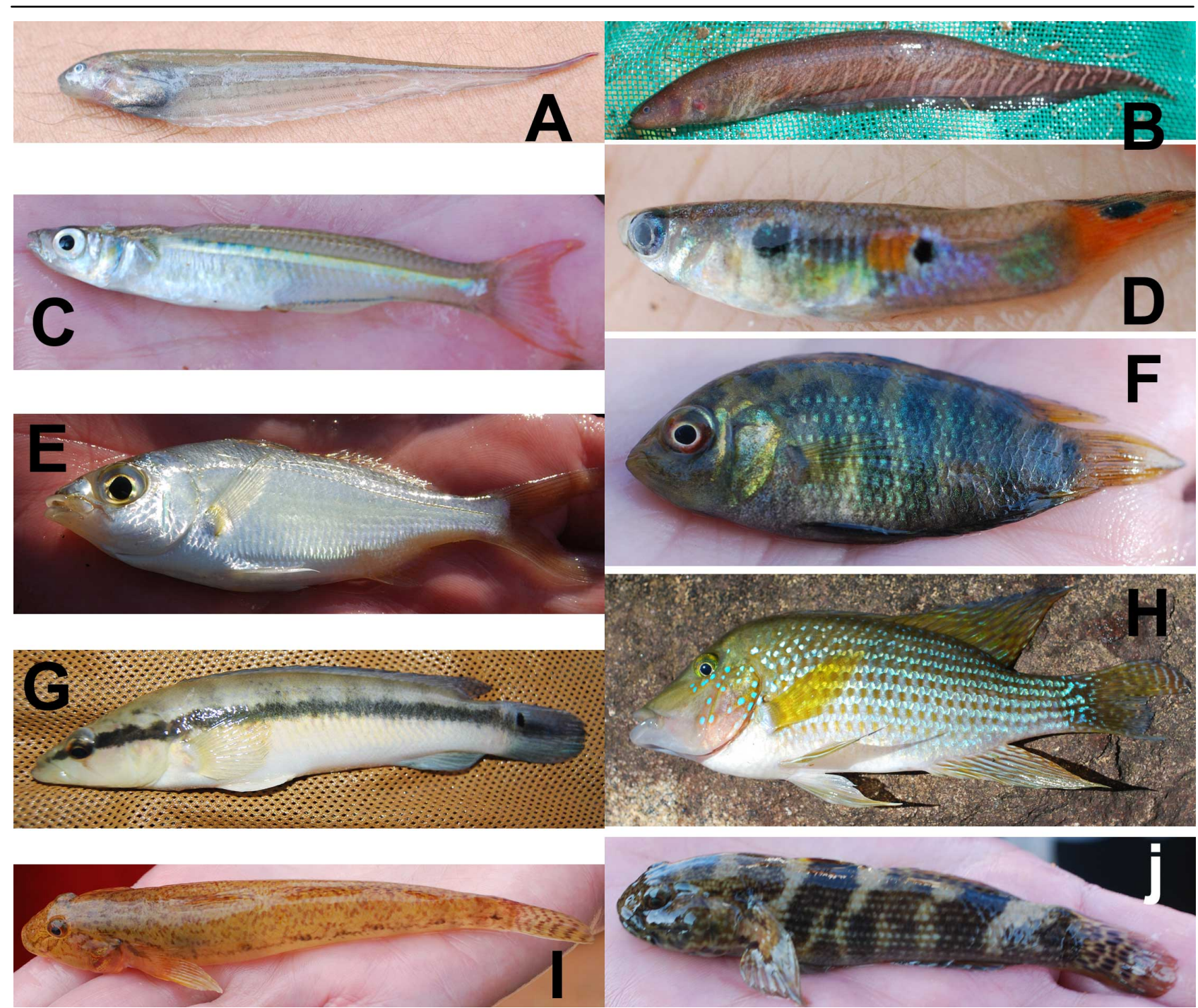

Figura 9. Espécies de peixes encontradas nas bacias do sul do Espírito Santo: A- Eigenmannia sp.; B- Gymnotus carapo; C- Atherinella brasiliensis; D- Poecilia reticulata; E- Eucinostomus melanopterus; F- Australoheros muriae; G- Crenicichla lacustris; H- Geophagus brasiliensis; I- Awaous tajasica; J- Bathygobius soporator.

genérico formal, optou-se por colocar o nome do gênero entre aspas simples, seguindo as recomendações de Reis et al. (2003), Lima et al. (2007) e Pereira (2010). 'Deuterodon' parahybae necessita de maiores investigações para aferir sua real identidade (C.A.S. Lucena, com. pess.), e não foi encontrada por nós no presente estudo, apesar da ampla verificação de amostras que realizamos. Todo o material colecionado do sul do Espírito Santo durante a expedição Thayer, incluindo tipos, encontra-se depositado no MCZ. Outras espécies descritas posteriormente, a partir de material coletado nos rios do Sul, são Astyanax microschemos, Oligosarcus acutirostris e Trichogenes claviger, com localidades-tipo para a bacia do rio Itapemirim.

A Expedição Thayer desceu o rio Itabapoana, desde Bom Jesus do Norte até a foz, sendo perfeitamente possível que muitos lotes tenham sido capturados em vários trechos do rio. Como não há informação de outras localidades, todas as amostragens do rio Itabapoana foram catalogadas como procedentes da foz (ponto 92). Por outro lado, o Ponto 90, na baixada rodeada pela Serra de São José das Torres, chama especial atenção pela elevada riqueza em relação a outros pontos da bacia, podendo ser indício de uma região com alta riqueza de espécies, e merece ser investigada em maior detalhe.

Riqueza e diversidade. Rios torrenciais, protegidos pela Serra do Caparaó, contrastam pela menor riqueza da ictiofauna, com poucas espécies nos altos vales fluviais, cujas altitudes chegam a $1.450 \mathrm{~m}$. As espécies mais comuns nos contrafortes do Caparaó foram os Trichomycterus, conhecidos como cambevas, com duas espécies descritas regionalmente, T. caudofasciatus e $T$. brunnoi. As cambevas são os únicos peixes conhecidos pela população no alto vale do Caparaó. Os moradores do entorno costumam pescar cambevas usando o "parão", uma varinha de pesca com minhocas e sem anzol. Costumam apanhá-los em uma panelinha e depois fritam. Indivíduos de Trichomycterus chegam a alcançar mais de $6 \mathrm{~cm}$ de comprimento padrão na 
Tabela 2. Espécies de peixes das bacias do sul do Espírito Santo. Espécies exóticas estão assinaladas por um asterisco (*). AIP- Alto Itapemirim; MIP- Médio Itapemirim; AIB- Alto Itabapoana; MIB- Médio Itabapoana; BBS- Baixo Bacias do sul

\begin{tabular}{|c|c|c|c|c|c|c|c|c|}
\hline \multirow[b]{2}{*}{ Ordem } & \multicolumn{2}{|c|}{ CLASSIFICAÇÂO TAXONÔMICA } & \multicolumn{6}{|c|}{ SUB-REGIÃO HIDROGRÁFICA } \\
\hline & Família & Espécie & AIP & MIP & AIB & MIB & BBS & Fig. \\
\hline \multirow[t]{2}{*}{ Clupeiformes } & Engraulidae & Anchovia clupeoides (Swainson, 1839) & & & & & $\mathbf{X}$ & - \\
\hline & Clupeidae & Brevoortia pectinata (Jenyns, 1842) & & & & & $\mathbf{X}$ & $7 \mathrm{~A}$ \\
\hline \multirow[t]{19}{*}{ Characiformes } & Curimatidae & Cyphocharax gilbert (Quoy \& Gaimard, 1824) & $\mathbf{X}$ & $\mathbf{X}$ & $\mathbf{X}$ & $\mathbf{X}$ & $\mathbf{X}$ & - \\
\hline & Prochilodontidae & Prochilodus vimboides Kner, 1829 & $\mathbf{X}$ & & & $\mathbf{X}$ & $\mathbf{X}$ & - \\
\hline & Anostomidae & Leporinus copelandii Steindachner, 1875 & $\mathbf{X}$ & $\mathbf{X}$ & $\mathbf{X}$ & $\mathbf{X}$ & $\mathbf{X}$ & $7 \mathrm{~B}$ \\
\hline & & Leporinus mormyrops Steindachner, 1875 & $\mathbf{X}$ & & & & & - \\
\hline & Crenuchidae & Characidium sp. & $\mathbf{X}$ & $\mathbf{X}$ & $\mathbf{X}$ & $\mathbf{X}$ & $\mathbf{X}$ & $7 \mathrm{C}$ \\
\hline & Characidae & Astyanax giton Eigenmann, 1908 & $\mathbf{X}$ & $\mathbf{X}$ & $\mathbf{X}$ & $\mathbf{X}$ & $\mathbf{X}$ & $7 \mathrm{D}$ \\
\hline & & Astyanax janeiroensis Eigenmann, 1908 & $\mathbf{X}$ & $\mathbf{X}$ & $\mathbf{X}$ & $\mathbf{X}$ & $\mathbf{X}$ & $7 \mathrm{E}$ \\
\hline & & Astyanax microschemos Bertaco \& Lucena, 2006 & $\mathbf{X}$ & $\mathbf{X}$ & & & & - \\
\hline & & Astyanax parahybae Eigenmann, 1908 & $\mathbf{X}$ & $\mathbf{X}$ & & & $\mathbf{X}$ & - \\
\hline & & Astyanax sp. 2 aff. A. lacustris & $\mathbf{X}$ & $\mathbf{X}$ & $\mathbf{X}$ & $\mathbf{X}$ & $\mathbf{X}$ & $7 \mathrm{~F}$ \\
\hline & & Brycon insignis Steindachner, 1877 & & & & $\mathbf{X}$ & $\mathbf{X}$ & - \\
\hline & & Bryconamericus tenuis Bizerril \& Araujo, 1992 & $\mathbf{X}$ & & $\mathbf{X}$ & & & - \\
\hline & & Knodus sp. aff. K. moenkhausii & $\mathbf{X}$ & & $\mathbf{X}$ & $\mathbf{X}$ & $\mathbf{X}$ & - \\
\hline & & Hasemania sp. & & & $\mathbf{X}$ & & & $7 \mathrm{G}$ \\
\hline & & Hyphessobrycon bifasciatus Ellis, 1911 & & $\mathbf{X}$ & & & $\mathbf{X}$ & $7 \mathrm{H}$ \\
\hline & & Mimagoniates microlepis (Steindachner, 1876) & & & & $\mathbf{X}$ & & - \\
\hline & & Oligosarcus acutirostris Menezes, 1987 & $\mathbf{X}$ & $\mathbf{X}$ & & $\mathbf{X}$ & $\mathbf{X}$ & $7 \mathrm{I}$ \\
\hline & & Probolodus heterostomus Eigenmann, 1911 & $\mathbf{X}$ & $\mathbf{X}$ & & & $\mathbf{X}$ & - \\
\hline & Erythrinidae & Hoplias malabaricus (Bloch, 1794) & $\mathbf{X}$ & $\mathbf{X}$ & $\mathbf{X}$ & $\mathbf{X}$ & $\mathbf{X}$ & $7 \mathrm{~J}$ \\
\hline \multirow[t]{25}{*}{ Siluriformes } & Trichomycteridae & Ituglanis parahybae (Eigenmann, 1918) & & & & $\mathbf{X}$ & $\mathbf{X}$ & $7 \mathrm{~K}$ \\
\hline & & $\begin{array}{l}\text { Trichogenes claviger de Pinna, Helmer, Britski \& } \\
\text { Nunes, } 2010\end{array}$ & & $\mathbf{X}$ & & & & - \\
\hline & & Trichomycterus brunoi Barbosa \& Costa, 2010 & $\mathbf{X}$ & $\mathbf{X}$ & $\mathbf{X}$ & $\mathbf{X}$ & $\mathbf{X}$ & $7 \mathrm{~L}$ \\
\hline & & Trichomycterus caudofasciatus Alencar \& Costa, 2004 & $\mathbf{X}$ & & $\mathbf{X}$ & $\mathbf{X}$ & $\mathbf{X}$ & $7 \mathrm{~N}$ \\
\hline & Callichthyidae & Aspidoras virgulatus Nijssen \& Isbrüecker, 1980 & $\mathbf{X}$ & $\mathbf{X}$ & & & & - \\
\hline & & Callichthys callichthys (Linnaeus, 1758) & $\mathbf{X}$ & & & & & $8 \mathrm{~A}$ \\
\hline & & Corydoras nattereri Steindachner, 1877 & & $\mathbf{X}$ & & & $\mathbf{X}$ & $8 \mathrm{~B}$ \\
\hline & & Hoplosternum littorale (Hancock, 1828) & & $\mathbf{X}$ & & & $\mathbf{X}$ & - \\
\hline & & Scleromystax prionotos (Nijssen \& Isbrüecker, 1980) & & & & $\mathbf{X}$ & $\mathbf{X}$ & - \\
\hline & Loricariidae & Ancistrus multispinis (Regan, 1912) & & & & $\mathbf{X}$ & & - \\
\hline & & Harttia loricariformis Chabanaud, 1940 & $\mathbf{X}$ & $\mathbf{X}$ & & $\mathbf{X}$ & $\mathbf{X}$ & $8 \mathrm{C}$ \\
\hline & & Hisonotus notatus Eigenmann \& Eigenmann, 1889 & $\mathbf{X}$ & $\mathbf{X}$ & & $\mathbf{X}$ & $\mathbf{X}$ & $8 \mathrm{D}$ \\
\hline & & Hypostomus affinis (Steindachner, 1877) & $\mathbf{X}$ & $\mathbf{X}$ & $\mathbf{X}$ & $\mathbf{X}$ & $\mathbf{X}$ & $8 \mathrm{E}$ \\
\hline & & Hypostomus auroguttatus Kner, 1854 & $\mathbf{X}$ & $\mathbf{X}$ & & & & - \\
\hline & & Loricariichthys castaneus (Castelnau, 1855) & & & & $\mathbf{X}$ & & - \\
\hline & & Neoplecostomus microps (Steindachner, 1877) & $\mathbf{X}$ & $\mathbf{X}$ & $\mathbf{X}$ & $\mathbf{X}$ & & $8 \mathrm{~F}$ \\
\hline & & Otothyris lophophanes (Eigenmann \& Eigenmann, 1889) & & & & & $\mathbf{X}$ & - \\
\hline & & Pareiorhaphis garbei Ihering, 1911 & $\mathbf{X}$ & & $\mathbf{X}$ & & & - \\
\hline & & Parotocinclus maculicauda (Steindachner, 1877) & $\mathbf{X}$ & $\mathbf{X}$ & & $\mathbf{X}$ & $\mathbf{X}$ & $8 \mathrm{G}$ \\
\hline & & Parotocinclus sp. aff. P. jimi & & & & $\mathbf{X}$ & & - \\
\hline & & Pterygoplichthys sp. & & & & & & $8 \mathrm{H}$ \\
\hline & & Rineloricaria steindachneri (Regan, 1904) & $\mathbf{X}$ & $\mathbf{X}$ & & & $\mathbf{X}$ & $8 \mathrm{I}$ \\
\hline & Ariidae & Genidens genidens (Cuvier, 1829) & & & & & $\mathbf{X}$ & - \\
\hline & Auchenipteridae & Glanidium melanopterum Miranda Ribeiro, 1918 & & $\mathbf{X}$ & & $\mathbf{X}$ & & - \\
\hline & & Trachelyopterus striatulus (Steindachner, 1877) & & $\mathbf{X}$ & & $\mathbf{X}$ & & - \\
\hline
\end{tabular}


Tabela 2 (continuação)

\begin{tabular}{|c|c|c|c|c|c|c|c|c|}
\hline \multirow[b]{2}{*}{ Ordem } & \multicolumn{2}{|c|}{ CLASSIFICAÇÂO TAXONÔMICA } & \multicolumn{6}{|c|}{ SUB-REGIÃO HIDROGRÁFICA } \\
\hline & Família & Espécie & AIP & MIP & AIB & MIB & BBS & Fig. \\
\hline & Heptapteridae & Imparfinis sp. & $\mathbf{X}$ & $\mathbf{X}$ & & $\mathbf{X}$ & $\mathbf{X}$ & $8 \mathrm{~J}$ \\
\hline & & Pimelodella pectinifer Eigenmann \& Eigenmann, 1889 & $\mathbf{X}$ & $\mathbf{X}$ & $\mathbf{X}$ & $\mathbf{X}$ & $\mathbf{X}$ & $8 \mathrm{~K}$ \\
\hline & & Rhamdia sp. & $\mathbf{X}$ & $\mathbf{X}$ & $\mathbf{X}$ & $\mathbf{X}$ & $\mathbf{X}$ & $8 \mathrm{~L}$ \\
\hline & Pseudopimelodidae & Microglanis parahybae (Steindachner, 1880) & $\mathbf{X}$ & $\mathbf{X}$ & & $\mathbf{X}$ & $\mathbf{X}$ & $8 \mathrm{M}$ \\
\hline \multirow[t]{2}{*}{ Gymnotiformes } & Sternopygidae & Eigenmannia sp. & $\mathbf{X}$ & & & $\mathbf{X}$ & $\mathbf{X}$ & $9 \mathrm{~A}$ \\
\hline & Gymnotidae & Gymnotus carapo Linnaeus, 1758 & $\mathbf{X}$ & $\mathbf{X}$ & $\mathbf{X}$ & $\mathbf{X}$ & $\mathbf{X}$ & $9 \mathrm{~B}$ \\
\hline Mugiliformes & Mugilidae & Mugil curema Valenciennes, 1836 & & & & & $\mathbf{X}$ & - \\
\hline Atheriniformes & Atherinidae & Atherinella brasiliensis (Quoy \& Gaimard, 1825) & & & & & $\mathbf{X}$ & $9 \mathrm{C}$ \\
\hline \multirow[t]{3}{*}{ Cyprinodontiformes } & Poeciliidae & Phalloceros harpagos Lucinda, 2008 & $\mathbf{X}$ & $\mathbf{X}$ & $\mathbf{X}$ & $\mathbf{X}$ & $\mathbf{X}$ & - \\
\hline & & *Poecilia reticulata Peters, 1859 & $\mathbf{X}$ & $\mathbf{X}$ & & $\mathbf{X}$ & $\mathbf{X}$ & $9 \mathrm{D}$ \\
\hline & & Poecilia vivipara Bloch \& Schneider, 1801 & $\mathbf{X}$ & $\mathbf{X}$ & $\mathbf{X}$ & $\mathbf{X}$ & $\mathbf{X}$ & - \\
\hline Gasterosteiformes & Syngnathidae & Microphis brachyurus (Blecker, 1853) & & & & & $\mathbf{X}$ & - \\
\hline Synbranchiformes & Synbranchidae & Synbranchus marmoratus Bloch, 1795 & & & & $\mathbf{X}$ & $\mathbf{X}$ & - \\
\hline \multirow[t]{18}{*}{ Perciformes } & Centropomidae & Centropomus undecimalis (Bloch, 1792) & & $\mathbf{X}$ & & & & - \\
\hline & Carangidae & Caranx latus Agassiz, 1831 & & & & & $\mathbf{X}$ & - \\
\hline & Lutjanidae & Lutjanus jocu (Bloch \& Schneider, 1801) & & & & & $\mathbf{X}$ & - \\
\hline & Gerreidae & Diapterus rhombeus (Cuvier, 1829) & & & & & $\mathbf{X}$ & - \\
\hline & & Ulaema lefroyi (Goode, 1874) & & & & & $\mathbf{X}$ & - \\
\hline & & Eucinostomus melanopterus (Bleeker, 1863) & & & & & $\mathbf{X}$ & $9 \mathrm{E}$ \\
\hline & & Eugerres brasilianus (Cuvier, 1830) & & & & & $\mathbf{X}$ & - \\
\hline & Sparidae & Archosargus probatocephalus (Walbaum, 1792) & & & & & $\mathbf{X}$ & - \\
\hline & Cichlidae & Australoheros muriae Ottoni \& Costa, 2008 & & $\mathbf{X}$ & & $\mathbf{X}$ & $\mathbf{X}$ & $9 \mathrm{~F}$ \\
\hline & & Crenicichla lacustris (Castelnau, 1855) & $\mathbf{X}$ & $\mathbf{X}$ & $\mathbf{X}$ & $\mathbf{X}$ & $\mathbf{X}$ & $9 \mathrm{G}$ \\
\hline & & Geophagus brasiliensis (Quoy \& Gaimard, 1824) & $\mathbf{X}$ & $\mathbf{X}$ & $\mathbf{X}$ & $\mathbf{X}$ & $\mathbf{X}$ & $9 \mathrm{H}$ \\
\hline & & *Tilapia rendalli (Boulenger, 1897) & $\mathbf{X}$ & $\mathbf{X}$ & $\mathbf{X}$ & & $\mathbf{X}$ & - \\
\hline & Gobiidae & Awaous tajasica Lichtenstein, 1822 & $\mathbf{X}$ & $\mathbf{X}$ & & & $\mathbf{X}$ & 9I \\
\hline & & Bathygobius soporator (Valenciennes, 1837) & & & & & $\mathbf{X}$ & $9 \mathrm{~J}$ \\
\hline & & Ctenogobius boleosoma (Jordan and Gilbert, 1882) & & & & & $\mathbf{X}$ & - \\
\hline & & Dormitator maculatus (Bloch, 1792) & & & & & $\mathbf{X}$ & - \\
\hline & & Eleotris pisonis (Gmelin, 1789) & & $\mathbf{X}$ & & & $\mathbf{X}$ & - \\
\hline & & Gobionellus stomatus Starks, 1913 & & & & & $\mathbf{X}$ & - \\
\hline \multirow[t]{2}{*}{ Pleuronectiformes } & Paralichthyidae & Citharichthys arenaceus Evermann \& Marsh, 1900 & & & & & $\mathbf{X}$ & - \\
\hline & Achiridae & Achirus declivis Chabanaud, 1940 & & & & & $\mathbf{X}$ & - \\
\hline
\end{tabular}

região. Nos baixos vales fluviais, por outro lado, foi contabilizada uma excepcional diversidade de peixes de riacho, no entorno da Serra das Torres, entre Mimoso do Sul, Muqui e Atílio Vivacqua, onde as altitudes são inferiores a $45 \mathrm{~m}$. Ali, existem remanescentes florestais em bom estado de conservação, formando uma área de interesse para estudos biológicos (IPEMA 2005, 2010). A Serra das Torres funciona como um divisor de águas, separando os contribuintes dos rios Muqui do Norte, no baixo Itapemirim, e os tributários do rio Muqui do Sul, no baixo Itabapoana. Esta área da Serra das Torres pode ser apontada como de máxima importância para a conservação da biodiversidade de água doce no sul do
Espírito Santo. Recentemente, foi criado o Monumento Natural (MONA) de Serra das Torres através da lei $\mathrm{n}^{\mathrm{o}} 9.463$, de 14 de junho de 2010, com o intuito de proteger as bacias hidrográficas dos rios Itapemirim e Itabapoana, além da beleza cênica dos picos e afloramentos rochosos do local (IEMA 2012).

A alta diversidade no Baixo Rios do Sul, em contraste com os altos vales fluviais, corrobora a teoria do rio contínuo, onde é esperada maior diversidade nas zonas baixas do rio, devido, principalmente, à maior complexidade de hábitats (Pianka 2000; Vanote et al. 1980). A maior diversidade nas baixadas litorâneas também pode ser atribuída à proximidade da região estuarina, onde várias espécies marinhas eurialinas que 
Tabela 3. Estimativas não paramétricas de riqueza de espécies e descritores da ictiofauna nas bacias do sul do Espírito Santo (com e sem a presença dos peixes marinhos). Sub-regiões: AIP- Alto Itapemirim (Pontos 1-41); MIP- Médio Itapemirim (Pontos 42-59); AIB- Alto Itabapoana (Pontos 60-67); MIB- Médio Itabapoana (Pontos 68-77); BBS- Baixo Bacias do sul (Pontos 78-92); BSU- Bacias do sul (Pontos $1-92)$.

\begin{tabular}{|c|c|c|c|c|c|c|}
\hline \multicolumn{7}{|c|}{ COM MARINHOS } \\
\hline ESTIMADORES & AIP & MIP & AIB & MIB & BBS & BSU \\
\hline Chao 2 & 44,6 & 62,2 & 25,6 & 55,3 & 85,5 & 103,8 \\
\hline Jackknife 1 & 47,8 & 59,9 & 28,3 & 55,3 & 88,9 & 102,7 \\
\hline Jackknife 2 & 50,8 & 71,0 & 30,2 & 63,9 & 102,9 & 116,5 \\
\hline Bootstrap & 43,8 & 49,8 & 25,6 & 46,9 & 73,0 & 89,6 \\
\hline
\end{tabular}

\section{DESCRITORES}

\begin{tabular}{|c|c|c|c|c|c|c|}
\hline Espécies coletadas (S) & 40 & 42 & 23 & 40 & 60 & 79 \\
\hline Exemplares (n) & 4.610 & 1.184 & 1.251 & 861 & 3.408 & 11.314 \\
\hline Dominância (D) & 0,09 & 0,19 & 0,21 & 0,10 & 0,11 & 0,06 \\
\hline Diversidade Shannon (H) & 2,77 & 2,42 & 2,10 & 2,78 & 2,75 & 3,25 \\
\hline Riqueza Margalef (M) & 4,62 & 5,79 & 3,09 & 5,77 & 7,25 & 8,36 \\
\hline Uniformidade (e) & 0,75 & 0,65 & 0,67 & 0,75 & 0,67 & 0,74 \\
\hline \multicolumn{7}{|c|}{ SEM MARINHOS } \\
\hline ESTIMADORES & AIP & MIP & AIB & MIB & BBS & BSU \\
\hline Chao 2 & 44,6 & 62,2 & 25,6 & 55,3 & 51,5 & 66,9 \\
\hline Jackknife 1 & 47,8 & 59,9 & 28,3 & 55,3 & 58,9 & 71,9 \\
\hline Jackknife 2 & 50,8 & 71,0 & 30,2 & 63,9 & 62,3 & 73,9 \\
\hline Bootstrap & 43,8 & 49,8 & 25,6 & 46,9 & 50,8 & 67,2 \\
\hline \multicolumn{7}{|l|}{ DESCRITORES } \\
\hline Espécies coletadas (S) & 40 & 42 & 23 & 40 & 43 & 62 \\
\hline Exemplares (n) & 4.610 & 1.184 & 1.251 & 861 & 2.474 & 10.380 \\
\hline Dominância (D) & 0,09 & 0,19 & 0,21 & 0,10 & 0,12 & 0,06 \\
\hline Diversidade Shannon (H) & 2,77 & 2,42 & 2,10 & 2,78 & 2,60 & 3,14 \\
\hline Riqueza Margalef (M) & 4,62 & 5,79 & 3,09 & 5,77 & 5,38 & 6,60 \\
\hline Uniformidade (e) & 0,75 & 0,65 & 0,67 & 0,75 & 0,69 & 0,76 \\
\hline
\end{tabular}

adentram os rios foram registradas. Os índices de riqueza de Margalef e de diversidade de Shannon mais baixos na sub-região hidrográfica do Alto Itabapoana podem ser atribuídos ao fato de que apenas uma pequena parte desta região foi considerada, pois a maior parte dela está fora do estado do Espírito Santo.

Impactos ambientais. A alta energia e o volume das quedas d'água no alto e médio terços fluviais têm atraído empreendimentos de Pequenas Centrais Hidrelétricas (PCHs) nas últimas décadas. Foram construídas quatro PCHs, em trechos do médio Itabapoana, e ainda seis no Alto e Médio Itapemirim. O Alto Itapemirim e Itababoapana contam ainda com uma usina hidrelétrica cada. A construção de barragens provoca a alteração do regime hídrico de rio para lago, com implicações decisivas sobre a fauna, em especial sobre a população de peixes (Tundisi 1993; Godoy 1995; Agostinho \& Zalewski 1996). Peixes mais impactados pelos barramentos são os reofílicos, ou seja, que necessitam do ambiente lótico para completarem o seu ciclo de vida. Dentre as espécies reofílicas, estão os grandes migradores, localmente representados pelos gêneros Brycon Müller \& Troschel, 1844, alguns Leporinus Agassiz, 1829, e Prochilodus Agassiz, 1829, que têm sua rota migratória natural interrompida. Peixes de ambientes de corredeiras com pedras, como cascudos Loricariidae, incluindo Neoplecostomus Eigenmann \& Eigenmann, 1888, Hypostomus Lacepède, 1803, Harttia Miranda-Ribeiro, 1939, e Loricariichthys Bleeker, 1862, também são impactados pelas drásticas mudanças. Durante resgate da ictiofauna na PCH Santa Fé (atual PCH Francisco Gros), no rio Itapemirim foi registrada maior abundância de cascudos Harttia loricariformis, e ainda Prochilodus vimboides (Dutra et al. 2010). Estudos de Silva Neto et al. (2011) corroboram os resultados de Dutra et al. (2010), quanto à presença de grandes cascudos e reofílicos migradores na área de influência da PCH Francisco Gros. Barragens funcionam como ecossistemas artificiais, e podem ocasionar alterações do fluxo dos rios, do 
transporte de nutrientes e de sedimentos, alterando a rota migratória natural de peixes reofílicos (Antonio et al. 2007). Se, por um lado, os estudos para a construção das hidrelétricas podem permitir uma ampliação do quadro sobre a distribuição das espécies, por outro, as barragens têm sido consideradas a principal causa de impacto para a ictiofauna (Drummond et al. 2005). Convém observar, no entanto, que apesar dos esforços, não foi possível resgatar nenhum material citado nos relatórios ambientais das diferentes PCHs construídas. Estudos em outras áreas demonstram a redução das populações de espécies migradoras diante de barramentos. Em alternativa ao isolamento genético de populações (Petrere 1996), a transposição de peixes pode ser uma solução. A influência das PCHs sobre as populações de peixes dos rios tem sido discutida por vários autores e precisa ser analisada com cuidado (Silva Neto et al. 2011).

Outro impacto potencial é a introdução de espécies exóticas. Os pescadores do rio Itabapoana temem o avanço do bagre africano Clarias gariepinnus nos rios da região (Bernardes 2004). Contudo, essa espécie não conta com registros para os rios do sul, e tampouco foi coletada durante este projeto. A aquicultura é uma fonte importante de introdução de espécies exóticas. Devido às dificuldades para se evitar a fuga de peixes dos criadoros, é provável que mais espécies venham a se estabelecer em ambientes aquáticos naturais (Drummond et al. 2005).

Characiformes. A família Characidae foi das mais representativas nos rios do Sul, com 13 espécies reconhecidas regionalmente. Os Characidae possuem uma composição consideravelmente heterogênea quanto à morfologia e carecem de uma diagnose filogenética aplicável (Menezes et al. 2007). Estes peixes, popularmente conhecidos como piabas ou lambaris, incluíram regionalmente uma surpreendente diversidade de espécies de Astyanax, Baird \& Girard, 1854, e ainda, representantes de Brycon, Bryconamericus Eigenmann, 1907, Knodus Eigenmann, 1911, Hasemania Ellis, 1911, Hyphessobrycon Eigenmann, 1908, Mimagoniates Regan, 1907, Oligosarcus Günther, 1864, e Probolodus Eigenmann, 1911. Astyanax merece destaque por tratar-se de um grande gênero cuja sistemática não se encontra bem estabelecida. Astyanax apresenta muitos problemas taxonômicos e incertezas filogenéticas, visto que o monofiletismo do gênero é duvidoso; existem muitas espécies descritas e não há uma revisão recente (Castro \& Vari 2004; Vari \& Castro 2007; Bertaco \& Lucena 2006; Tagliacollo et al. 2011). As espécies de Astyanax em geral variam geograficamente e, para seu reconhecimento, utilizamos combinações de formato e posição dos dentes, número de cúspides, contagens de raios das nadadeiras dorsal e anal, número de escamas na linha lateral, e ainda diferenças morfométricas na cabeça e no tronco. Foram reconhecidas cinco espécies de
Astyanax nas bacias do sul do Espírito Santo: Astyanax giton, A. janeiroensis, A. microschemos, A. parahybae e Astyanax sp. 2 aff. A. lacustris. A maioria das espécies nominais de Astyanax referenciadas para as Bacias do Sul foi descrita para sistemas fluviais no Rio de Janeiro, em especial para o rio Paraíba do Sul, no trecho que entrecorta o estado do Rio de Janeiro. Astyanax microschemos foi a única espécie de Astyanax originalmente descrita para bacias fluviais no Espírito Santo (Bertaco \& Lucena 2006). Astyanax microschemos parece ser endêmica das cabeceiras do rio Itapemirim, tendo sido encontrada na localidadetipo, em Iúna, e também uma população no córrego Mata Pau, em Muniz Freire. Astyanax giton foi uma das espécies mais comuns nos rios do Sul, tendo sido encontrada em todas as sub-regiões hidrográficas, em diferentes ambientes. Por outro lado, Astyanax parahybae foi registrada apenas para trechos da bacia do rio Itapemirim, especialmente em rios maiores e com forte correnteza. Astyanax parahybae foi a espécie que apresentou maiores dimensões de tamanho, dentre os Astyanax da região. Os trechos onde Astyanax parahybae foi registrada coincidiram com aqueles onde Probolodus heterostomus também foi. Populações de A. janeiroensis distribuem-se por praticamente todas as bacias do Sul, mas não foram registradas no Alto Itabapoana. Lambaris $A$. janeiroensis têm sido registrados para as planícies costeiras do Rio de Janeiro e para o baixo rio Paraíba do Sul (Melo 2001). Seus limites de distribuição norte possivelmente seriam nas drenagens litorâneas das microbacias de Serra, na região da grande Vitória (Sarmento-Soares \& MartinsPinheiro 2010). Uma das espécies de Astyanax reconhecida para as bacias do sul foi tratada como Astyanax sp. 2 aff. A. lacustris, sendo caracterizada pela mancha humeral ovalada conspícua e mancha escura no pedúnculo caudal, estendendo-se até a extremidade dos raios caudais medianos, pertence ao grupo A. bimaculatus (sensu Eigenmann 1921). Espécies de piabas do grupo A. bimaculatus são extremamente comuns nas bacias hidrográficas neotropicais, e apresentam grande plasticidade ecológica, o que aumenta as dificuldades de estudos (V. Garutti, com. pess). Garutti \& Britski (2000) indicam que as formas do grupo $A$. bimaculatus portadoras de dente maxilar e padrão reticulado de cromatóforos, ocorrem na bacia Amazônica e ao norte. Indivíduos de Astyanax sp. 2 aff. A. lacustris não apresentam dentes no maxilar e não possuem colorido reticulado (sensu Britski et al. 1986; Garutti 1995). Astyanax sp. 2 aff. A. lacustris foi associada a $A$. lacustris pela ausência de dentes no maxilar e mancha escura no pedúnculo caudal estendendo-se até a extremidade dos raios caudais medianos, diferindo desta pelo par de dentes simétricos na sínfise mandibular, os olhos próximos ao focinho, e faixa prateada conspícua nos lados do corpo. Outra espécie congênere e de distribuição parapátrica à do sul, Astyanax sp. 1 aff. A. lacustris, foi registrada para os 
rios do norte do Espírito Santo (Sarmento-Soares \& Martins-Pinheiro 2012c). Os nomes dados aos complexos de espécies em Astyanax, como as do grupo A. bimaculatus, necessitam maiores investigações para que se possa definir com acurácia sua identidade taxonômica, tratando-a como uma nova espécie ou apenas variações de espécies já descritas.

Astyanax abriga espécies nectônicas de Characidae, de hábitos onívoros, e dependem da coluna d’água para capturar presas trazidas pela correnteza (Casatti et al. 2009). Nos rios do Sul, espécies de Astyanax apresentam registro de distribuição sintópica, como Astyanax sp. 2 aff. A. lacustris, A. giton e A. janeiroensis coespecíficas em trechos do médio rio Itabapoana; e A. microschemos e A. janeiroensis, coespecíficas em Maravilha, na sub-bacia do rio Braço Norte Esquerdo do Itapemirim; $A$. giton $\mathrm{e}$ $A$. janeiroensis na sub-bacia do rio Castelo; A. janeiroensis, A. parahybae e Astyanax sp.2 aff. A. lacustris em trechos do baixo rio Itapemirim.

Outra espécie nectônica de Characidae é Probolodus heterostomus, que ocorreu pontualmente para o Alto e Médio Itapemirim e ainda para o Baixo Itabapoana. É uma espécie com hábitos lepidófagos (Roberts 1970), distribuindo-se em riachos de águas escuras ou claras (Menezes et al. 2007). Possuem a fileira externa de dentes no premaxilar curvados para fora, e dentes no dentário decrescendo suavemente. Indivíduos jovens são morfologicamente semelhantes a Astyanax parahybae, porém apresentam menor amplitude de raios ramificados na nadadeira anal. A semelhança morfológica entre indivíduos de Probolodus e Astyanax foi sugerida como sendo uma forma de mimetismo agressivo por Sazima (1977), uma vez que em estudos com populações do rio Paraíba do Sul observou-se que espécimes de Astyanax seriam a principal presa de Probolodus. Probolodus heterostomus foi registrada em sintopia com $A$. parahybae no Médio Itapemirim e ainda com $A$. giton no Itabapoana.

Hyphessobrycon bifasciatus e Mimagoniates microlepis foram associados às porções média e baixa dos rios do Sul, tendo sido encontrados em pequenos córregos e lagoas. Mimagoniates microlepis teve ocorrência em um único ponto ( $\mathrm{P}$ 75) no Médio Itabapoana. A espécie habita riachos costeiros sombreados, de águas claras, rasas e de correnteza fraca (Mazzoni \& Iglesias-Rios 2002). Sua ocorrência em riachos da floresta atlântica está correlacionada à presença de vegetação ripária, e justamente por esse motivo teve registros esparsos nos rios do sul, fora de áreas protegidas. Hyphessobrycon bifasciatus é habitante de córregos, alagados e lagoas no Baixo Rios do Sul e Médio Itapemirim. Indivíduos jovens muito pequenos de Hyphessobrycon bifasciatus (machos e fêmeas) são avermelhados, mas os machos logo se tornam amarelados, e normalmente são maiores que as fêmeas (F. Carvalho, com. Pess); as fêmeas continuam avermelhadas quando adultas (Malabarba 2006).
Hyphessobrycon bifasciatus pode apresentar grande biomassa em ambientes lênticos com abundante matéria orgânica nas baixadas litorâneas.

As espécies de Mimagoniates e Probolodus habitam rios da Mata Atlântica ou de pequenos sistemas hídricos do sul do Brasil, representando diferentes graus de endemismo para a ictiofauna de água doce dos rios do litoral atlântico.

Siluriformes. Dentre os Siluriformes, a família mais representativa nos rios do Sul foi Loricariidae, com 13 espécies. Dentre as espécies de Loricariidae reconhecidas regionalmente, seis apresentam endemismo para o rio Paraíba do Sul e rios costeiros entre o Rio de Janeiro e sul do Espírito Santo. Harttia loricariformis, Hypostomus affinis, H. auroguttatus, Neoplecostomus microps, Otothyris lophophanes e Rineloricaria steindachneri.

Os Loricariinae, Harttia loricariformis e Rineloricaria steindachneri, popularmente chamados de cascudos-chata-pedra, ocupam ambientes lóticos, de forte correnteza, com águas claras e frias, especialmente em riachos nos vales e encostas de montanha. Apesar de ocuparem ambientes similares, estas duas espécies foram encontradas em sintopia apenas no rio Itapemirim à jusante da foz do córrego Itaoca (P 50). A maior incidência de espécimes de Harttia loricariformis foi associada a rios com leito pedregoso. Por outro lado, indivíduos de Rineloricaria steindachneri foram encontrados principalmente em águas rasas, com leito de cascalho. Ghazzi (2008) sugeriu que muitas espécies de Rineloricaria permanecem por serem descritas em diversos sistemas hidrográficos brasileiros, e levantou a possibilidade de que os rios Itabapoana e Doce abriguem espécies ainda desconhecidas.

Cascudos Hypostomus têm hábitos bentônicos e alimentação perifitívora ou detritívora (Casatti et al. 2009), tendo sido localizadas duas espécies nos rios do Sul: $H$. affinis e $H$. auroguttatus, facilmente distinguidas pela cabeça alta e quatro quilhas longitudinais no tronco de $H$. affinis (vs. cabeça baixa e corpo sem quilhas). Hypostomus affinis é bastante comum nos rios do sul, tendo sido encontrada em todos os trechos da bacia. Hypostomus auroguttatus teve ocorrência restrita ao Alto e Médio Itapemirim, com poucos registros, especialmente para a calha central do rio.

Delturus parahybae é uma espécie criticamente ameaçada de extinção (Rosa \& Lima 2008); os poucos indivíduos conhecidos são procedentes da bacia do rio Paraíba do Sul. Dos seis espécimens, dois são tipos colecionados durante a Expedição Thayer, em 1865 (Reis et al. 2006). Registros recentes no rio Pomba, em 2002, indicaram sua presença no terço inferior da bacia, em áreas de corredeiras com fundo rochoso e parcialmente cobertas por vegetação aquática (Reis et al. 2006; Rosa \& Lima 2008). Pompeu \& Vieira (2003) assinalaram que Delturus parahybae seja 
extremamente vulnerável à degradação ambiental experimentada pelo terço inferior da bacia do rio Paraíba do Sul. Até o momento, não foram localizados indivíduos de Delturus parahybae nos rios do Sul do Espírito Santo.

Por outro lado, foram identificados, no Médio Itapemirim, cascudos com 11 raios ramificados na nadadeira dorsal, coloridos com numerosas máculas escuras: estes cascudos foram reconhecidos como Pterygoplichthys sp. Cascudos Pterygoplichthys têm dimorfismo sexual secundário, podem alcançar grandes dimensões e geralmente habitam rios maiores (C. Zawadski, com. pess.). Os peixes coletados no Médio Itapemirim são jovens, tendo sido capturados unicamente em um afluente do córrego São Gabriel, um tributário do rio Muqui do Norte, margem direita do rio Itapemirim. A ocorrência de Pterygoplichthys sp. em um sistema hídrico da Mata Atlântica pode tratar-se de uma possível introdução de tanques ou poços para fins de cultivo. Pescadores da região nomeiam tais peixes como "acari" associando-os como distintos dos "cascudos" Hypostomus, comuns na área (J.L. Helmer, com. pess.).

Além dos cascudos, os rios do sul são habitados por cascudinhos, que são os loricarídeos locais de pequenas dimensões, raramente ultrapassando $10 \mathrm{~cm}$ de comprimento padrão. Otothyris lophophanes teve sua ocorrência restrita ao baixo curso fluvial dos rios Itabapoana e Itapemirim, mas sem registro para as microbacias de Marataízes. Otothyris são pequenos cascudinhos sem nadadeira adiposa, que vivem ocultos sob a vegetação marginal de pequenos córregos de correnteza moderada. Correspondem à espécie de menor tamanho dentre os loricarídeos regionais, alcançando pouco mais de $3 \mathrm{~cm}$ de comprimento padrão. Por outro lado, Neoplecostomus microps é uma espécie bastante comum em ambientes lóticos, encaichoeirados e torrenciais, onde se alimenta de perifiton e larvas de insetos (Braga et al. 2008). Outros cascudinhos nos rios do Sul foram Parotocinclus maculicauda, Parotocinclus sp. aff. P. jimi e Hisonotus notatus. Parotocinclus sp. aff. $P$. jimi é morfologicamente semelhante a $P$. jimi, uma espécie descrita para a bacia do Rio de Contas, na Bahia, pela disposição das pequenas placas abdominais (vs. placas grandes em $P$. maculicauda). Indivíduos de Parotocinclus sp. aff. P. jimi foram reconhecidos também para as microbacias de Guarapari, no sudeste do Espírito Santo (F.O. Martins, com. pess.), e maiores investigações são necessárias.

Biogeografia. Os sistemas hídricos do sudeste e leste do Brasil são ainda habitados por táxons reminiscentes de uma história biogeográfica antiga. Ribeiro (2006) propos o Cretáceo, como idade inicial da diversificação da fauna endêmica das drenagens costeiras do Brasil. Hipóteses de eventos antigos, com a presença de táxons basais podem ser extraídos dentre os Centromochlinae e Trichomycteridae no sul do
Espírito Santo. Duas espécies de linhagens basais foram registradas para os rios do sul do Espírito Santo: Glanidium melanopterum, grupo irmão de todos os demais Centromochlinae, subfamília de Auchenipteridae (Soares-Porto 1998), e ainda Trichogenes claviger (de Pinna et al. 2010), um Trichomycteridae basal (sensu de Pinna 1998). Glanidium é grupo monofilético com sete espécies. Corresponde ao único gênero de Centromochlinae com representantes na bacia do rio São Francisco e drenagens costeiras do Brasil, um padrão de distribuição disjunto em relação aos demais membros da subfamília. Glanidium melanopterum ocorre entre o Rio de Janeiro e o centro-sul do Espírito Santo, ocupando ambientes lóticos na calha central de grandes rios, no Médio Itabapoana e Médio Itapemirim.

Trichogenes é monofilético, com duas espécies, e o único gênero reconhecido dentre a subfamília Trichogeninae. Juntamente com os Copionodontinae, os Trichogeninae formam o grupo irmão dos demais Trichomycteridae. Táxons antigos são muitas vezes depauperados em número de espécies e apresentam, em sua maioria, distribuição geográfica extremamente limitada (Stiassny \& de Pinna 1994). Trichogenes claviger, recentemente descrita para a sub-bacia do rio Caxixe, contribuinte do Itapemirim, ocorre em setores sombreados de um riacho de água preta, de correnteza lenta, com substrato arenoso e aglomerações de matéria vegetal em alguns pontos (de Pinna et al. 2010). A localidade-tipo corresponde a um pequeno córrego, numa área particular entre duas unidades de conservação: os Parques Estaduais de Forno Grande e Pedra Azul. Medidas de conservação são necessárias para garantir a sobrevivência da única população de Trichogenes claviger conhecida. Esforços de amostragem no entorno do local também são desejáveis para se aferir os limites de distribuição da espécie. Neste sentido, a região do rio Caxixe destacase na preservação da ictiofauna da bacia do Itapemirim.

A fauna de peixes de água doce da América do Sul, composta principalmente de peixes primariamente de água doce, como os Ostariophysi, possui sua história evolutiva principal ligada à história geológica, quando os sistemas hídricos no continente foram formados e modificados (Lundberg et al. 1998; Castro 1999). O reconhecimento das linhagens e grupos de espécies nos permite inferir alguns resultados do ponto de vista biogeográfico, diante dos marcantes padrões de distribuição geográfica destas espécies. Os sistemas hídricos da Mata Atlântica do sul do Espírito Santo foram pouco estudados, quando comparados com o vizinho rio Paraíba do Sul, nos trechos médio baixo e baixo, no Rio de Janeiro e Minas Gerais. As bacias dos rios do sul do Espírito Santo apresentaram acentuado endemismo para peixes de água doce, e muitos táxons endêmicos dos rios do sul do Espírito Santo têm a distribuição geográfica compartilhada com o Baixo Paraíba do Sul. As espécies Astyanax parahybae, Pimelodella pectinifer, Rineloricaria steindachneri, 
Harttia loricariformis e Australoheros muriae foram reconhecidas como tendo distribuição entre o rio Paraíba do Sul, rios costeiros do Rio de Janeiro e os rios do sul do Espírito Santo. Neste sentido, os poucos peixes conhecidos dos rios do sul do Espírito Santo podem fornecer pistas para o entendimento da biogeografia dos sistemas aquáticos em escala regional.

\section{AgRADECIMENTOS}

Queremos deixar nossos agradecimentos aos colegas do Museu de Biologia Prof. Mello Leitão (MBML) e à equipe do Projeto DiversidadES; à equipe do Setor de Ictiologia do Museu Nacional/ UFRJ, pela cordialidade durante visitas; a Carlos A. S. Lucena, José L. Helmer e Valdener Garutti, pelas informações sobre ambientes e peixes; a Cláudio $\mathrm{H}$. Zawadski, Fabio M. R. S. Puppo, Fernanda O. Martins, Fernando R. Carvalho, Jane P. Serra, L. F. C. Tencatt e Marcelo R. Britto pela ajuda na identificação de espécies e pela troca de ideias; à equipe do MBML (Maria Margareth C. Roldi, Raphael B. Soares, R. L. Teixeira, Juliana P. Silva, Cristina Jaques e Maridiesse M. Lopes), do MNRJ (Marcelo R. Britto, Fabio M. R. S. Puppo e Vinicius C. Espíndola) e do CCA/ UFES (Giulianna R. Carmassi, Alberto L. Carmassi, Leydiane N. Rodrigues, Laísa M. Soneghet e Rodrigo N. Gama), pelo empenho e ajuda durante os trabalhos de campo e/ou laboratório; à equipe do Parque Nacional do Caparaó, em especial a Thais F. Rodrigues e Waldomiro de Paula Lopes, pelo apoio durante as atividades na unidade e entorno. Os trabalhos de campo foram financiados pelo CNPq, Edital Universal processo $n^{\circ} 473749 / 2008-4$ e pela FAPES (Fundação de Amparo a Pesquisa do Estado do Espírito Santo) através do Projeto "Efetividade de Unidades de Conservação do estado do Espírito Santo para a proteção da biodiversidade", processo no 51187434/10. Agradecemos ao Instituto Chico Mendes pelas autorizações para atividades com finalidade científica $\mathrm{n}^{\mathrm{o}} 20096-1$ e n $\mathrm{n}^{\mathrm{O}} 27880-1$.

\section{REFERÊNCIAS}

Agostinho, A.A. \& Zalewski, M. 1996. A Planície Alagável do Alto Rio Paraná: importância e preservação. Editora da Universidade Estadual de Maringá (EDUEM), Maringá.

Alves, J. \& Barbosa, M. 2009. Recursos Minerais do Estado do Rio de Janeiro. Serviço Geológico do Estado do Rio de Janeiro. Departamento de Recursos Minerais, Rio de Janeiro. Disponível em <http://www.drm.rj.gov.br/index.php/projetos-e-atividades/ pedagogico/99-pedagogicorecurso>; acesso em 19 mar. 2012.

Amador, E.S. \& Dias, G.T. 1978. Considerações preliminares sobre depósitos do Terciário Superior do Norte do Espírito Santo. Anais da Academia Brasileira de Ciências 50(1): 121.
Antonio, R.R.; Agostinho, A.A.; Pelicice, F.M.; Bailly, D.; Okada, E.K. \& Dias, J.H.P. 2007. Blockage of migration routes by dam construction: can migratory fish find alternative routes? Neotropical Ichthyology 5(2): 177-184.

Barros, A.B. 1999. Projeto Managé uma nova proposta de gestão de bacia hidrográfica voltada para o desenvolvimento regional sustentável. In: Anais III Encontro Brasileiro de Organismos de Bacias Hidrográficas, Piracicaba.

Bernardes, F. 2004. Peixes exóticos ameaçam vida de peixes nativos no ES. Revista Século Diário. Meio Ambiente. Vitória, 13 abril 2004.

Bernini, E. \& Rezende, C.E. 2010. Variação estrutural em florestas de mangue do estuário do rio Itabapoana, ES-RJ. Biotemas 23(1): 49-60.

Bernini, E.; Carvalho, R.S.B.; Liguori, T.P.; Passarelli, L.S.; Machado, P.N. \& Rezende, C.E. 2010. Aspectos estruturais do Manguezal do estuário do rio Itabapoana, ES-RJ. In: Anais do III Congresso Brasileiro de Oceanografia, Rio Grande.

Bertaco, V.A. \& Lucena, C.A.S. 2006. Two new species of Astyanax (Ostariophysi, Characiformes, Characidae) from eastern Brazil, with a synopsis of the Astyanax scabripinnis species complex. Neotropical Ichthyology 4(1): 53-60.

Bigarella, J.J. \& Andrade, G.O. 1964. Considerações sobre a estratigrafia dos sedimentos cenozóicos em Pernambuco (Grupo Barreiras). Arquivos do Instituto das Ciências da Terra 2: 2-14.

Bizerril, C.R.S.F. \& Primo, P.B.S. 2001. Peixes de Águas Interiores do Estado do Rio de Janeiro. Projeto Planágua SEMADS/ GTZ. Fundação de Estudos do Mar, Rio de Janeiro.

Braga, F.M.S.; Gomiero, L.M. \& Souza, U.P. 2008. Aspectos da reprodução e alimentação de Neoplecostomus microps (Loricariidae, Neoplecostominae) na microbacia do Ribeirão Grande, serra da Mantiqueira oriental (Estado de São Paulo). Acta Scientiarum, Biological Sciences 30(4): 455-463.

Britski, H.A.; Sato, Y \& Rosa, A.B.S. 1986. Manual de Identificação de Peixes da Região de Três Marias: com chaves de identificação para os peixes da bacia do São Francisco. 2 ed. Companhia de Desenvolvimento do Vale do São Francisco, Brasília.

Buckup, P.A.; Menezes, N.A. \& Ghazzi, M.S. (eds) 2007. Catálogo das Espécies de Peixes de Água Doce do Brasil. Série livros 23, Museu Nacional, Rio de Janeiro.

Burgos, C.D.; Fornaciari, A. \& Wanderley, C.T. 2006. Caracterização dos patamares escalonados do sul capixaba com enfoque no estudo do processo de esfoliação em rocha (Espírito Santo - Brasil). IV Simpósio Nacional de Geomorfologia, Goiânia. Disponível em http://www.labogef.iesa.ufg.br/links/ sinageo/articles/492.pdf; acesso em 22 jan. 2012.

Carvalho Filho A. 1999. Peixes: Costa Brasileira. 3 ed. Ed. Melro, São Paulo.

Casatti, L.; Ferreira C.P. \& Langeani, F. 2009. A fish-based biotic integrity index for assessment of lowland streams in southeastern Brazil. Hydrobiologia 623: 173-189.

Castro, R.M.C. 1999. Evolução da ictiofauna de riachos sulamericanos: padrões gerais e possíveis processos causais. In: E.P. Caramaschi, R. Mazzoni \& P.R. Peres-Neto (eds), Ecologia de Peixes de Riachos. Vol. 6. PPGE-UFRJ, Série Oecologia Brasiliensis, Rio de Janeiro, p.139-155.

Castro, R.M.C. \& Vari, R.P. 2004. Astyanax biotae, a new species of stream fish from the Rio Paranapanema basin, upper Rio Paraná system, southeastern Brazil (Ostariophysi: Characiformes: Characidae). Proceedings of the Biological Society of Washington 117(3): 330-338. 
CESAN (Companhia Espírito Santense de Saneamento) 2012. Programa Águas Limpas. Disponível em <http://www.cesan. com.br/page.php?142>; acesso em 29 jan. 2012.

CNRH (Conselho Nacional de Recursos Hídricos) 2003. Resolução $\mathrm{n}^{\mathrm{o}}$ 32, 15 de outubro de 2003. Diário Oficial da União. 17 dezembro 2003

Colwell, R.K. \& Coddington, J.A. 1994. Estimating terrestrial biodiversity through extrapolation. Philosophical Transactions of the Royal Society (Series B) 345: 101-118.

Colwell, R.K.; Mao, C.X. \& Chang, J. 2004. Interpolating, extrapolating, and comparing incidence-based species accumulation curves. Ecology 85: 2717-2727.

Dajoz, R. 1983. Ecologia Geral. 4 ed. Vozes, Petrópolis.

De Pinna, M.C.C. 1998. Phylogenetic relationships of neotropical Siluriformes (Teleostei: Ostariophysi); historical overview and synthesis of hypothesis. In: L.R. Malabarba, R.E. Reis, R.P. Vari, Z.M. Lucena \& C.A.S. Lucena (eds), Phylogeny and Classification of Neotropical Fishes. Edipucrs, Porto Alegre, p. 279-330.

De Pinna, M.C.C.; Helmer, J.L.; Britski, H.A.; Nunes, L.R. 2010. A new species of Trichogenes from the Rio Itapemirim drainage, southeastern Brazil, with comments on the monophyly of the genus (Siluriformes, Trichomycteridae). Neotropical Ichthyology 8(4): 707-717.

Dick, M.M. 1977. Stations of the Thayer Expedition to Brazil 1865-1866. Breviora 444: 1-37.

Drummond, G.M.; Martins, C.S.; Machado, A.B.M.; Sebaio, F.A. \& Antonini, Y. (orgs) 2005. Biodiversidade em Minas Gerais. 2 ed. Fundação Biodiversitas, Belo Horizonte. Disponível em http://www.biodiversitas.org.br/atlas/ mamiferos.pdf; acesso em 11 mar. 2012.

Dutra, F.M.; Hermes, C.A; Zanete, C. \& Machado, W.J. 2010 Resgate de ictiofauna nos trechos de vazão reduzida após o fechamento das adufas da PCH Santa-Fé. In: Seminário Nacional de Meio Ambiente e Extensão Universitária. Universidade Estadual do Oeste do Paraná, Marechal Cândido Rondon. Disponível em <http://www.unioeste.br/eventos/ senama>; acesso em 21 mar. 2012.

Eigenmann, C.H. 1921. The American Characidae. Memoirs of the Museum of Comparative Zoology 43(3): 209-310.

Falcão, H.G. \& Teixeira, S. 2010. Construindo a história dos povos indígenas no norte e noroeste fluminense através do olhar dos viajantes. In: ANPUH-Rio, XIV Encontro Regional da Associação Nacional de História, Rio de Janeiro.

Ferreira Júnior, O. 2012. GPS Trackmaker Guia de Referência. Belo Horizonte. Disponível em http://www.gpstm.com/ download/ref_guide_port.pdf; acesso em 19 out. 2012.

Freire, J.R.B. \& Malheiros, M.F. 2010. Aldeamentos Indigenas do Rio de Janeiro. EDUERJ, Rio de Janeiro.

Garutti, V. 1995. Revisão Taxonômica dos Astyanax (Pisces, Characidae), com Mancha Umeral Ovalada e Mancha do Pedúnculo Caudal, Estendendose à Extremidade dos Raios Caudais Medianos, das Bacias do Paraná, São Francisco e Amazônica. Tese de Livre Docência. Instituto de Biociências, Letras e Ciências Exatas, Universidade Estadual Paulista.

Garutti, V. \& Britski, H.A. 2000. Descrição de uma espécie nova de Astyanax (Teleostei: Characidae) da bacia do alto rio Paraná e considerações sobre as demais espécies do gênero na bacia. Comunicações do Museu de Ciências e Tecnologia da Pontifícia Universidade Católica do Rio Grande do Sul série Zoologia 13: 65-88.
Ghazzi, M.S. 2008. Nove espécies novas do gênero Rineloricaria (Siluriformes, Loricariidae) do rio Uruguai, do sul do Brasil. Iheringia série Zoologia 98(1): 100-122.

Godoy, M.P. (1995). Piracema: peixes brasileiros também têm história. Pirassununga - SP, Brasil. Anais de Etologia 13: 3-19.

Hammer, Ø.; Harper, D.A.T. \& Ryan, P.D. 2001. Past: Paleontological Statistics Software Package For Education and Data Analysis. Palaeontologia Electronica 4(1): 1-9. Disponível em <http://Palaeo-Electronica.Org/2001_1/ Past/Issue1_01.htm>; acesso em 22 fev. 2012.

Hartt, C.F. 1870. Scientific Results of a Journey in Brazil. Osgood and Company, Boston.

Hartt, C.F. 1941. Geologia e Geografia Física do Brasil [1870]. Companhia Editora Nacional, São Paulo.

Higuchi, H. 1996. An Updated List of Ichthyological Collecting Stations of the Thayer Expedition to Brazil (1865-1866). Disponível em http://www.mcz.harvard.edu/Departments/Fish/ thayer.htm; acesso em 11 mar. 2012.

IBGE (Instituto Brasileiro de Geografia e Estatística) 2004. Mapa de Vegetação do Brasil. Ministério do Planejamento, Orçamento e Gestão, Instituto Brasileiro de Geografia e Estatísticas, Diretoria de Geociências, Brasília.

IEMA (Instituto Estadual de Meio Ambiente e Recursos Hídricos) 2012. Monumento Natural da Serra das Torres. Disponível em www.meioambiente.es.gov; acesso em 5 mar. 2012.

IPEMA (Instituto de Pesquisas da Mata Atlântica) 2005. Conservação da Mata Atlântica no Estado do Espírito Santo: cobertura florestal e unidades de conservação. Conservação Internacional Brasil e Secretaria de Meio Ambiente e Recursos Hídricos do Espírito Santo. IPEMA, Vitória.

IPEMA (Instituto de Pesquisas da Mata Atlântica) 2010. Saberes da Mata. Um jeito participativo de cuidar da Mata Atlântica. IPEMA, Vitória.

Lamego, A.R. 1945. O Homem e o Brejo. Série A Livros $n^{\circ} 1$. Instituto Brasileiro de Geografia e Estatística, Conselho Nacional de Geografia, Rio de Janeiro.

Lamego, A.R. 1946. O Homem e a Restinga. Série A Livros $n^{\text {o. }} 1.2$ ed. Instituto Brasileiro de Geografia e Estatística, Conselho Nacional de Geografia, Rio de Janeiro.

Lamego, A.R. 1963. O Homem e a Serra. Série A "Livros" $n^{\text {o. }} 8.2$ ed. Instituto Brasileiro de Geografia e Estatística, Conselho Nacional de Geografia, Rio de Janeiro.

Lima, F.C.T.; Buckup, P.A.; Menezes, N.A.; Lucena, C.A.S.; Lucena, Z.M.S.; Toledo-Piza, M. \& Zanata, A. 2007. Família Characidae: gêneros incertae sedis. In: P.A. Buckup, N.A. Menezes \& M.S. Ghazzi (eds), Catálogo das Espécies de Peixes de Água Doce do Brasil. Série livros 23. Museu Nacional, Rio de Janeiro, p. 44-62.

Lucena, C.A.S. \& Lucena, Z.M.S. 2002. Redefinição do gênero Deuterodon Eigenmann, 1907 (Ostariophysi: Characiformes: Characidae). Comunicações do Museu de Ciências e Tecnologia da Pontifícia Universidade Católica do Rio Grande do Sul 15: 113-135.

Lucinda, P.H.F. \& Costa, W.J.E.M. 2007. Família Poeciliidae. In: P.A. Buckup, N.A. Menezes \& M.S. Ghazzi (eds), Catálogo das Espécies de Peixes de Água Doce do Brasil. Série livros 23. Museu Nacional, Rio de Janeiro, p. 134-137. 
Lundberg, J.G.; Marshall L.G.; Guerrero, J.; Horton, B.; Malabarba, M.C.S.L. \& Wesselingh, F. 1998. The stage for Neotropical diversification: a history of tropical South American rivers. In: L.R. Malabarba, R.E. Reis, R.P. Vari, Z.M.S. Lucena \& C.A.S. Lucena (eds), Phylogeny and Classification of Neotropical Fishes. EDIPUCRS, Porto Alegre, p. 13-48.

Magurran, A.E. 1988. Ecological Diversity and Its Measurement. Princeton University Press, Princenton.

Malabarba, L.R. 2006. Book Review: Peixes de Riachos da Mata Atlântica nas Unidades de Conservação do Vale do Rio Ribeira de Iguape no Estado de São Paulo. Neotropical Ichthyology 4(3): 377.

Mazzoni, R. \& Iglesias-Rios, R. 2002. Distribution pattern of two fish species in a coastal stream in the Southeast of Brazil. Brazilian Journal of Biology 62: 171-178.

Melo, F.A.G. 2001. Revisão taxonômica das espécies do gênero Astyanax Baird e Girard, 1854 (Teleostei, Characiformes, Characidae) da região da Serra dos Órgãos. Arquivos do Museu Nacional 59: 1-46.

Melo Júnior, J.C.F.; Sediyama, G.C.; Ferreira, P.A.; Leal, B.G. \& Minusi, R.B. 2006. Distribuição espacial da frequência de chuvas na região hidrográfica do Atlântico, Leste de Minas Gerais. Revista Brasileira de Engenharia Agrícola e Ambiental 10(2): 417-425.

Menezes, N.A.; Buckup, P.A.; Figueiredo, J.L. \& de Moura, R.L. 2003. Catálogo das Espécies de Peixes Marinhos do Brasil. Museu de Zoologia, Universidade de São Paulo, São Paulo.

Menezes, N.A.; Weitzman, S.H.; Oyakawa, O.T.; Lima, F.C.T.; Castro, R.M.C. \& Weitzman, M.J. 2007. Peixes de Água Doce da Mata Atlântica - lista preliminar das espécies e comentários sobre conservação de peixes de água doce neotropicais. Museu de Zoologia, Universidade de São Paulo.

Papavero, N. 1973. Essays on the History on Neotropical Dipterology with Special Reference to Collectors (1750-1905). Vol. 2. Museu de Zoologia, Universidade de São Paulo, São Paulo.

Pereira, T.N.A. 2010. Filogenia das Espécies de Deuterodon Eigenmann, 1907 (Characiformes: Characidae), Um Gênero de Lambaris da Mata Atlântica. Dissertação de Mestrado. Instituto de Biociências de Botucatu, UNESP, Botucatu.

Petrere, M. 1996. Fisheries in large tropical reservoirs in South America. Lakes \& Reservoirs: Research and Management 2: $111-133$.

Pianka, E.R. 2000. Evolutionary Ecology. 6 ed. BenjaminCummings, Addison-Wesley-Longman, San Francisco.

Pielou, E.C. 1969. Association tests versus homogeneity tests: their use in subdividing quadrats into groups. Vegetation 18: 4-18.

Pompeu, P.S. \& Vieira, F. 2003. Treatened fishes of the world: Delturus parahybae Eigenmann \& Eigenmann, 1889 (Loricariidae). Environmental Biology of Fishes 66: 66.

Portal da Transparência 2011. Bom Jesus do Norte (ES). Convênios do governo federal com o município. 1996-2011. Sistema de esgotamento sanitário. Disponível em: http://es.transparencia.gov.br/Bom_Jesus_do_Norte/receitas/con venios; acesso em 1 mar. 2012.

Reis, R.E.; Kullander, O. \& Ferraris Jr, C.J. 2003. Check List of the Freshwater Fishes of South and Central America. EDIPUCRS, Porto Alegre.
Reis, R.E.; Pereira, E.H.L. \& Armbruster, J.W. 2006. Delturinae, a new loricariid catfish subfamily (Teleostei, Siluriformes), with revisions of Delturus and Hemipsilichthys. Zoological Journal of the Linnean Society 147: 277-299.

Ribeiro, A.C. 2006. Tectonic history and the biogeography of the freshwater fishes from the coastal drainages of eastern Brazil: an example of faunal evolution associated with a divergent continental margin. Neotropical Ichthyology 4(2): 225-246.

Roberts, T.R. 1970. Scale-eating American characoid fishes, with special reference to Probolodus heterostomus. Proceedings of the California Academy of Sciences 38: 383-390.

Rosa, R.S. \& Lima, F.C.T. 2008. Os peixes brasileiros ameaçados de extinção. In: A.B.M. Machado, G.M. Drummond \& A.P. Paglia (eds), Livro Vermelho da Fauna Brasileira Ameaçada de Extinção. Vol. 2. Biodiversidade 19. Ministério do Meio Ambiente, Brasília, p. 1-278.

Santos, L. 2005. Classificação do Litoral de Marataizes, Espírito Santo, quanto à Vulnerabilidade erosiva. Monografia de Bacharelado em Oceanografia. Universidade Federal do Espírito Santo.

Sarmento-Soares, L.M. \& Martins-Pinheiro, R.F. 2010. A fauna de peixes da bacia dos Reis Magos e microbacias de Serra, Espírito Santo, Brasil. Boletim do Museu de Biologia Mello Leitão (N. Sér.) 28: 105-141.

Sarmento-Soares, L.M. \& Martins-Pinheiro, R.F. 2012a. A fauna de peixes nas bacias do norte do Espírito Santo, Brasil. Sitientibus série Ciências Biológicas 12(1): 1-25.

Sarmento-Soares, L.M. \& Martins-Pinheiro, R.F. 2012b. Relação de lotes de peixes de água doce coletados no Espírito Santo durante os Projetos BIOdiversES e DiversidadES. Disponível em: http://www.nossacasa.net/nossosriachos/ doc/anexo_a.pdf; acesso em 7 nov. 2012.

Sarmento-Soares, L.M. \& Martins-Pinheiro, R.F. 2012c. Relação de lotes de peixes de água doce do Espírito Santo disponíveis nos bancos de dados públicos das principais coleções ictiólogicas do país considerados nos Projetos BIOdiversES e DiversidadES. Disponível em: http://www.nossacasa.net/ nossosriachos/doc/anexo_b.pdf; acesso em 7 nov. 2012.

Sarmento-Soares, L.M. \& Martins-Pinheiro, R.F. 2012d. Contribuição ao Conhecimento das Bacias Hidrográficas do Espirito Santo. Disponível em http://www.nossacasa.net/ nossosriachos/doc/ccbhes.pdf; acesso em 7 nov. 2012.

Sarmento-Soares, L.M.; Martins-Pinheiro, R.F. \& Martinelli, M.M. 2012. A fauna de peixes nas bacias do sudeste do Espírito Santo, Brasil. Sitientibus série Ciências Biológicas 12(1): 27 52 .

Sazima, I. 1977. Possible case of aggressive mimicry in a neotropical scale-eating fish. Nature 270: 510-512.

Scaramuza, C.A.M.; Simões, L.L.; Rodrigues, S.T.; Accacio, G.M.; Hercowitz, M.; Rosa R.M.; Goulart, W.; Pinagé, E.R \& Soares, M.S. 2011. Bioma Mata Atlântica - visão da biodiversidade da ecorregião Serra do Mar. WWF Brasil. Disponível em http://assets.wwfbr.panda.org/downloads/ visao_conservacao_serra_do_mar.pdf; acesso em 11 mar. 2012.

Silva Neto, A.P.; Gonçalves Junior, L.P.; Nogueira, E.C.; Stoffel, S.M.; Junger, E.N.; Matielo, M.D.; Pereira, S.L. \& Amaral, A.A. 2011. Riqueza ictiofaunística encontrada no Rio Norte, Bacia do Itapemirim. In: Anais do X Congresso de Ecologia do Brasil. Sociedade de Ecologia do Brasil, São Lourenço. 
Silveira, J.D. 1964. Morfologia do litoral. In: A. Azevedo (Ed.), Brasil: a terra e o homem. Vol. 1. Cia. Editora Nacional, São Paulo,. p. 253-305.

Soares-Porto, L.M. 1998. Monophyly and interrelationships of the Centromochlinae (Siluriformes, Aucheniperidae). In: L.R. Malabarba, R.E. Reis, R.P. Vari, Z.M.S. Lucena \& C.A.S Lucena (eds), Phylogeny and Classification of Neotropical Fishes. EDIPUCRS, Porto Alegre, p. 331-350.

Soffiati Netto, A.A. 2007. Memórias do Rio Itabapoana Disponível em http://www.jornalorebate.com.br/site/ index 2.php?option $=$ com_content\&do_pdf $=1 \& \mathrm{id}=894 ; \quad$ acesso em 24 jan. 2012

Soffiati Netto, A.A. 2011. Proteção de Ecossistemas e da Biodiversidade Nativos na Ecorregião de São Tomé. In: $I V$ Seminário de Pesquisa. Universidade Federal Fluminense, Campos dos Goytacazes.

Stiassny, M.L.J. \& de Pinna, M.C.C. 1994. Basal taxa and the role of cladistic patterns in the evaluation of conservation priorities: a view from freshwater. In: P.L. Forey, C.J. Humphries \& R.I. Vane-Wright (eds), Systematics and Conservation Evaluation.
Systematics Association, Special Volume n. 50. Clarendon Press, Oxford, p. 235-249.

Tagliacollo, V.A.; Britzke, R.; Silva, G.S.C. \& Benine, R.C. 2011. Astyanax pirapuan: a new characid species from the upper Rio Paraguay system, Mato Grosso, Central Brazil (Characiformes, Characidae). Zootaxa 2749: 40-46

Tundisi, J.G. 1993. Represas do Paraná Superior: Limnologia e bases científicas para o gerenciamento. In: A. Boltovskoy \& H. L. Lopez (eds), Conferências de Limnologia. Argentina, La Plata, p. 41-52.

Universidade Federal Fluminense 1996. Projeto Managé. Perfil socioeconômico e ambiental da bacia hidrográfica do rio Itabapoana. Universidade Federal Fluminense, Niterói.

Vannote, R.L.; Minshall, G.W.; Cummins, K.W.; Sedell, J.R. \& Cushing, C.E. 1980. The river continuum concept. Canadian Journal of Fisheries and Aquatic Sciences 37: 130-137.

Vari, R.P. \& Castro, R.M.C. 2007. New species of Astyanax (Ostariophysi: Characiformes: Characidae) from the Upper Rio Paraná System, Brazil. Copeia (1): 150-162.

\title{
MATERIAL DAS BACIAS DO SUL Do ESPÍRITO SANTO
}

\author{
(1.161 lotes)
}

Bacia do Itapemirim (748 lotes, sendo que 602 foram examinados, 146 foram consultados em banco de dados). Lotes examinados (602 lotes): Aspidoras virgulatus MBML 540 (3), MBML 3677 (1). Astyanax giton MBML 430 (2), MBML 563 (12), MBML 566 (17), MBML 589 (16), MBML 1019 (10), MBML 1025 (6), MBML 1090 (16), MBML 1130 (24), MBML 1162 (4), MBML 1168 (14), MBML 1194 (2), MBML 1207 (26), MBML 1218 (8), MBML 1326 (12), MBML 1733 (3), MBML 1743 (10), MBML 1760 (35), MBML 2324 (1), MBML 2325 (5), MBML 2326 (52), MBML 2329 (2), MBML 2359 (4), MBML 2439 (1), MBML 2447 (10), MBML 2450 (8), MBML 2481 (22), MBML 2488 (1), MBML 2497 (10), MBML 2726 (5), MBML 2754 (3), MBML 3067 (4), MBML 3096 (5), MBML 3437 (34), MBML 3440 (6), MBML 3446 (5), MBML 3451 (3), MBML 3738 (3), MBML 3993 (2), MBML 3994 (7), MBML 4475 (1), MBML 5658 (1), MBML 5671 (4), MBML 5721 (1), MBML 5826 (16), MBML 5828 (3), MBML 5917 (31), MBML 5939 (4), MBML 5941 (2), MBML 5947 (9), MBML 5950 (6), MBML 5963 (2), MBML 5993 (12), MBML 5994 (3), MBML 6003 (1), MBML 6305 (4), MBML 6390 (66), MNRJ 36307 (3). Astyanax janeiroensis MBML 580 (6), MBML 988 (7), MBML 1020 (4), MBML 1278 (6), MBML 1291 (1), MBML 1811 (14), MBML 2328 (1), MBML 2464 (5), MBML 2465 (6), MBML 2480 (2), MBML 2498 (9), MBML 2758 (10), MBML 2770 (9), MBML 3443 (29), MBML 3681 (4), MBML 3695 (8), MBML 3736 (6), MBML 3995 (4), MBML 4480 (1), MBML 4580 (4), MBML 5670 (1), MBML 5746 (1), MNRJ 36313 (1), MNRJ 36314 (10), MNRJ 36323 (12), MNRJ 36332 (10), MNRJ 36341 (6), MNRJ 36348 (27), MNRJ 36363 (2). Astyanax microschemos MBML 1116 (1), MBML 1736 (7), MBML 3442 (19). Astyanax parahybae MBML 2483 (1), MBML 2766 (1), MNRJ 36357 (2), MNRJ 36667 (12). Astyanax sp.2 aff. A. lacustris MBML 422 (1), MBML 448 (1), MBML 1026 (3), MBML 1110 (4), MBML 1195 (12), MBML 2442 (1), MBML 2470 (1), MBML 2746 (3), MBML 2749 (3), MBML 3682 (1), MBML 5687 (3), MBML 5918 (7), MBML 5940 (2), MNRJ 36346 (9). Australoheros muriae MBML 3435 (1), MBML 3445 (9). Awaous tajasica MBML 3733 (1), MBML 3906 (1), MBML 5688 (1). Bryconamericus tenuis MBML 452 (1). Callichthys callichthys MNRJ 36331 (1). Centropomus undecimalis MBML 3919 (1). Characidium sp. MBML 525 (2), MBML 560 (1), MBML 570 (1), MBML 1087 (17), MBML 1167 (4), MBML 1327 (9), MBML 1732 (17), MBML 1737 (13), MBML 2419 (1), MBML 2423 (1), MBML 2431 (1), MBML 2445 (5), MBML 2461 (8), MBML 2478 (4), MBML 2490 (1), MBML 2492 (2), MBML 3739 (2), MBML 4152 (1), MBML 4310 (142), MBML 4331 (1), MBML 4476 (1), MBML 5689 (2), MBML 5911 (3), MBML 6394 (14), MNRJ 36302 (2), MNRJ 36315 (9), MNRJ 36333 (4), MNRJ 36350 (3), MNRJ 36589 (2), MNRJ 36593 (3), MNRJ 36668 (3). Crenicichla lacustris MBML 2460 (3), MBML 2990 (2), MBML 3909 (2), MBML 3920 (1), MBML 5655 (1), MBML 5692 (3). Cyphocharax gilbert MBML 2747 (2), MBML 2950 (4), MBML 3911 (1), MBML 3922 (3), MBML 5690 (1), MBML 5916 (4). Eigenmannia sp. MBML 2457 (1), MBML 3247 (5). Geophagus brasiliensis MBML 420 (2), MBML 443 (10), MBML 532 (17), MBML 545 (3), MBML 1015 (26), MBML 1017 (24), MBML 1021 (12), MBML 1078 (1), MBML 1084 (2), MBML 1131 (2), MBML 1165 (1), MBML 1267 (33), MBML 1309 (4), MBML 1759 (6), MBML 1812 (20), MBML 2420 (2), MBML 2427 (4), MBML 2433 (2), MBML 2438 (1), MBML 2446 (3), MBML 2452 (7), MBML 2476 (3), MBML 2491 (1), MBML 2499 (1), MBML 3093 (1), MBML 3434 (7), MBML 3449 (2), MBML 3680 (3), MBML 3692 (21), MBML 3698 (3), MBML 3734 (10), MBML 3744 (1), MBML 3752 (2), MBML 3774 (10), MBML 3908 (1), MBML 3921 (1), MBML 3929 (1), MBML 4473 (1), MBML 5659 (1), MBML 5669 (1), MBML 5686 (1), MBML 5747 (1), MBML 5827 (3), MBML 5914 (1), MBML 5959 (8), MBML 5961 (1), MBML 5998 (3), MBML 6009 (22), MBML 6040 (1), MBML 6393 (8), MNRJ 36306 (3), MNRJ 36312 (2), MNRJ 36322 (4), MNRJ 36329 (9), MNRJ 36338 (1), MNRJ 36354 (3), MNRJ 36356 (1), MNRJ 36590 (2), MNRJ 36599 (6), MNRJ 36673 (1). Glanidium melanopterum MBML 3913 (1). Gobionellus stomatus MBML 3743 (2). Gymnotus carapo MBML 431 (2), MBML 440 (3), MBML 509 
(1), MBML 537 (3), MBML 544 (5), MBML 562 (1), MBML 568 (1), MBML 1062 (2), MBML 1065 (17), MBML 1077 (1), MBML 1085 (5), MBML 1111 (4), MBML 1161 (1), MBML 1164 (2), MBML 1268 (29), MBML 2425 (1), MBML 2882 (14), MBML 3675 (1), MBML 4478 (1), MBML 5657 (1), MBML 5719 (1), MBML 5745 (1), MBML 5964 (1), MBML 6001 (2), MNRJ 36597 (2). Harttia loricariformis MBML 541 (1), MBML 552 (12), MBML 582 (6), MBML 987 (28), MBML 1016 (9), MBML 1018 (3), MBML 1208 (3), MBML 1209 (1), MBML 1306 (20), MBML 1758 (19), MBML 2421 (14), MBML 2434 (2), MBML 2487 (3), MBML 2494 (3), MBML 2687 (3), MBML 3910 (2), MBML 4481 (1), MBML 5691 (1), MBML 5825 (14), MBML 5949 (5), MBML 5960 (3), MBML 6397 (5), MNRJ 36309 (2), MNRJ 36364 (4), MNRJ 36672 (6). Hisonotus notatus MBML 1270 (70), MBML 2462 (6), MBML 2472 (5), MBML 3670 (1), MBML 3674 (8), MBML 3989 (4), MNRJ 36334 (8), MNRJ 36351 (5). Hoplias sp. aff. H. malabaricus MBML 475 (2), MBML 574 (2), MBML 1088 (1), MBML 1114 (1), MBML 2870 (4), MBML 3438 (1), MBML 3447 (1), MBML 3689 (1), MBML 3701 (1), MBML 3740 (1), MBML 3916 (1), MBML 5751 (1), MBML 5913 (2), MBML 6039 (1), MBML 6307 (1), MNRJ 36316 (1), MNRJ 36594 (3). Hoplosternum littorale MBML 3914 (1). Hyphessobrycon bifasciatus MBML 3750 (1). Hypostomus affinis MBML 441 (3), MBML 447 (1), MBML 520 (6), MBML 565 (13), MBML 1023 (3), MBML 1277 (1), MBML 1325 (2), MBML 1659 (6), MBML 1756 (1), MBML 2436 (1), MBML 2443 (1), MBML 2469 (2), MBML 2495 (3), MBML 2689 (2), MBML 2711 (7), MBML 2903 (1), MBML 3066 (45), MBML 3092 (1), MBML 3672 (2), MBML 3696 (1), MBML 3735 (1), MBML 3917 (3), MBML 3924 (2), MBML 3925 (1), MBML 5717 (2), MBML 5749 (2), MBML 5909 (7), MBML 6002 (2), MBML 6041 (1), MBML 6303 (21), MNRJ 36320 (1), MNRJ 36345 (5), MNRJ 36360 (1), MNRJ 36378 (2), MNRJ 36596 (3), MNRJ 36670 (1). Hypostomus auroguttatus MBML 3216 (3), MBML 3912 (1), MBML 3918 (1), MBML 3926 (2). Imparfinis sp. MBML 2458 (2), MBML 3676 (1), MBML 5718 (1), MBML 5910 (7), MNRJ 36336 (4). Knodus sp. aff. K. moenkhausii MBML 2428 (38), MBML 5750 (2), MNRJ 36592 (45). Leporinus copelandii MBML 476 (1), MBML 986 (1), MBML 1024 (2), MBML 1064 (2), MBML 1193 (2), MBML 1329 (3), MBML 1744 (2), MBML 1757 (2), MBML 2721 (2), MBML 3690 (1), MBML 5824 (1). Leporinus mormyrops MBML 435 (1), MBML 1119 (1), MBML 1160 (1), MBML 1210 (1). Microglanis parahybae MBML 5660 (1). Neoplecostomus microps MBML 419 (8), MBML 426 (5), MBML 449 (3), MBML 450 (2), MBML 535 (3), MBML 536 (32), MBML 557 (2), MBML 587 (18), MBML 1022 (2), MBML 1117 (17), MBML 1290 (1), MBML 1293 (4), MBML 1307 (15), MBML 1741 (3), MBML 2430 (3), MBML 2435 (1), MBML 3069 (1), MBML 3988 (1), MBML 4153 (2), MBML 4327 (3), MBML 4330 (10), MBML 6000 (11), MBML 6038 (1), MBML 6396 (5), MNRJ 36301 (7), MNRJ 36310 (2), MNRJ 36591 (17), MNRJ 36674 (1). Oligosarcus acutirostris MBML 2477 (1), MBML 2485 (1), MBML 2729 (6), MBML 3691 (7), MBML 3697 (9), MBML 3767 (2), MNRJ 36349 (1), MNRJ 36361 (1). Pareiorhaphis garbei MBML 451 (7), MBML 526 (1), MBML 558 (3), MBML 588 (2), MBML 4497 (1), MBML 6036 (2), MBML 6042 (1), MBML 6302 (1). Parotocinclus maculicauda MBML 510 (6), MBML 534 (2), MBML 564 (3), MBML 1354 (2), MBML 2449 (4), MBML 2463 (1), MBML 2496 (3), MBML 3345 (3), MBML 3673 (1), MBML 4477 (1), MBML 5656 (1), MBML 5912 (2), MBML 5948 (4), MBML 6004 (1), MBML 6395 (52), MNRJ 36327 (7), MNRJ 36335 (1), MNRJ 36671 (5). Phalloceros harpagos MBML 1271 (3), MBML 3095 (3), MBML 3436 (50), MBML 3444 (4), MBML 3742 (2). Pimelodella pectinifer MBML 1328 (1), MBML 2459 (3), MBML 2475 (1), MBML 2489 (1), MBML 2793 (1), MBML 3684 (8), MBML 3688 (1), MBML 3741 (1), MBML 3766 (2), MBML 3907 (1), MBML 5668 (2), MBML 5720 (1), MBML 5962 (1), MNRJ 36325 (1), MNRJ 36337 (4), MNRJ 36355 (1), MNRJ 36358 (1), MNRJ 36376 (12). Poecilia reticulata MBML 442 (10), MBML 511 (6), MBML 542 (2), MBML 546 (1), MBML 1310 (12), MBML 2424 (3), MBML 2432 (14), MBML 2437 (4), MBML 2444 (1), MBML 2454 (87), MBML 2468 (28), MBML 2479 (6), MBML 2500 (3), MBML 3094 (4), MBML 3700 (8), MBML 4154 (1), MBML 5748 (1), MBML 6037 (4), MBML 6392 (16), MNRJ 36304 (19), MNRJ 36311 (3), MNRJ 36321 (3), MNRJ 36330 (103), MNRJ 36344 (48), MNRJ 36353 (15), MNRJ 36379 (5). Poecilia vivipara MBML 2448 (1), MBML 2455 (18), MBML 2456 (16), MBML 2471 (1), MBML 2482 (5), MBML 2484 (1), MBML 2723 (7), MBML 3068 (10), MBML 3450 (2), MBML 3678 (9), MBML 3685 (43), MBML 3694 (102), MBML 3699 (113), MBML 3737 (1), MBML 3753 (30), MBML 3765 (25), MBML 3783 (10), MBML 3784 (10), MBML 3927 (5), MBML 3928 (8), MBML 3930 (22), MBML 3931 (13), MBML 3932 (19), MBML 5672 (1), MBML 5722 (2), MBML 5744 (1), MBML 5915 (5), MBML 6005 (4), MBML 6007 (2), MBML 6306 (2), MNRJ 36328 (22), MNRJ 36342 (4), MNRJ 36359 (2), MNRJ 36675 (1). Probolodus heterostomus MBML 2794 (3). Prochilodus vimboides MBML 1112 (1). Pterygoplichthys sp. MBML 3687 (10). Rhamdia sp. MBML 444 (3), MBML 556 (1), MBML 569 (8), MBML 583 (1), MBML 1079 (5), MBML 1089 (2), MBML 1115 (1), MBML 1163 (5), MBML 1166 (5), MBML 1269 (3), MBML 1279 (1), MBML 1292 (1), MBML 1813 (1), MBML 2440 (3), MBML 2451 (1), MBML 2466 (1), MBML 3070 (1), MBML 3439 (14), MBML 3441 (1), MBML 3448 (4), MBML 3679 (1), MBML 3693 (1), MBML 5716 (1), MBML 5958 (1), MBML 5999 (5), MBML 6008 (3), MBML 6391 (1), MNRJ 36305 (7), MNRJ 36308 (2), MNRJ 36317 (4), MNRJ 36326 (2), MNRJ 36377 (1), MNRJ 36669 (1). Rineloricaria steindachneri MBML 2474 (1), MBML 2486 (1), MBML 3202 (3), MBML 3683 (1), MBML 3915 (2), MBML 3923 (1), MNRJ 36352 (2), MNRJ 36362 (1). Tilapia rendalli MBML 985 (1), MBML 3686 (2), MBML 3702 (4), MBML 3764 (36), MNRJ 36303 (7). Trichogenes claviger MBML 3289 (1), MBML 3290 (17), MBML 3987 (23). Trichomycterus brunoi MBML 590 (1), MBML 1742 (1), MBML 2426 (1), MBML 2441 (3), MBML 2493 (1), MBML 4312 (1), MBML 4326 (4), MBML 4329 (3), MBML 4482 (1), MNRJ 36595 (2). Trichomycterus caudofasciatus MBML 427 (4), MBML 434 (2), MBML 539 (1), MBML 547 (15), MBML 559 (2), MBML 567 (1), MBML 1080 (9), MBML 1086 (4), MBML 1308 (5), MBML 1734 (25), MBML 1735 (3), MBML 2418 (3), MBML 2422 (1), MBML 2429 (20), MBML 2453 (39), MBML 2467 (4), MBML 2473 (1), MBML 4151 (4), MBML 4311 (1), MBML 4328 (3), MBML 4332 (1), MBML 6006 (1), MBML 6304 (3), MBML 6398 (13), MNRJ 36300 (23), MNRJ 36319 (4), MNRJ 36324 (42), MNRJ 36343 (5), MNRJ 36588 (5). Ulaema lefroyi MBML 3751 (1). Lotes consultados em banco de dados (146 lotes): Astyanax giton MCP 27737 (4), MCP 29475 (2), MCP 29476 (1), MCP 29488 (3), MCP 29503 (1), MCP 29511 (1), MNRJ 22978 (7), MNRJ 22988 (12), MZUSP 27576 (116). Astyanax janeiroensis MCP 29504 (2), MCZ 20933 (8), MNRJ 22248 (32), MNRJ 22249 (58). Astyanax microschemos MCP 34366 (31), MCP 37569 (1). Astyanax parahybae MCP 13964 (753), MZUSP 17059 (102), MZUSP 41737 (121), MZUSP 79631 (1). Astyanax sp.2 aff. A. lacustris MCP 27746 (2), MCP 27751 (4), MCP 29469 (2), MCP 29505 (3), MZUSP 17057 (29). Characidium sp. MCP 13773 (1), MCP 14363 (34), MCP 29472 (1), MNRJ 23806 (1), MNRJ 
23816 (4), MNRJ 23819 (3), MZUSP 41740 (13). Corydoras nattereri MNRJ 22367 (3). Crenicichla lacustris MZUSP 27579 (1). Cyphocharax gilbert MNRJ 22987 (1), MZUSP 20850 (10). Eleotris pisonis MCP 17867 (1). Geophagus brasiliensis MCP 18155 (22), MCP 27724 (1), MNRJ 22300 (7), MNRJ 22303 (38), MZUSP 27580 (29), MZUSP 27660 (1), MZUSP 41734 (2), MZUSP 44992 (4), MZUSP 54851 (20). Gymnotus carapo MNRJ 21046 (2). Harttia loricariformis MCP 13778 (2), MCP 27674 (4), MCP 27690 (1), MCP 27699 (7), MCP 29483 (1), MCP 29485 (3), MCP 29502 (9), MCP 29509 (7), MZUSP 41733 (1). Hisonotus notatus MCP 18096 (9), MNRJ 22984 (2), MZUSP 27583 (4). Hoplias sp. aff. H. malabaricus MNRJ 22332 (3), MNRJ 22342 (2), MZUSP 27578 (1). Hoplosternum littorale MNRJ 22369 (3). Hyphessobrycon bifasciatus MCP 13679 (8), MZUSP 41736 (5). Hypostomus affinis MCP 27338 (2), MCP 27665 (2), MCP 27668 (8), MCP 27672 (13), MCP 29474 (1), MCP 29480 (12), MCP 29486 (1), MNRJ 21028 (1), MNRJ 21048 (2), MNRJ 22983 (2), MNRJ 22991 (1). Hypostomus auroguttatus MCP 29471 (1). Knodus sp. aff. K. moenkhausii MNRJ 21049 (1), MZUSP 17058 (1). Leporinus copelandii MCP 17869 (10), MCP 29470 (1), MZUSP 27581 (2). Microglanis parahybae MCP 17777 (1), MNRJ 22981 (1). Neoplecostomus microps MCP 27340 (5), MCP 27667 (34), MCP 27669 (1), MCP 27683 (3), MCP 27691 (10), MCP 27692 (9), MCP 29481 (6), MCP 29482 (2), MCP 29487 (10), MCP 34023 (7), MCP 34024 (2), MNRJ 21027 (5). Oligosarcus acutirostris MCP 17982 (2), MNRJ 22979 (12), MNRJ 22989 (2), MZUSP 4765 (1), MZUSP 27582 (5), MZUSP 37525 (1). Otothyris lophophanes MNRJ 22985 (64). Pareiorhaphis garbei MCP 13806 (1), MCP 27295 (1), MCP 27337 (2), MCP 27704 (10), MCP 27706 (36), MCP 29484 (1), MCP 29506 (1). Parotocinclus maculicauda MCP 27673 (1), MCP 27686 (1), MCP 29500 (16), MCP 29501 (6). Pimelodella pectinifer MCP 13761 (1), MCP 29473 (1), MZUSP 22968 (72), Poecilia reticulata MCP 27666 (2), MCP 27687 (2), MCP 29510 (2), MNRJ 21047 (1), MZUSP 41735 (3). Poecilia vivipara MCP 18120 (11), MNRJ 22986 (41), MNRJ 22992 (99), MZUSP 54814 (10), MZUSP 64143 (1). Probolodus heterostomus MZUSP 27577 (1). Prochilodus vimboides MZUSP 20849 (1). Rhamdia sp. MCP 27730 (2), MCP 29633 (1), MNRJ 22982 (7). Scleromystax prionotos MZUSP 22969 (1). Tilapia rendalli MNRJ 22294 (1). Trachelyopterus striatulus MNRJ 22990 (4). Trichomycterus caudofasciatus MCP 13699 (2), MCP 13759 (1), MCP 13799 (2), MCP 27719 (8), MCP 27721 (3), MCP 27722 (6), MCP 29507 (1), MNRJ 21029 (2), MNRJ 22980 (3), MNRJ 23818 (5), MZUSP 41738 (2), MZUSP 41739 (2).

Bacia do Itabapoana (401 lotes, sendo que 219 foram examinados, 182 foram consultados em banco de dados). Lotes examinados (219 lotes): Ancistrus multispinis MBML 1776 (2). Astyanax giton MBML 2389 (1), MBML 2407 (4), MBML 3708 (2), MBML 3711 (20), MBML 3731 (7), MBML 5680 (1), MBML 5728 (3), MBML 6311 (13), MBML 6313 (21), MNRJ 36571 (7), MNRJ 36584 (3). Astyanax janeiroensis MBML 1765 (10), MBML 1779 (15), MBML 2371 (58), MBML 2381 (27), MBML 2387 (13), MBML 2397 (2), MBML 2414 (4), MBML 3720 (11), MBML 3996 (1), MBML 5681 (1), MBML 5725 (1), MBML 6290 (1), MBML 6319 (21), MBML 6331 (54), MNRJ 36540 (70), MNRJ 36549 (26), MNRJ 36553 (15). Astyanax sp.2 aff. A. lacustris MBML 2377 (4), MBML 2394 (1), MBML 2408 (1), MBML 3713 (1), MBML 3992 (1), MNRJ 36541 (1), MNRJ 36542 (1), MNRJ 36562 (1), MNRJ 36567 (2). Australoheros muriae MBML 3703 (1). Bryconamericus tenuis MNRJ 36543 (86). Characidium sp. MBML 1778 (86), MBML 1810 (36), MBML 2365 (5), MBML 2375 (14), MBML 2382 (17), MBML 2392 (8), MBML 2399 (68), MBML 2400 (77), MBML 2411 (23), MBML 2412 (34), MBML 2417 (1), MBML 5726 (1), MBML 6310 (46), MBML 6314 (12), MBML 6321 (3), MBML 6328 (10), MNRJ 36529 (6), MNRJ 36544 (14), MNRJ 36552 (17), MNRJ 36554 (10), MNRJ 36569 (78), MNRJ 36570 (89), MNRJ 36579 (23), MNRJ 36582 (33), MNRJ 36586 (1). Corydoras nattereri MBML 3722 (9), MBML 3777 (6), MBML 1780 (1), MBML 2366 (1), MBML 5679 (2), MNRJ 36647 (1). Cyphocharax gilbert MBML 5682 (1), MNRJ 36538 (1). Eigenmannia sp. MBML 976 (1), MBML 3723 (1). Geophagus brasiliensis MBML 1764 (1), MBML 1777 (2), MBML 2369 (3), MBML 2384 (3), MBML 3707 (13), MBML 3718 (10), MBML 3730 (1), MBML 3748 (1), MBML 5685 (1), MBML 5727 (2), MBML 5757 (1), MBML 6318 (2), MBML 6324 (1), MBML 6325 (12), MNRJ 36530 (1), MNRJ 36535 (4), MNRJ 36559 (3), MNRJ 36565 (8), MNRJ 36578 (1). Gymnotus carapo MBML 2368 (3), MBML 2383 (4), MBML 3714 (4), MBML 5723 (1), MBML 6315 (6), MBML 6322 (4), MBML 6330 (5), MNRJ 36536 (2), MNRJ 36557 (5). Harttia loricariformis MBML 1763 (1), MNRJ 36528 (1). Hasemania sp. MBML 2390 (17), MBML 2398 (3), MBML 2406 (27), MNRJ 36560 (20), MNRJ 36568 (7), MNRJ 36576 (31). Hisonotus notatus MBML 1766 (3), MBML 1770 (7), MBML 3716 (1), MBML 3728 (14), MBML 3786 (10), MBML 4080 (1). Hoplias sp. aff. H. malabaricus MBML 2374 (2), MBML 2385 (1), MBML 3725 (1), MBML 6332 (1), MNRJ 36534 (2). Hoplosternum littorale MBML 1027 (1). Hyphessobrycon bifasciatus MBML 3747 (71). Hypostomus affinis MBML 1771 (2), MBML 2393 (10), MBML 2401 (3), MBML 5758 (1), MBML 6316 (5), MBML 6326 (8), MNRJ 36531 (1), MNRJ 36537 (1), MNRJ 36545 (1), MNRJ 36561 (12). Imparfinis sp. MBML 1762 (1), MBML 1769 (4). Ituglanis parahybae MBML 3717 (1), MBML 3721 (1). Knodus sp. aff. K. moenkhausii MBML 2376 (73), MBML 3710 (14). Leporinus copelandii MBML 2370 (1), MBML 3719 (1), MBML 3785 (10). Mimagoniates microlepis MBML 1768 (11). Neoplecostomus microps MBML 2380 (3), MBML 2395 (2), MBML 2403 (1), MBML 2409 (1), MBML 2415 (3), MBML 2416 (2), MNRJ 36532 (1), MNRJ 36548 (3), MNRJ 36563 (3), MNRJ 36573 (1), MNRJ 36574 (3), MNRJ 36581 (3), MNRJ 36585 (4), MNRJ 36587 (1). Oligosarcus acutirostris MBML 1761 (1), MBML 3726 (2). Parotocinclus maculicauda MBML 1772 (2), MBML 3706 (3), MBML 3729 (2). Parotocinclus sp. MBML 6295 (1). Phalloceros harpagos MBML 2404 (1), MBML 3715 (1). Pimelodella pectinifer MBML 2373 (11), MBML 5684 (2), MNRJ 36539 (12). Poecilia reticulata MBML 3705 (12), MBML 3712 (7), MBML 6309 (3). Poecilia vivipara MBML 1767 (9), MBML 2391 (2), MBML 2405 (8), MBML 3727 (6), MBML 3749 (74), MBML 5683 (1), MBML 6333 (4), MNRJ 36533 (1), MNRJ 36547 (2), MNRJ 36558 (3), MNRJ 36577 (11). Rhamdia sp. MBML 2367 (1), MBML 2372 (1), MBML 3709 (2), MBML 5756 (1), MBML 6317 (4), MBML 6320 (3), MBML 6327 (3), MNRJ 36550 (1), MNRJ 36566 (8). Rineloricaria steindachneri MBML 3724 (1). Scleromystax prionotos MBML 1775 (1). Synbranchus marmoratus MBML 1774 (1), MBML 3732 (1). Tilapia rendalli MBML 2388 (3), MBML 1773 (2), MBML 2396 (6), MBML 2410 (2), MBML 2413 (2), MBML 4325 (1), MBML 5724 (1). Trichomycterus caudofasciatus MBML 2378 (2), MBML 2386 (1), MBML 2402 (1), MBML 3704 (1), MBML 6308 (3), MBML 6312 (47), MBML 6323 (2), MBML 6329 (1), MNRJ 36546 (1), MNRJ 36555 (1), MNRJ 36556 (3), MNRJ 36564 (8), MNRJ 36572 (1), MNRJ 36575 (2), MNRJ 36580 (2), MNRJ 36583 (2). Lotes consultados em banco de dados (182 lotes): Achirus declivis MCZ 11436 (1). Anchovia 
clupeoides LIRP 995 (2). Archosargus probatocephalus MCZ 154356 (1). Astyanax giton LIRP 6404 (10), LIRP 6413 (4), LIRP 6460 (4), LIRP 6464 (1), LIRP 6851 (2), LIRP 6862 (2), LIRP 6871 (3), LIRP 6887 (2), MNRJ 22994 (154), MZUSP 27568 (12). Astyanax janeiroensis LIRP 961 (1), LIRP 6405 (2), LIRP 6414 (2), LIRP 6431 (1), LIRP 6461 (4), LIRP 6462 (2), LIRP 6860 (1), LIRP 6893 (2), LIRP 7030 (4), LIRP 7040 (2), MCZ 20899 1), MNRJ 22995 (21), MNRJ 23008 (12), MZUSP 27569 (27). Astyanax parahybae LIRP 6852 (1). Astyanax sp.2 aff. A. lacustris LIRP 6402 (1), LIRP 6412 (4), LIRP 6430 (1), LIRP 6463 (1), LIRP 6853 (1), LIRP 6857 (2), LIRP 6869 (3), LIRP 6882 (3), MCP 17750 (1), MCZ 20900 (3). Atherinella brasiliensis LIRP 996 (1). Australoheros muriae MCZ 15369 (2). Bathygobius soporator LIRP 827 (4), LIRP 968 (6), MCZ 13093 (2). Brycon insignis MCZ 21116 (9), MZUSP 79087 (4). Caranx latus LIRP 826 (2), MCZ 16085 (1). Characidium sp. MCP 17733 (5), MNRJ 2644 (5), MNRJ 22415 (63), MNRJ 22435 (2). Citharichthys arenaceus LIRP 997 (2). Corydoras nattereri MNRJ 22368 (16), LIRP 6408 (1), LIRP 6427 (1), LIRP 6845 (2), LIRP 6861 (1), LIRP 6886 (1), LIRP 7034 (2), LIRP 7056 (1), MCP 18143 (2), MZUSP 27570 (1). Ctenogobius boleosoma MCZ 16059 (2). Cyphocharax gilbert LIRP 6397 (15), LIRP 6400 (2), LIRP 6411 (1), LIRP 6438 (6), LIRP 6465 (6), LIRP 6863 (2), LIRP 6868 (3), LIRP 6885 (31), LIRP 6892 (3), LIRP 7054 (18), MCZ 20281 (2), MCZ 20282 (4), MCZ 16484 (11). Dormitator maculatus LIRP 964 (1). Eigenmannia sp. LIRP 6844 (1), MCP 18111 (2), MNRJ 23007 (2). Eleotris pisonis LIRP 965 (2), LIRP 966 (27), LIRP 960 (1), LIRP 967 (17), LIRP 971 (4). Geophagus brasiliensis LIRP 6399 (5), LIRP 6409 (2), LIRP 6418 (1), LIRP 6428 (1), LIRP 6867 (3), LIRP 6884 (2), LIRP 7033 (1), LIRP 7037 (5), MCP 17854 (3), MCZ 15748 (2), MNRJ 22301 (8), MZUSP 54863 (2). Glanidium melanopterum LIRP 6406 (12), LIRP 6416 (1), LIRP 6859 (2), LIRP 7029 (8), LIRP 7036 (4). Gymnotus carapo LIRP 7038 (1), MCP 17831 (2). Harttia loricariformis LIRP 6407 (3), LIRP 6417 (1), LIRP 6870 (1). Hisonotus notatus MCP 18098 (208), MNRJ 23006 (217). Hoplias sp. aff. H. malabaricus LIRP 6458 (3), LIRP 6890 (1), LIRP 7052 (1), MCZ 21617 (2), MCZ 21618 (1). Hyphessobrycon bifasciatus MZUSP 27567 (2). Hypostomus affinis LIRP 970 (1), LIRP 6454 (4), MCP 18066 (6), MNRJ 23004 (4). Imparfinis sp. MCP 17997 (1), MNRJ 23000 (2). Leporinus copelandii LIRP 6396 (1), LIRP 6401 (1), LIRP 6410 (1), LIRP 6426 (1), LIRP 6429 (1), LIRP 6865 (1), LIRP 6889 (5), LIRP 7035 (3), MNRJ 22993 (9). Loricariichthys castaneus LIRP 6858 (1), LIRP 830 (2), LIRP 962 (4). Microglanis parahybae MCP 18008 (5), MNRJ 22999 (23), MZUSP 27571 (2). Microphis brachyurus LIRP 972 (20). Mugil curema LIRP 828 (3), MCZ 17566 (2). Oligosarcus acutirostris LIRP 6398 (4), LIRP 6403 (3), LIRP 6415 (1), LIRP 6437 (4), LIRP 6466 (3), LIRP 6883 (2), LIRP 6888 (3), LIRP 7028 (1), LIRP 7041 (2), LIRP 7055 (2), LIRP 7057 (2), MCZ 20605 (1), Oligosarcus acutirostris MZUSP 27573 (41). Otothyris lophophanes MNRJ 23003 (3). Parotocinclus maculicauda MZUSP 27575 (1). Phalloceros harpagos MCP 17839 (2), LIRP 6839 (3), LIRP 7039 (1), MCP 17786 (1), MNRJ 23002 (3). Poecilia vivipara LIRP 969 (1). Probolodus heterostomus MNRJ 22996 (2). Prochilodus vimboides LIRP 6841 (1), MZUSP 27572 (1). Rhamdia sp. LIRP 6455 (1), LIRP 6842 (1), LIRP 6866 (1), LIRP 7032 (1), LIRP 7053 (1), MNRJ 23001 (3). Rineloricaria steindachneri MCP 18109 (2), MNRJ 23005 (2). Scleromystax prionotos MCP 17791 (4), MNRJ 22364 (2). Trachelyopterus striatulus LIRP 6864 (3), LIRP 6872 (2), LIRP 6891 (1), LIRP 7031 (2), LIRP 7051 (1). Trichomycterus brunoi MNRJ 22997 (1), MCP 17784 (1), MNRJ 22998 (3). Ulaema lefroyi LIRP 829 (9).

Microbacias de Marataízes: (12 lotes examinados): Atherinella brasiliensis MBML 3759 (714). Bathygobius soporator MBML 3763 (2). Brevoortia pectinata MBML 3760 (26). Geophagus brasiliensis MBML 3754 (13), MBML 3745 (3). Hyphessobrycon bifasciatus MBML 3755 (9), MBML 3746 (1). Phalloceros harpagos MBML 3758 (539). Poecilia vivipara MBML 3762 (14), MBML 3757 (113). Ulaema lefroyi MBML 3761 (82), MBML 3756 (3). 


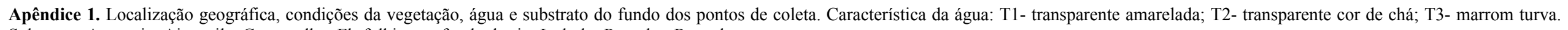
Substrato: Ae- areia; Ai- argila; C- cascalho; Fl- folhiço no fundo do rio; L- lodo; P- pedra; R- rocha.

\begin{tabular}{|c|c|c|c|c|c|c|c|c|c|c|}
\hline \multirow[t]{2}{*}{ Pt } & \multirow[t]{2}{*}{ Fig. } & \multirow[t]{2}{*}{ Localidade abreviada } & \multirow[t]{2}{*}{ Coordenadas } & \multirow[t]{2}{*}{ Altitude (m) } & \multirow{2}{*}{$\begin{array}{c}\text { Prof. } \\
\text { amostral } \\
(\mathbf{m}) \\
\end{array}$} & \multirow[t]{2}{*}{ Água } & \multirow[t]{2}{*}{ Substrato } & \multicolumn{3}{|c|}{ Vegetação } \\
\hline & & & & & & & & marginal & aquática & de entorno \\
\hline P01 & - & $\begin{array}{l}\text { Córrego Mata Pau em } \\
\text { Maravilha }\end{array}$ & $\begin{array}{l}20^{\circ} 18^{\prime} 53^{\prime \prime S} \\
41^{\circ} 23^{\prime} 02^{\prime \prime} \mathrm{W}\end{array}$ & 619 & $0,3-0,5$ & $\mathrm{~T} 2$ & Ae- Ai- C & Abundantes gramíneas & Pouca vegetação emergente & Capoeira ou agricultura \\
\hline $\mathrm{P} 02$ & - & Córrego Bela Vista & $\begin{array}{l}20^{\circ} 27^{\prime} 27^{\prime \prime} \mathrm{S} \\
41^{\circ} 23^{\prime} 36^{\prime \prime} \mathrm{W}\end{array}$ & 564 & $0,3-0,5$ & $\mathrm{~T} 2$ & $\mathrm{Ae}$ & Poucas gramíneas & Pouca vegetação submersa & Capoeira \\
\hline P03 & - & $\begin{array}{l}\text { Rio Braço Norte } \\
\text { Esquerdo próximo a } \\
\text { Piaçu }\end{array}$ & $\begin{array}{l}20^{\circ} 21^{\prime} 04^{\prime \prime S} \\
41^{\circ} 23^{\prime} 51^{\prime \prime W}\end{array}$ & 546 & $1,0-1,5$ & $\mathrm{~T} 2$ & Ae- Ai- Fl & Moderadas gramíneas e samambaias & Macrófitas e vegetação submersa & Capoeira ou mata secundária \\
\hline P04 & - & $\begin{array}{l}\text { Córrego Rico em } \\
\text { Menino Jesus }\end{array}$ & $\begin{array}{l}20^{\circ} 22^{\prime} 42^{\prime \prime} \mathrm{S} \\
41^{\circ} 24^{\prime} 17^{\prime \prime} \mathrm{W}\end{array}$ & 500 & $0,5-1,0$ & $\mathrm{~T} 1$ & $\mathrm{Ae}-\mathrm{Ai}$ & Poucas gramíneas & Vegetação submersa algas e perifiton & Capoeira \\
\hline P05 & - & $\begin{array}{l}\text { Córrego da Vista } \\
\text { Alegre }\end{array}$ & $\begin{array}{l}20^{\circ} 23^{\prime} 47^{\prime \prime} \mathrm{S} \\
41^{\circ} 25^{\prime} 59^{\prime \prime} \mathrm{W}\end{array}$ & 524 & $1,0-1,5$ & $\mathrm{~T} 1$ & $\mathrm{Ae}$ & Moderadas gramíneas & Pouca vegetação submersa & Capoeira ou agricultura \\
\hline P06 & - & $\begin{array}{l}\text { Córrego Santo } \\
\text { Antônio }\end{array}$ & $\begin{array}{l}20^{\circ} 25^{\prime} 00^{\prime \prime} \mathrm{S} \\
41^{\circ} 26^{\prime} 10^{\prime \prime} \mathrm{W}\end{array}$ & 424 & $0,5-1,0$ & $\mathrm{~T} 1$ & $\mathrm{Ae}-\mathrm{Ai}$ & Poucas gramíneas & Vegetação submersa algas e perifiton & Capoeira \\
\hline P07 & 3 & $\begin{array}{l}\text { Rio Braço Norte } \\
\text { Esquerdo trecho } \\
\text { médio em Muniz } \\
\text { Freire }\end{array}$ & $\begin{array}{l}20^{\circ} 26^{\prime} 32^{\prime \prime} \mathrm{S} \\
41^{\circ} 27^{\prime} 05^{\prime \prime} \mathrm{W}\end{array}$ & 421 & $1,0-1,5$ & $\mathrm{~T} 1$ & $\mathrm{Ae}-\mathrm{Ai}$ & Poucas gramíneas & Vegetação submersa algas e perifiton & Capoeira \\
\hline P08 & 3 & $\begin{array}{l}\text { Córrego Vargem } \\
\text { Grande }\end{array}$ & $\begin{array}{l}20^{\circ} 27^{\prime} 16^{\prime \prime S} \\
41^{\circ} 26^{\prime} 42^{\prime \prime} \mathrm{W}\end{array}$ & 433 & $0,5-1,0$ & $\mathrm{~T} 1$ & $\mathrm{Ae}-\mathrm{Ai}$ & Abundantes gramíneas & Pouca vegetação emergente & Capoeira \\
\hline P09 & - & $\begin{array}{l}\text { Córrego Seio de } \\
\text { Abraão }\end{array}$ & $\begin{array}{l}20^{\circ} 25^{\prime} 29^{\prime \prime} \mathrm{S} \\
41^{\circ} 27^{\prime} 59^{\prime \prime} \mathrm{W}\end{array}$ & 766 & $1,0-1,5$ & $\mathrm{~T} 2$ & Ae- Ai- Fl & Mata ciliar & Moderada vegetação flutuante e emergente & Capoeira ou mata secundária \\
\hline $\mathrm{P} 10$ & - & Córrego Cristal & $\begin{array}{l}20^{\circ} 28^{\prime} 09^{\prime \prime S} \\
41^{\circ} 27^{\prime} 21^{\prime \prime} \mathrm{W}\end{array}$ & 535 & $0,5-1,0$ & $\mathrm{~T} 1$ & Ae- Ai- C & Abundantes gramíneas & Pouca vegetação emergente & Capoeira ou mata secundária \\
\hline P11 & 3 & $\begin{array}{l}\text { Rio Pardo na ponte da } \\
\text { BR262 próximo a } \\
\text { Ibatiba }\end{array}$ & $\begin{array}{l}20^{\circ} 14^{\prime} 15^{\prime \prime S} \\
41^{\circ} 30^{\prime} 42^{\prime \prime} \mathrm{W}\end{array}$ & 741 & $1,0-1,5$ & $\mathrm{~T} 3$ & Ae- Ai- C & Moderadas gramíneas & Pouca vegetação submersa & Capoeira ou habitação \\
\hline $\mathrm{P} 12$ & - & $\begin{array}{l}\text { Rio Pardinho, } \\
\text { confluência com } \\
\text { Córrego Santa Rosa }\end{array}$ & $\begin{array}{l}20^{\circ} 21^{\prime} 47^{\prime \prime S} \\
41^{\circ} 36^{\prime} 27^{\prime \prime} \mathrm{W}\end{array}$ & 693 & $0,5-1,0$ & $\mathrm{~T} 1$ & Ae- Ai- C & Moderadas gramíneas & Vegetação submersa algas e perifiton & Capoeira ou agricultura \\
\hline
\end{tabular}




\begin{tabular}{|c|c|c|c|c|c|c|c|c|c|c|}
\hline \multirow[t]{2}{*}{$\mathbf{P t}$} & \multirow[t]{2}{*}{ Fig. } & \multirow[t]{2}{*}{ Localidade abreviada } & \multirow[t]{2}{*}{ Coordenadas } & \multirow[t]{2}{*}{ Altitude (m) } & \multirow{2}{*}{$\begin{array}{c}\text { Prof. } \\
\text { amostral } \\
(\mathbf{m}) \\
\end{array}$} & \multirow[t]{2}{*}{ Água } & \multirow[t]{2}{*}{ Substrato } & \multicolumn{3}{|c|}{ Vegetação } \\
\hline & & & & & & & & marginal & aquática & de entorno \\
\hline $\mathrm{P} 13$ & - & Córrego Ponte Alta & $\begin{array}{l}20^{\circ} 22^{\prime} 40^{\prime \prime} \mathrm{S} \\
41^{\circ} 29^{\prime} 44^{\prime \prime} \mathrm{W}\end{array}$ & 824 & $0,3-0,5$ & $\mathrm{~T} 1$ & Ae- $P$ & Poucas gramíneas & Pouca vegetação submersa & Capoeira ou agricultura \\
\hline P14 & 3 & Córrego Jatobá & $\begin{array}{l}20^{\circ} 24^{\prime} 16^{\prime \prime S} \\
41^{\circ} 30^{\prime} 51^{\prime \prime} \mathrm{W}\end{array}$ & 611 & $0,5-1,0$ & $\mathrm{~T} 1$ & Ae- P- R & Poucas gramíneas & Pouca vegetação submersa & Capoeira \\
\hline P15 & - & $\begin{array}{l}\text { Córrego Terra } \\
\text { Comprida }\end{array}$ & $\begin{array}{l}20^{\circ} 26^{\prime} 24^{\prime \prime} \mathrm{S} \\
41^{\circ} 30^{\prime} 24^{\prime \prime} \mathrm{W}\end{array}$ & 680 & $0,5-1,0$ & $\mathrm{~T} 1$ & Ae- P- R & Poucas gramíneas & Vegetação submersa algas e perifiton & Capoeira ou agricultura \\
\hline P16 & 3 & $\begin{array}{l}\text { Rio Pardo trecho } \\
\text { médio em Muniz } \\
\text { Freire }\end{array}$ & $\begin{array}{l}20^{\circ} 26^{\prime} 44^{\prime \prime} \mathrm{S} \\
41^{\circ} 29^{\prime} 34^{\prime \prime} \mathrm{W}\end{array}$ & 589 & $1,0-1,5$ & $\mathrm{~T} 1$ & Ae- P- R & Poucas gramíneas & Vegetação submersa algas e perifiton & Capoeira \\
\hline P17 & 3 & $\begin{array}{l}\text { Rio Pardo na barragem } \\
\text { da Usina Hidroelétrica }\end{array}$ & $\begin{array}{l}20^{\circ} 27^{\prime} 22^{\prime \prime S} \\
41^{\circ} 28^{\prime} 45^{\prime \prime} \mathrm{W}\end{array}$ & 591 & $1,5-2,0$ & $\mathrm{~T} 2$ & Ae- Ai- Fl & Mata ciliar & Moderada vegetação emergente & Mata secundária \\
\hline P18 & - & $\begin{array}{l}\text { Rio Braço Norte } \\
\text { Esquerdo na foz do } \\
\text { Rio Pardo }\end{array}$ & $\begin{array}{l}20^{\circ} 28^{\prime} 03^{\prime \prime S} \\
41^{\circ} 28^{\prime} 17^{\prime \prime} \mathrm{W}\end{array}$ & 391 & $1,0-1,5$ & $\mathrm{~T} 2$ & $\mathrm{Ae}-\mathrm{Ai}$ & Mata ciliar & Pouca vegetação submersa & Capoeira \\
\hline P19 & & Ribeirão da Boa Vista & $\begin{array}{l}20^{\circ} 32^{\prime} 35^{\prime \prime W} \\
41^{\circ} 31^{\prime} 27^{\prime \prime} \mathrm{W}\end{array}$ & 344 & $1,0-1,5$ & $\mathrm{~T} 1$ & Ae- P- C & Abundantes gramíneas & Vegetação submersa algas e perifiton & Mata secundária \\
\hline $\mathrm{P} 20$ & 3 & Córrego Bugarim & $\begin{array}{l}20^{\circ} 30^{\prime} 20^{\prime \prime} \mathrm{S} \\
41^{\circ} 25^{\prime} 25^{\prime \prime} \mathrm{W}\end{array}$ & 521 & $0,5-1,0$ & $\mathrm{~T} 1$ & Ae- Ai- C & Moderadas gramíneas & Vegetação submersa algas e perifiton & Capoeira ou agricultura \\
\hline $\mathrm{P} 21$ & 3 & Córrego São Simão & $\begin{array}{l}20^{\circ} 32^{\prime} 49^{\prime \prime} \mathrm{S} \\
41^{\circ} 26^{\prime} 19^{\prime \prime} \mathrm{W}\end{array}$ & 430 & $0,5-1,0$ & $\mathrm{~T} 1$ & $\mathrm{Ae}-\mathrm{Ai}$ & Moderadas gramíneas & Pouca vegetação submersa & Capoeira \\
\hline $\mathrm{P} 22$ & 3 & Córrego do Travessão & $\begin{array}{l}20^{\circ} 37^{\prime} 37^{\prime \prime} \mathrm{S} \\
41^{\circ} 27^{\prime} 54^{\prime \prime} \mathrm{W}\end{array}$ & 244 & $1,0-1,5$ & $\mathrm{~T} 2$ & $\mathrm{Ae}-\mathrm{Ai}$ & Vestígios de mata ciliar & Pouca vegetação emergente & Capoeira ou ata secundária \\
\hline $\mathrm{P} 23$ & 3 & $\begin{array}{l}\text { Rio Braço Norte } \\
\text { Direito no PARNA do } \\
\text { Caparaó }\end{array}$ & $\begin{array}{l}20^{\circ} 26^{\prime} 38^{\prime \prime} \mathrm{S} \\
41^{\circ} 43^{\prime} 35^{\prime \prime} \mathrm{W}\end{array}$ & 1.044 & $0,5-1,0$ & $\mathrm{~T} 1$ & P- R & Mata ciliar & Vegetação submersa algas e perifiton & Mata preservada \\
\hline P24 & 3 & $\begin{array}{l}\text { Rio Pedra Roxa no } \\
\text { PARNA do Caparaó }\end{array}$ & $\begin{array}{l}20^{\circ} 23^{\prime} 50^{\prime \prime} \mathrm{S} \\
41^{\circ} 44^{\prime} 08^{\prime \prime} \mathrm{W}\end{array}$ & 1.060 & $0,5-1,0$ & $\mathrm{~T} 1$ & P- R- C & Mata ciliar & Vegetação submersa algas e perifiton & Mata preservada \\
\hline P25 & - & $\begin{array}{l}\text { Córrego Palmital sob a } \\
\text { BR-262 }\end{array}$ & $\begin{array}{l}20^{\circ} 17^{\prime} 48^{\prime \prime S} \\
41^{\circ} 41^{\prime} 29^{\prime \prime} \mathrm{W}\end{array}$ & 859 & $1,0-1,5$ & $\mathrm{~T} 1$ & Ae- P- R & Poucas gramíneas & Vegetação submersa algas e perifiton & Capoeira \\
\hline
\end{tabular}




\begin{tabular}{|c|c|c|c|c|c|c|c|c|c|c|}
\hline \multirow[t]{2}{*}{ Pt } & \multirow[t]{2}{*}{ Fig. } & \multirow[t]{2}{*}{ Localidade abreviada } & \multirow[t]{2}{*}{ Coordenadas } & \multirow[t]{2}{*}{ Altitude (m) } & \multirow{2}{*}{$\begin{array}{c}\text { Prof. } \\
\text { amostral } \\
(\mathbf{m})\end{array}$} & \multirow[t]{2}{*}{ Água } & \multirow[t]{2}{*}{ Substrato } & \multicolumn{3}{|c|}{ Vegetação } \\
\hline & & & & & & & & marginal & aquática & de entorno \\
\hline P26 & 3 & $\begin{array}{l}\text { Rio Pedregulho no } \\
\text { PARNA do Caparaó }\end{array}$ & $\begin{array}{l}20^{\circ} 20^{\prime} 56^{\prime \prime} \mathrm{S} \\
41^{\circ} 45^{\prime} 19^{\prime \prime} \mathrm{W}\end{array}$ & 1.039 & $0,5-1,0$ & $\mathrm{~T} 1$ & P- R- C & Mata ciliar & Vegetação submersa algas e perifiton & Mata preservada \\
\hline P27 & 3 & $\begin{array}{l}\text { Córrego do Calçado } \\
\text { no PARNA do } \\
\text { Caparaó }\end{array}$ & $\begin{array}{l}20^{\circ} 27^{\prime} 59^{\prime \prime} \mathrm{S} \\
41^{\circ} 44^{\prime} 01^{\prime \prime} \mathrm{W}\end{array}$ & 1.063 & $0,5-1,0$ & $\mathrm{~T} 1$ & P- R & Mata ciliar & Vegetação submersa algas e perifiton & $\begin{array}{l}\text { Mata preservada } \\
\text { truticultura }\end{array}$ \\
\hline P28 & 3 & $\begin{array}{l}\text { Córrego do Calçado } \\
\text { fora do PARNA do } \\
\text { Caparaó }\end{array}$ & $\begin{array}{l}20^{\circ} 28^{\prime} 41^{\prime \prime S} \\
41^{\circ} 42^{\prime} 14^{\prime \prime} \mathrm{W}\end{array}$ & 828 & $1,0-1,5$ & $\mathrm{~T} 1$ & P- R- C & Mata ciliar & Vegetação submersa algas e perifiton & Mata preservada \\
\hline P29 & 4 & Córrego do Caldeirão & $\begin{array}{l}20^{\circ} 29^{\prime} 06^{\prime \prime} \mathrm{S} \\
41^{\circ} 42^{\prime} 26^{\prime \prime} \mathrm{W}\end{array}$ & 815 & $0,5-1,0$ & $\mathrm{~T} 1$ & $\mathrm{Ae}-\mathrm{Ai}$ & Vestígios de mata ciliar & Pouca vegetação submersa & Capoeira ou mata secundária \\
\hline P30 & 4 & $\begin{array}{l}\text { Ribeirão Santa Marta } \\
\text { na cachoeira Santa } \\
\text { Marta }\end{array}$ & $\begin{array}{l}20^{\circ} 39^{\prime} 19^{\prime \prime S} \\
41^{\circ} 43^{\prime} 08^{\prime \prime} \mathrm{W}\end{array}$ & 854 & $1,0-1,5$ & $\mathrm{~T} 1$ & P- R- C & Mata ciliar & Vegetação submersa algas e perifiton & Mata secundária ou habitação \\
\hline P31 & - & $\begin{array}{l}\text { Ribeirão Cachoeira } \\
\text { Alegre em Celina }\end{array}$ & $\begin{array}{l}20^{\circ} 46^{\prime} 00^{\prime \prime S} \\
41^{\circ} 35^{\prime} 36^{\prime \prime} \mathrm{W}\end{array}$ & 627 & $0,5-1,0$ & $\mathrm{~T} 2$ & $\mathrm{Ae}-\mathrm{Ai}$ & Abundantes gramíneas & Pouca vegetação emergente & Capoeira \\
\hline P32 & 4 & $\begin{array}{l}\text { Ribeirão Vargem } \\
\text { Alegre acima da } \\
\text { represa }\end{array}$ & $\begin{array}{l}20^{\circ} 47^{\prime} 23 " \mathrm{~S} \\
41^{\circ} 33^{\prime} 34^{\prime \prime W}\end{array}$ & 381 & $1,0-1,5$ & $\mathrm{~T} 2$ & $\mathrm{Ae}-\mathrm{Ai}$ & Abundantes gramíneas & Moderada vegetação emergente & $\begin{array}{l}\text { Capoeira } \\
\text { Via não pavimentada }\end{array}$ \\
\hline P33 & 4 & $\begin{array}{l}\text { Ribeirão Vargem } \\
\text { Alegre em Celina }\end{array}$ & $\begin{array}{l}20^{\circ} 47^{\prime} 53^{\prime \prime S} \\
41^{\circ} 35^{\prime} 17^{\prime \prime} \mathrm{W}\end{array}$ & 634 & $0,5-1,0$ & $\mathrm{~T} 1$ & P- R & Vestígios de mata ciliar & Vegetação submersa algas e perifiton & Capoeira ou mata secundária \\
\hline P34 & 4 & $\begin{array}{l}\text { Ribeirão Arraial do } \\
\text { Café }\end{array}$ & $\begin{array}{l}20^{\circ} 48^{\prime} 33^{\prime \prime} \mathrm{S} \\
41^{\circ} 32^{\prime} 39^{\prime \prime} \mathrm{W}\end{array}$ & 315 & $0,5-1,0$ & $\mathrm{~T} 1$ & $\mathrm{Ai}-\mathrm{C}$ & Moderadas gramíneas & Pouca vegetação submersa & Capoeira \\
\hline P35 & 4 & $\begin{array}{l}\text { Córrego Horizonte em } \\
\text { Rive }\end{array}$ & $\begin{array}{l}20^{\circ} 45^{\prime} 18^{\prime \prime} \mathrm{S} \\
41^{\circ} 05^{\prime} 30^{\prime \prime} \mathrm{W}\end{array}$ & 115 & $1,0-1,5$ & $\mathrm{~T} 2$ & Ae- Ai- C & Abundantes gramíneas & Pouca vegetação emergente & Capoeira ou mata secundária \\
\hline P36 & 4 & $\begin{array}{l}\text { Ribeirão São } \\
\text { Bartolomeu à jusante } \\
\text { de Cachoeira Braúna }\end{array}$ & $\begin{array}{l}20^{\circ} 46^{\prime} 53^{\prime \prime S} \\
41^{\circ} 27^{\prime} 12^{\prime \prime W}\end{array}$ & 123 & $0,5-1,0$ & $\mathrm{~T} 2$ & $\mathrm{Ae}-\mathrm{Ai}$ & Moderadas gramíneas & Pouca vegetação emergente & Capoeira \\
\hline P37 & 4 & $\begin{array}{l}\text { Ribeirão São } \\
\text { Bartolomeu }\end{array}$ & $\begin{array}{l}20^{\circ} 46^{\prime} 08^{\prime \prime S} \\
41^{\circ} 26^{\prime} 16^{\prime \prime} \mathrm{W}\end{array}$ & 122 & $0,5-1,0$ & $\mathrm{~T} 2$ & $\mathrm{Ae}-\mathrm{Ai}$ & Moderadas gramíneas & Pouca vegetação emergente & Capoeira ou agricultura \\
\hline P38 & 4 & $\begin{array}{l}\text { Córrego Oriente em } \\
\text { Oriente }\end{array}$ & $\begin{array}{l}20^{\circ} 42^{\prime} 51^{\prime \prime} \mathrm{S} \\
41^{\circ} 21^{\prime} 55^{\prime \prime} \mathrm{W}\end{array}$ & 142 & $0,3-0,5$ & $\mathrm{~T} 1$ & Ae- Ai- C & Abundantes gramíneas & Pouca vegetação submersa & Capoeira ou agricultura \\
\hline
\end{tabular}




\begin{tabular}{|c|c|c|c|c|c|c|c|c|c|c|}
\hline \multirow[t]{2}{*}{$\mathbf{P t}$} & \multirow[t]{2}{*}{ Fig. } & \multirow[t]{2}{*}{ Localidade abreviada } & \multirow[t]{2}{*}{ Coordenadas } & \multirow[t]{2}{*}{ Altitude (m) } & \multirow{2}{*}{$\begin{array}{c}\text { Prof. } \\
\text { amostral } \\
\text { (m) }\end{array}$} & \multirow[t]{2}{*}{ Água } & \multirow[t]{2}{*}{ Substrato } & \multicolumn{3}{|c|}{ Vegetação } \\
\hline & & & & & & & & Marginal & aquática & de entorno \\
\hline P39 & 4 & $\begin{array}{l}\text { Rio Itapemirim entre } \\
\text { Pacotuba e Coutinho }\end{array}$ & $\begin{array}{l}20^{\circ} 44^{\prime} 50^{\prime \prime S} \\
41^{\circ} 21^{\prime} 42^{\prime \prime} \mathrm{W}\end{array}$ & 94 & $1,0-1,5$ & $\mathrm{~T} 1$ & P- R- C & Moderadas gramíneas & Pouca vegetação submersa & Capoeira \\
\hline P40 & 4 & $\begin{array}{l}\text { Ribeirão Floresta em } \\
\text { Burarama }\end{array}$ & $\begin{array}{l}20^{\circ} 41^{\prime} 20^{\prime \prime} \mathrm{S} \\
41^{\circ} 20^{\prime} 24^{\prime \prime} \mathrm{W}\end{array}$ & 94 & $0,5-1,0$ & $\mathrm{~T} 1$ & Ae- Ai- C & Vestígios de mata ciliar & Pouca vegetação emergente & Capoeira ou mata secundária \\
\hline P41 & 4 & $\begin{array}{l}\text { Rio Itapemirim sob a } \\
\text { ponte para Castelo }\end{array}$ & $\begin{array}{l}20^{\circ} 44^{\prime} 59^{\prime \prime} \mathrm{S} \\
41^{\circ} 11^{\prime} 19^{\prime \prime} \mathrm{W}\end{array}$ & 59 & $1,5-2,0$ & $\mathrm{~T} 2$ & Ae- P- C & Moderadas gramíneas & Pouca vegetação submersa & Capoeira \\
\hline P42 & 4 & Rio Taquaraçu & $\begin{array}{l}20^{\circ} 24^{\prime} 02^{\prime \prime S} \\
41^{\circ} 11^{\prime} 17^{\prime \prime} \mathrm{W}\end{array}$ & 706 & $0,5-1,0$ & $\mathrm{~T} 1$ & $\mathrm{Ae}-\mathrm{Ai}$ & Vestígios de mata ciliar & Moderada vegetação emergente & Capoeira ou mata secundária \\
\hline P43 & - & Córrego Desengano & $\begin{array}{l}20^{\circ} 31^{\prime} 29^{\prime \prime S} \\
41^{\circ} 18^{\prime} 19^{\prime \prime} \mathrm{W}\end{array}$ & 404 & $0,5-1,0$ & $\mathrm{~T} 1$ & $\mathrm{Ae}-\mathrm{Ai}$ & Poucas gramíneas & Pouca vegetação submersa & Capoeira \\
\hline P44 & - & Córrego Alto Chapéu & $\begin{array}{l}20^{\circ} 33^{\prime} 19^{\prime \prime} \mathrm{S} \\
41^{\circ} 15^{\prime} 09^{\prime \prime} \mathrm{W}\end{array}$ & 161 & $0,5-1,0$ & $\mathrm{~T} 2$ & $\mathrm{Ae}-\mathrm{Ai}$ & Abundantes gramíneas & Pouca vegetação emergente & Capoeira \\
\hline P45 & 4 & $\begin{array}{l}\text { Córrego Picada } \\
\text { Comprida }\end{array}$ & $\begin{array}{l}20^{\circ} 30^{\prime} 16^{\prime \prime} \mathrm{S} \\
41^{\circ} 02^{\prime} 39^{\prime \prime} \mathrm{W}\end{array}$ & 1120 & $0,5-1,0$ & $\mathrm{~T} 2$ & Ae- C- Fl & Mata ciliar & Pouca vegetação emergente ou flutuante & Mata secundária \\
\hline P46 & 4 & $\begin{array}{l}\text { Cachoeira no Rio } \\
\text { Caxixe }\end{array}$ & $\begin{array}{l}20^{\circ} 32^{\prime} 32^{\prime \prime S} \\
41^{\circ} 10^{\prime} 13^{\prime \prime} \mathrm{W}\end{array}$ & 328 & $0,5-1,0$ & $\mathrm{~T} 1$ & Ae- P- R & Poucas gramíneas & Pouca vegetação submersa & Capoeira \\
\hline P47 & 5 & Rio Caxixe & $\begin{array}{l}20^{\circ} 33^{\prime} 52^{\prime \prime} \mathrm{S} \\
41^{\circ} 11^{\prime} 54^{\prime \prime} \mathrm{W}\end{array}$ & 122 & $1,0-1,5$ & $\mathrm{~T} 1$ & Ae- P- R & Vestígios de mata ciliar & Pouca vegetação submersa & Capoeira ou mata secundária \\
\hline P48 & - & $\begin{array}{l}\text { Rio Fruteiras na ES- } \\
164\end{array}$ & $\begin{array}{l}20^{\circ} 38^{\prime} 08^{\prime \prime S} \\
41^{\circ} 00^{\prime} 46^{\prime \prime} \mathrm{W}\end{array}$ & 660 & $0,5-1,0$ & $\mathrm{~T} 1$ & Ae- Ai- C & Moderadasgramíneas & Pouca vegetação submersa & Capoeira ou agricultura \\
\hline P49 & 5 & $\begin{array}{l}\text { Rio Castelo, na estrada } \\
\text { para São Vicente }\end{array}$ & $\begin{array}{l}20^{\circ} 42^{\prime} 22^{\prime \prime S} \\
41^{\circ} 11^{\prime} 06^{\prime \prime} \mathrm{W}\end{array}$ & 67 & $1,0-1,5$ & $\mathrm{~T} 3$ & $\mathrm{Ae}-\mathrm{Ai}$ & Moderadas gramíneas & Pouca vegetação emergente ou flutuante & Capoeira \\
\hline P50 & - & $\begin{array}{l}\text { Rio Itapemirim à } \\
\text { jusante da foz do } \\
\text { Córrego Itaoca }\end{array}$ & $\begin{array}{l}20^{\circ} 45^{\prime} 26^{\prime \prime S} \\
41^{\circ} 08^{\prime} 00^{\prime \prime} \mathrm{W}\end{array}$ & 55 & $1,0-1,5$ & $\mathrm{~T} 3$ & $\mathrm{Ae}-\mathrm{Ai}$ & Moderadas gramíneas & Moderada vegetação emergente ou flutuante & Capoeira \\
\hline P51 & - & $\begin{array}{l}\text { Rio Itapemirim entre o } \\
\text { Córrego Itaoca e o } \\
\text { Córrego Jacaré }\end{array}$ & $\begin{array}{l}20^{\circ} 46^{\prime} 43^{\prime \prime S} \\
41^{\circ} 08^{\prime} 05^{\prime \prime} \mathrm{W}\end{array}$ & 45 & $0,5-1,0$ & $\mathrm{~T} 1$ & Ae- Ai- C & Poucas gramíneas & Pouca vegetação submersa & Capoeira \\
\hline
\end{tabular}




\begin{tabular}{|c|c|c|c|c|c|c|c|c|c|c|}
\hline \multirow[t]{2}{*}{$\mathbf{P t}$} & \multirow[t]{2}{*}{ Fig. } & \multirow[t]{2}{*}{ Localidade abreviada } & \multirow[t]{2}{*}{ Coordenadas } & \multirow[t]{2}{*}{ Altitude (m) } & \multirow{2}{*}{$\begin{array}{c}\text { Prof. } \\
\text { amostral } \\
(\mathbf{m})\end{array}$} & \multirow[t]{2}{*}{ Água } & \multirow[t]{2}{*}{ Substrato } & \multicolumn{3}{|c|}{ Vegetação } \\
\hline & & & & & & & & Marginal & aquática & de entorno \\
\hline P52 & - & $\begin{array}{l}\text { Rio Itapemirim à } \\
\text { montante da foz do } \\
\text { Córrego Jacaré }\end{array}$ & $\begin{array}{l}20^{\circ} 47^{\prime} 48^{\prime \prime} \mathrm{S} \\
41^{\circ} 08^{\prime} 09^{\prime \prime} \mathrm{W}\end{array}$ & 39 & $1,0-1,5$ & $\mathrm{~T} 3$ & Ae- Ai & Moderadas gramíneas & Pouca vegetação emergente & Capoeira \\
\hline P53 & - & $\begin{array}{l}\text { Córrego Jacaré } \\
\text { próximo à nascente }\end{array}$ & $\begin{array}{l}20^{\circ} 44^{\prime} 16^{\prime \prime} \mathrm{S} \\
41^{\circ} 05^{\prime} 30^{\prime \prime} \mathrm{W}\end{array}$ & 115 & $0,3-0,5$ & $\mathrm{~T} 1$ & Ae- C & Poucas gramíneas & Pouca vegetação emergente & Capoeira ou agricultura \\
\hline P54 & - & $\begin{array}{l}\text { Rio Itapemirim à } \\
\text { jusante da foz do } \\
\text { Córrego Jacaré }\end{array}$ & $\begin{array}{l}20^{\circ} 48^{\prime} 22^{\prime \prime S} \\
41^{\circ} 07^{\prime} 174^{\prime \prime} \mathrm{W}\end{array}$ & 36 & $1,0-1,5$ & $\mathrm{~T} 3$ & Ae- Ai- C & Moderadas gramíneas & Pouca vegetação emergente & Capoeira \\
\hline P55 & 5 & $\begin{array}{l}\text { Rio Itapemirim na BR- } \\
101\end{array}$ & $\begin{array}{l}20^{\circ} 55^{\prime} 03^{\prime \prime} \mathrm{S} \\
41^{\circ} 04^{\prime} 30^{\prime \prime} \mathrm{W}\end{array}$ & 23 & $1,0-1,5$ & $\mathrm{~T} 3$ & Ae- Ai & Moderadas gramíneas & Moderada vegetação emergente ou flutuante & Capoeira ou agricultura \\
\hline P56 & 5 & $\begin{array}{l}\text { Rio Muqui do Norte } \\
\text { na Estrada de Terra à } \\
\text { esquerda da ES-393 }\end{array}$ & $\begin{array}{l}20^{\circ} 55^{\prime} 20^{\prime \prime} \mathrm{S} \\
41^{\circ} 18^{\prime} 35^{\prime \prime} \mathrm{W}\end{array}$ & 214 & $0,5-1,0$ & $\mathrm{~T} 1$ & Ae- Ai & Moderadas gramíneas & Abundante vegetação emergente & Capoeira \\
\hline P57 & 5 & $\begin{array}{l}\text { Afluente do Córrego } \\
\text { São Gabriel }\end{array}$ & $\begin{array}{l}20^{\circ} 53^{\prime} 10^{\prime \prime S} \\
41^{\circ} 16^{\prime} 10^{\prime \prime} \mathrm{W}\end{array}$ & 205 & $0,5-1,0$ & $\mathrm{~T} 1$ & Ae- Ai- C & Moderadas gramíneas & Moderada vegetação emergente & Capoeira ou pasto \\
\hline P58 & 5 & $\begin{array}{l}\text { Rio Muqui do Norte } \\
\text { sob a ES- } 489\end{array}$ & $\begin{array}{l}20^{\circ} 55^{\prime} 57^{\prime \prime} \mathrm{S} \\
41^{\circ} 10^{\prime} 45^{\prime \prime} \mathrm{W}\end{array}$ & 52 & $1,0-1,5$ & $\mathrm{~T} 3$ & Ae- Ai- P & Poucas gramíneas & Pouca vegetação emergente & Capoeira ou pasto \\
\hline P59 & 5 & $\begin{array}{l}\text { Afluente do Rio } \\
\text { Muqui do Norte sob a } \\
\text { ES-489 }\end{array}$ & $\begin{array}{l}20^{\circ} 59^{\prime} 09^{\prime \prime S} \\
41^{\circ} 10^{\prime} 02^{\prime \prime} \mathrm{W}\end{array}$ & 38 & $0,5-1,0$ & $\mathrm{~T} 1$ & Ae- Ai- C & Poucas gramíneas & Pouca vegetação emergente & Capoeira ou pasto \\
\hline $\mathrm{P} 60$ & 5 & $\begin{array}{l}\text { Afluente do Córrego } \\
\text { da Forquilha no } \\
\text { PARNA do Caparaó }\end{array}$ & $\begin{array}{l}20^{\circ} 30^{\prime} 12^{\prime \prime S} \\
41^{\circ} 48^{\prime} 18^{\prime \prime} \mathrm{W}\end{array}$ & 1.450 & $0,3-0,5$ & $\mathrm{~T} 1$ & $\mathrm{P}-\mathrm{C}$ & Mata ciliar & Vegetação submersa algas e perifiton & Mata preservada \\
\hline P61 & 5 & Córrego Limo Verde & $\begin{array}{l}20^{\circ} 34^{\prime} 14^{\prime \prime S} \\
41^{\circ} 44^{\prime} 59^{\prime \prime} \mathrm{W}\end{array}$ & 831 & $0,5-1,0$ & $\mathrm{~T} 1$ & P- R- C & Vestígios de mata ciliar & Vegetação submersa algas e perifiton & Mata preservada \\
\hline P62 & 5 & Córrego do Veadinho & $\begin{array}{l}20^{\circ} 36^{\prime} 04^{\prime \prime S} \\
41^{\circ} 46^{\prime} 37^{\prime \prime} \mathrm{W}\end{array}$ & 845 & $0,3-0,5$ & $\mathrm{~T} 1$ & P- R- C & Mata ciliar & Vegetação submersa algas e perifiton & Mata preservada \\
\hline P63 & 5 & Córrego Azul & $\begin{array}{l}20^{\circ} 38^{\prime} 26^{\prime \prime} \mathrm{S} \\
41^{\circ} 48^{\prime} 23^{\prime \prime} \mathrm{W}\end{array}$ & 784 & $0,5-1,0$ & $\mathrm{~T} 1$ & $\mathrm{Ae}-\mathrm{Ai}$ & Moderadas gramíneas & Pouca vegetação emergente & Capoeira \\
\hline P64 & 5 & Córrego da Piedade & $\begin{array}{l}20^{\circ} 41^{\prime} 08^{\prime \prime} \mathrm{S} \\
41^{\circ} 50^{\prime} 13^{\prime \prime} \mathrm{W}\end{array}$ & 769 & $0,5-1,0$ & $\mathrm{~T} 1$ & Ae- Ai & Poucas gramíneas & Pouca vegetação submersa & Capoeira \\
\hline
\end{tabular}




\begin{tabular}{|c|c|c|c|c|c|c|c|c|c|c|}
\hline \multirow[t]{2}{*}{$\mathbf{P t}$} & \multirow[t]{2}{*}{ Fig. } & \multirow[t]{2}{*}{ Localidade abreviada } & \multirow[t]{2}{*}{ Coordenadas } & \multirow[t]{2}{*}{ Altitude (m) } & \multirow{2}{*}{$\begin{array}{c}\text { Prof. } \\
\text { amostral } \\
\text { (m) }\end{array}$} & \multirow[t]{2}{*}{ Água } & \multirow[t]{2}{*}{ Substrato } & \multicolumn{3}{|c|}{ Vegetação } \\
\hline & & & & & & & & marginal & aquática & de entorno \\
\hline P65 & 5 & Rio Caparaozinho & $\begin{array}{l}20^{\circ} 43^{\prime} 11^{\prime \prime} \mathrm{S} \\
41^{\circ} 45^{\prime} 33^{\prime \prime} \mathrm{W}\end{array}$ & 796 & $0,5-1,0$ & $\mathrm{~T} 1$ & Ae- C- P & Moderadas gramíneas & Pouca vegetação emergente & Capoeira \\
\hline P66 & 5 & $\begin{array}{l}\text { Córrego São } \\
\text { Domingos }\end{array}$ & $\begin{array}{l}20^{\circ} 47^{\prime} 04^{\prime \prime} \mathrm{S} \\
41^{\circ} 45^{\prime} 42^{\prime \prime} \mathrm{W}\end{array}$ & 638 & $0,5-1,0$ & $\mathrm{~T} 1$ & P- R-C & Vestígios de mata ciliar & Moderada vegetação emergente & Capoeira ou mata secundária \\
\hline 67 & 5 & Córrego da Cachoeira & $\begin{array}{l}20^{\circ} 48^{\prime} 57^{\prime \prime} \mathrm{S} \\
41^{\circ} 42^{\prime} 14^{\prime \prime} \mathrm{W}\end{array}$ & 582 & $0,5-1,0$ & $\mathrm{~T} 1$ & P- R-C & Vestígios de mata ciliar & Vegetação submersa algas e perifiton & Capoeira ou mata secundária \\
\hline P68 & - & $\begin{array}{l}\text { Rio Itabapoana na } \\
\text { UHE Rosal }\end{array}$ & $\begin{array}{l}20^{\circ} 54^{\prime} 01^{\prime \prime S} \\
41^{\circ} 43^{\prime} 03^{\prime \prime} \mathrm{W}\end{array}$ & 559 & $1,0-1,5$ & $\mathrm{~T} 3$ & P- R-C & Ausente & Pouca vegetação submersa & Ausente \\
\hline P69 & - & $\begin{array}{l}\text { Rio Itabapoana jusante } \\
\text { da barragem da UHE } \\
\text { Rosal }\end{array}$ & $\begin{array}{l}20^{\circ} 55^{\prime} 21 " \mathrm{~S} \\
41^{\circ} 43^{\prime} 20^{\prime \prime} \mathrm{W}\end{array}$ & 544 & $1,0-1,5$ & $\mathrm{~T} 3$ & Ae- P- C & Poucas gramíneas & Pouca vegetação submersa & Capoeira \\
\hline P70 & - & $\begin{array}{l}\text { Reservatório da UHE } \\
\text { Rosal }\end{array}$ & $\begin{array}{l}20^{\circ} 55^{\prime} 44^{\prime \prime} \mathrm{S} \\
41^{\circ} 42^{\prime} 39^{\prime \prime} \mathrm{W}\end{array}$ & 0 & $1,5-2,0$ & $\mathrm{~T} 3$ & P- R-C & Poucas gramíneas & Pouca vegetação submersa & Ausente \\
\hline P71 & - & $\begin{array}{l}\text { Rio Itabapoana jusante } \\
\text { da Casa de Força da } \\
\text { UHE Rosal }\end{array}$ & $\begin{array}{l}20^{\circ} 57^{\prime} 19^{\prime \prime S} \\
41^{\circ} 43^{\prime} 01^{\prime \prime W}\end{array}$ & 375 & $1,0-1,5$ & $\mathrm{~T} 3$ & Ae- P- C & Mata ciliar & Pouca vegetação submersa & Capoeira \\
\hline P72 & - & Rio Calçado & $\begin{array}{l}21^{\circ} 04^{\prime} 06^{\prime \prime} \mathrm{S} \\
41^{\circ} 40^{\prime} 09^{\prime \prime} \mathrm{W}\end{array}$ & 277 & $1,0-1,5$ & $\mathrm{~T} 1$ & Ae- Ai & Vestígios de mata ciliar & Pouca vegetação emergente & Capoeira ou mata secundária \\
\hline P73 & - & $\begin{array}{l}\text { Rio Itabapoana em } \\
\text { Mimoso do Sul }\end{array}$ & $\begin{array}{l}21^{\circ} 12^{\prime} 03^{\prime \prime S} \\
41^{\circ} 21^{\prime} 35^{\prime \prime} \mathrm{W}\end{array}$ & 21 & $1,0-1,5$ & $\mathrm{~T} 3$ & Ae- Ai & Moderadas gramíneas & Moderada vegetação emergente & Capoeira ou agricultura \\
\hline P74 & 6 & $\begin{array}{l}\text { Córrego Santa Marta } \\
\text { na ES-177 }\end{array}$ & $\begin{array}{l}21^{\circ} 02^{\prime} 18^{\prime \prime S} \\
41^{\circ} 21^{\prime} 12^{\prime \prime} \mathrm{W}\end{array}$ & 169 & $0,5-1,0$ & $\mathrm{~T} 3$ & Ae- Ai & Moderadas gramíneas & Pouca vegetação emergente & Capoeira ou pasto \\
\hline P75 & - & $\begin{array}{l}\text { Córrego da Serra na } \\
\text { foz (Córrego Boa } \\
\text { Vista) }\end{array}$ & $\begin{array}{l}21^{\circ} 03^{\prime} 41^{\prime \prime S} \\
41^{\circ} 22^{\prime} 04^{\prime \prime} \mathrm{W}\end{array}$ & 72 & $0,5-1,0$ & $\mathrm{~T} 3$ & Ae- Ai & Poucas gramíneas & Pouca vegetação submersa & Via não pavimentada habitação \\
\hline P76 & 6 & $\begin{array}{l}\text { Córrego Pratinha sob a } \\
\text { ES-391 }\end{array}$ & $\begin{array}{l}21^{\circ} 05^{\prime} 21^{\prime \prime S} \\
41^{\circ} 20^{\prime} 18^{\prime \prime} \mathrm{W}\end{array}$ & 30 & $0,5-1,0$ & $\mathrm{~T} 1$ & Ae- Ai & Poucas gramíneas & Moderada vegetação emergente & Capoeira \\
\hline P77 & 6 & $\begin{array}{l}\text { Córrego da Braúna sob } \\
\text { a ES-391 }\end{array}$ & $\begin{array}{l}21^{\circ} 06^{\prime} 14^{\prime \prime} \mathrm{S} \\
41^{\circ} 19^{\prime} 21^{\prime \prime} \mathrm{W}\end{array}$ & 25 & $0,5-1,0$ & $\mathrm{~T} 3$ & Ae- Ai & Moderadas gramíneas & Moderada vegetação emergente & Capoeira ou pasto \\
\hline
\end{tabular}




\begin{tabular}{|c|c|c|c|c|c|c|c|c|c|c|}
\hline \multirow[t]{2}{*}{$\mathbf{P t}$} & \multirow[t]{2}{*}{ Fig. } & \multirow[t]{2}{*}{ Localidade abreviada } & \multirow[t]{2}{*}{ Coordenadas } & \multirow[t]{2}{*}{ Altitude (m) } & \multirow{2}{*}{$\begin{array}{c}\text { Prof. } \\
\text { amostral } \\
\text { (m) }\end{array}$} & \multirow[t]{2}{*}{ Água } & \multirow[t]{2}{*}{ Substrato } & \multicolumn{3}{|c|}{ Vegetação } \\
\hline & & & & & & & & marginal & aquática & de entorno \\
\hline P78 & 6 & Córrego Poço D'Anta & $\begin{array}{l}20^{\circ} 53^{\prime} 56^{\prime \prime} \mathrm{S} \\
41^{\circ} 03^{\prime} 16^{\prime \prime} \mathrm{W}\end{array}$ & 19 & $0,5-1,0$ & $\mathrm{~T} 1$ & P-R-C & Vestígios de mata ciliar & Pouca vegetação submersa & Capoeira ou mata secundária \\
\hline P79 & - & Córrego do Frade & $\begin{array}{l}20^{\circ} 53^{\prime} 53^{\prime \prime} \mathrm{S} \\
41^{\circ} 01^{\prime} 48^{\prime \prime} \mathrm{W}\end{array}$ & 23 & $0,5-1,0$ & $\mathrm{~T} 1$ & Ae- Ai & Abundantes gramíneas & Pouca vegetação submersa & Capoeira \\
\hline P80 & 6 & Córrego Manhães & $\begin{array}{l}21^{\circ} 02^{\prime} 02^{\prime \prime} \mathrm{S} \\
41^{\circ} 10^{\prime} 48^{\prime \prime} \mathrm{W}\end{array}$ & 46 & $0,5-1,0$ & $\mathrm{~T} 1$ & Ae- Ai & Abundantes gramíneas & Moderada vegetação emergente & Capoeira ou agricultura \\
\hline P81 & 6 & $\begin{array}{l}\text { Rio Muqui do Norte } \\
\text { na ES-162 }\end{array}$ & $\begin{array}{l}21^{\circ} 01^{\prime} 00^{\prime \prime S} \\
41^{\circ} 05^{\prime} 12^{\prime \prime} \mathrm{W}\end{array}$ & 28 & $1,0-1,5$ & $\mathrm{~T} 3$ & Ae- Ai & Poucas gramíneas & Pouca vegetação submersa & Capoeira ou pasto \\
\hline P82 & - & $\begin{array}{l}\text { Rio Muqui do Norte } \\
\text { trecho médio em } \\
\text { Itapemirim }\end{array}$ & $\begin{array}{l}20^{\circ} 59^{\prime} 37^{\prime \prime} \mathrm{S} \\
40^{\circ} 58^{\prime} 58^{\prime \prime} \mathrm{W}\end{array}$ & 9 & $1,0-1,5$ & $\mathrm{~T} 3$ & Ae- Ai & Poucas gramíneas & Pouca vegetação submersa & Capoeira ou pasto \\
\hline P83 & 6 & $\begin{array}{l}\text { Rio Muqui do Norte } \\
\text { sob a ES-490 }\end{array}$ & $\begin{array}{l}20^{\circ} 59^{\prime} 56^{\prime \prime} \mathrm{S} \\
40^{\circ} 56^{\prime} 22^{\prime \prime} \mathrm{W}\end{array}$ & 8 & $1,0-1,5$ & $\mathrm{~T} 3$ & Ae- Ai & Poucas gramíneas & Moderada vegetação submersa & Capoeira ou pasto \\
\hline P84 & - & $\begin{array}{l}\text { Brejo Grande do Sul } \\
\text { na ES-060 }\end{array}$ & $\begin{array}{l}21^{\circ} 01^{\prime} 08^{\prime \prime} \mathrm{S} \\
40^{\circ} 55^{\prime} 57^{\prime \prime} \mathrm{W}\end{array}$ & 14 & $0,5-1,0$ & $\mathrm{~T} 3$ & Ae- Ai & Moderadas gramíneas & Moderada vegetação emergente & Capoeira ou pasto \\
\hline P85 & 6 & $\begin{array}{l}\text { Lagoa do Siri na ES- } \\
080\end{array}$ & $\begin{array}{l}21^{\circ} 06^{\prime} 34^{\prime \prime} \mathrm{S} \\
40^{\circ} 51^{\prime} 13^{\prime \prime} \mathrm{W}\end{array}$ & 6 & $0,5-1,0$ & $\mathrm{~T} 2$ & $\mathrm{Ae}$ & $\begin{array}{l}\text { Mata de restinga } \\
\text { Praia arenosa }\end{array}$ & $\begin{array}{l}\text { Abundantes macrófitas, taboas e } \\
\text { vegetação emergente }\end{array}$ & Restinga \\
\hline P86 & 6 & $\begin{array}{l}\text { Lagoa Boa Vista na } \\
\text { ES-060 }\end{array}$ & $\begin{array}{l}21^{\circ} 09^{\prime} 56^{\prime \prime} \mathrm{S} \\
40^{\circ} 54^{\prime} 50^{\prime \prime} \mathrm{W}\end{array}$ & 12 & $1,5-2,0$ & $\mathrm{~T} 2$ & Ae- L & Mata de restinga & Abundantes taboas (Typha sp.) & Restinga \\
\hline P87 & 6 & $\begin{array}{l}\text { Córrego São Salvador } \\
\text { na ES-162 }\end{array}$ & $\begin{array}{l}21^{\circ} 04^{\prime} 32^{\prime \prime} \mathrm{S} \\
41^{\circ} 02^{\prime} 45^{\prime \prime} \mathrm{W}\end{array}$ & 35 & $0,5-1,0$ & $\mathrm{~T} 3$ & $\mathrm{Ae}-\mathrm{Ai}$ & Abundantes gramíneas & Pouca vegetação emergente & Capoeira ou pasto \\
\hline P88 & - & Ribeirão das Flores & $\begin{array}{l}21^{\circ} 03^{\prime} 12^{\prime \prime} \mathrm{S} \\
41^{\circ} 133^{\prime} 32^{\prime \prime} \mathrm{W}\end{array}$ & 42 & $0,5-1,0$ & $\mathrm{~T} 1$ & Ae- Ai- C & Vestígios de mata ciliar & Pouca vegetação emergente & Capoeira ou mata secundária \\
\hline P89 & 6 & $\begin{array}{l}\text { Ribeirão da Flores na } \\
\text { Rodovia José Alves } \\
\text { Toledo }\end{array}$ & $\begin{array}{l}21^{\circ} 04^{\prime} 18^{\prime \prime S} \\
41^{\circ} 13^{\prime} 44^{\prime \prime} \mathrm{W}\end{array}$ & 16 & $0,5-1,0$ & $\mathrm{~T} 1$ & Ae- Ai- C & Abundantes gramíneas & Moderada vegetação submersa & Capoeira ou mata secundária \\
\hline $\mathrm{P} 90$ & - & Ribeirão das Flores & $\begin{array}{l}21^{\circ} 04^{\prime} 43^{\prime \prime S} \\
41^{\circ} 14^{\prime} 02^{\prime \prime} \mathrm{W}\end{array}$ & 17 & $0,5-1,0$ & $\mathrm{~T} 1$ & Ae- Ai- C & Vestígios de mata ciliar & Moderada vegetação submersa & Capoeira ou mata secundária \\
\hline
\end{tabular}




\begin{tabular}{|c|c|c|c|c|c|c|c|c|c|c|}
\hline \multirow[t]{2}{*}{$\mathbf{P t}$} & \multirow[t]{2}{*}{ Fig. } & \multirow[t]{2}{*}{ Localidade abreviada } & \multirow[t]{2}{*}{ Coordenadas } & \multirow[t]{2}{*}{ Altitude (m) } & \multirow{2}{*}{$\begin{array}{c}\text { Prof. } \\
\text { amostral } \\
\text { (m) }\end{array}$} & \multirow[t]{2}{*}{ Água } & \multirow[t]{2}{*}{ Substrato } & \multicolumn{3}{|c|}{ Vegetação } \\
\hline & & & & & & & & Marginal & aquática & de entorno \\
\hline P91 & 6 & $\begin{array}{l}\text { Afluente do Córrego } \\
\text { Marobá no lado } \\
\text { esquerdo da ES-162 }\end{array}$ & $\begin{array}{l}21^{\circ} 07^{\prime} 09^{\prime \prime S} \\
41^{\circ} 01^{\prime} 19^{\prime \prime} \mathrm{W}\end{array}$ & 30 & $0,3-0,5$ & $\mathrm{~T} 2$ & Ae- Ai- L & $\begin{array}{l}\text { Mata de restinga } \\
\text { gramíneas }\end{array}$ & Abundantes macrófitas e vegetação emergente & Restinga ou pasto \\
\hline P92 & - & $\begin{array}{l}\text { Mangue, divisa do } \\
\text { Estado do Rio de } \\
\text { Janeiro e Espírito } \\
\text { Santo. }\end{array}$ & $\begin{array}{l}21^{\circ} 16^{\prime} 08^{\prime \prime} \mathrm{S} \\
40^{\circ} 59^{\prime} 19^{\prime \prime} \mathrm{W}\end{array}$ & 2 & $1,5-2,0$ & $\mathrm{~T} 2$ & Ae- L & Manguezal & Abundante vegetação emergente & Manguezal \\
\hline
\end{tabular}


Apêndice 2. Constância de ocorrência (Dajoz 1983) das espécies nas bacias do sul do Espírito Santo. n- número de exemplares; Pts- número de pontos onde a espécie foi encontrada; Marinho- espécies marinhas com presença nos estuários.

\begin{tabular}{|c|c|c|c|c|c|}
\hline Espécie & Pts & $\%$ & $\mathbf{n}$ & Ocorrência & Marinho \\
\hline Geophagus brasiliensis & 62 & $67,4 \%$ & 580 & Constante & \\
\hline Hypostomus affinis & 42 & $45,7 \%$ & 261 & Acessória & \\
\hline Astyanax giton & 41 & $44,6 \%$ & 990 & Acessória & \\
\hline Astyanax janeiroensis & 40 & $43,5 \%$ & 729 & Acessória & \\
\hline Characidium sp. & 36 & $39,1 \%$ & 1185 & Acessória & \\
\hline Poecilia vivipara & 34 & $37,0 \%$ & 927 & Acessória & \\
\hline Rhamdia sp. & 33 & $35,9 \%$ & 135 & Acessória & \\
\hline Trichomycterus caudofasciatus & 30 & $32,6 \%$ & 369 & Acessória & \\
\hline Neoplecostomus microps & 28 & $30,4 \%$ & 316 & Acessória & \\
\hline Astyanax sp. 2 aff. A. lacustris & 27 & $29,3 \%$ & 124 & Acessória & \\
\hline Hoplias sp. aff. H. malabaricus & 25 & $27,2 \%$ & 46 & Acessória & \\
\hline Gymnotus carapo & 24 & $26,1 \%$ & 141 & Acessória & \\
\hline Harttia loricariformis & 24 & $26,1 \%$ & 212 & Acessória & \\
\hline Pimelodella pectinifer & 21 & $22,8 \%$ & 150 & Ocasional & \\
\hline Poecilia reticulata & 19 & $20,7 \%$ & 439 & Ocasional & \\
\hline Oligosarcus acutirostris & 18 & $19,6 \%$ & 123 & Ocasional & \\
\hline Parotocinclus maculicauda & 18 & $19,6 \%$ & 131 & Ocasional & \\
\hline Trichomycterus brunoi & 17 & $18,5 \%$ & 63 & Ocasional & \\
\hline Leporinus copelandii & 16 & $17,4 \%$ & 60 & Ocasional & \\
\hline Pareiorhaphis garbei & 16 & $17,4 \%$ & 83 & Ocasional & \\
\hline Cyphocharax gilbert & 15 & $16,3 \%$ & 122 & Ocasional & \\
\hline Crenicichla lacustris & 14 & $15,2 \%$ & 30 & Ocasional & \\
\hline Hisonotus notatus & 13 & $14,1 \%$ & 583 & Ocasional & \\
\hline Phalloceros harpagos & 8 & $8,7 \%$ & 605 & Ocasional & \\
\hline Rineloricaria steindachneri & 8 & $8,7 \%$ & 17 & Ocasional & \\
\hline Astyanax parahybae & 7 & $7,6 \%$ & 994 & Ocasional & \\
\hline Hyphessobrycon bifasciatus & 7 & $7,6 \%$ & 97 & Ocasional & \\
\hline Imparfinis sp. & 7 & $7,6 \%$ & 23 & Ocasional & \\
\hline Tilapia rendalli & 7 & $7,6 \%$ & 54 & Ocasional & \\
\hline Eigenmannia sp. & 6 & $6,5 \%$ & 13 & Ocasional & \\
\hline Knodus sp. aff. K. moenkhausii & 6 & $6,5 \%$ & 174 & Ocasional & \\
\hline Hypostomus auroguttatus & 5 & $5,4 \%$ & 8 & Ocasional & \\
\hline Microglanis parahybae & 5 & $5,4 \%$ & 44 & Ocasional & \\
\hline Trachelyopterus striatulus & 5 & $5,4 \%$ & 13 & Ocasional & \\
\hline Astyanax microschemos & 4 & $4,3 \%$ & 62 & Ocasional & \\
\hline Prochilodus vimboides & 4 & $4,3 \%$ & 4 & Ocasional & \\
\hline Ulaema lefroyi & 4 & $4,3 \%$ & 95 & Ocasional & $\operatorname{Sim}$ \\
\hline Australoheros muriae & 3 & $3,3 \%$ & 13 & Ocasional & \\
\hline Awaous tajasica & 3 & $3,3 \%$ & 3 & Ocasional & \\
\hline Corydoras nattereri & 3 & $3,3 \%$ & 34 & Ocasional & \\
\hline Glanidium melanopterum & 3 & $3,3 \%$ & 28 & Ocasional & \\
\hline Hasemania sp. & 3 & $3,3 \%$ & 105 & Ocasional & \\
\hline Hoplosternum littorale & 3 & $3,3 \%$ & 5 & Ocasional & \\
\hline Probolodus heterostomus & 3 & $3,3 \%$ & 6 & Ocasional & \\
\hline Scleromystax prionotos & 3 & $3,3 \%$ & 8 & Ocasional & \\
\hline Aspidoras virgulatus & 2 & $2,2 \%$ & 4 & Ocasional & \\
\hline Atherinella brasiliensis & 2 & $2,2 \%$ & 715 & Ocasional & $\operatorname{Sim}$ \\
\hline
\end{tabular}


Apêndice 2 (continuação)

\begin{tabular}{|c|c|c|c|c|c|}
\hline Espécie & Pts & $\%$ & $\mathbf{n}$ & Ocorrência & Marinho \\
\hline Bathygobius soporator & 2 & $2,2 \%$ & 14 & Ocasional & Sim \\
\hline Brycon insignis & 2 & $2,2 \%$ & 13 & Ocasional & \\
\hline Bryconamericus tenuis & 2 & $2,2 \%$ & 87 & Ocasional & \\
\hline Eleotris pisonis & 2 & $2,2 \%$ & 3 & Ocasional & \\
\hline Ituglanis parahybae & 2 & $2,2 \%$ & 2 & Ocasional & \\
\hline Leporinus mormyrops & 2 & $2,2 \%$ & 4 & Ocasional & \\
\hline Otothyris lophophanes & 2 & $2,2 \%$ & 67 & Ocasional & \\
\hline Synbranchus marmoratus & 2 & $2,2 \%$ & 2 & Ocasional & \\
\hline Achirus declivis & 1 & $1,1 \%$ & 1 & Ocasional & Sim \\
\hline Anchovia clupeoides & 1 & $1,1 \%$ & 2 & Ocasional & Sim \\
\hline Ancistrus multispinis & 1 & $1,1 \%$ & 2 & Ocasional & \\
\hline Archosargus probatocephalus & 1 & $1,1 \%$ & 1 & Ocasional & $\operatorname{Sim}$ \\
\hline Brevoortia pectinata & 1 & $1,1 \%$ & 26 & Ocasional & Sim \\
\hline Callichthys callichthys & 1 & $1,1 \%$ & 1 & Ocasional & \\
\hline Caranx latus & 1 & $1,1 \%$ & 3 & Ocasional & Sim \\
\hline Centropomus undecimalis & 1 & $1,1 \%$ & 1 & Ocasional & \\
\hline Citharichthys arenaceus & 1 & $1,1 \%$ & 2 & Ocasional & Sim \\
\hline Ctenogobius boleosoma & 1 & $1,1 \%$ & 2 & Ocasional & Sim \\
\hline Diapterus rhombeus & 1 & $1,1 \%$ & 11 & Ocasional & Sim \\
\hline Dormitator maculatus & 1 & $1,1 \%$ & 1 & Ocasional & \\
\hline Eucinostomus melanopterus & 1 & $1,1 \%$ & 27 & Ocasional & Sim \\
\hline Eugerres brasilianus & 1 & $1,1 \%$ & 1 & Ocasional & Sim \\
\hline Genidens genidens & 1 & $1,1 \%$ & 21 & Ocasional & Sim \\
\hline Gobionellus stomatus & 1 & $1,1 \%$ & 2 & Ocasional & $\operatorname{Sim}$ \\
\hline Loricariichthys castaneus & 1 & $1,1 \%$ & 1 & Ocasional & \\
\hline Lutjanus jocu & 1 & $1,1 \%$ & 6 & Ocasional & Sim \\
\hline Microphis brachyurus & 1 & $1,1 \%$ & 20 & Ocasional & \\
\hline Mimagoniates microlepis & 1 & $1,1 \%$ & 11 & Ocasional & \\
\hline Mugil curema & 1 & $1,1 \%$ & 5 & Ocasional & Sim \\
\hline Parotocinclus sp. aff. P. jimi & 1 & $1,1 \%$ & 1 & Ocasional & \\
\hline Pterygoplichthys sp. & 1 & $1,1 \%$ & 10 & Ocasional & \\
\hline Trichogenes claviger & 1 & $1,1 \%$ & 41 & Ocasional & \\
\hline
\end{tabular}

